\title{
GROWTH AND STRUCTURAL DAMAGES OF TREES HOSTING LIANAS IN SEMI-EVERGREEN TROPICAL FORESTS IN NORTHEASTERN YUCATAN PENINSULA (MEXICO)
}

\author{
Dissertation \\ zur Erlangung des Doktorgrades \\ der Mathematisch-Naturwissenschaftlichen Fakultäten \\ der Georg-August-Universität zu Göttingen \\ vorgelegt von \\ Edgardo Israel Garrido Pérez \\ aus Panama, Panama
}

Göttingen 2008 
D 7

Referent: $\quad$ Prof. Dr. Gerhard Gerold

Korreferent: $\quad$ P.D. Dr. Michael Kessler

Tag der mündlichen Prüfung: (05.05.2008) 
To Paulina, Kathrin, Magnolia and Virgilio (My Daugther, Wife, Mother and Father) with all of the Love that fits in a Soul

To the Memory of Ingrid Olmsted and Camilo Ancona

To the Honour of all the Men and Women who, like the Mayans of Today, developed a Culture of respect to The Nature and The Mankind 


\section{ACKNOWLEDGMENTS}

Less than four weeks before dying due to a painful disease, Dr. Ingrid Olmsted introduced me to the Peasants Community of Ejido Solferino in order to look for ideas for a Research. I really thank Ingrid for such an effort. I am indebted to the inhabitants of Solferino for their sincere friendship, specially the land owners: Mr. José "Pepe" Quintal, Saúl Ancona, Roberto Antonio Lara, Rosendo Can and Mario Ucan May. Mario himself provided the most valuable help in the field and gave me the honor of us to call Brother to each other. Miguel Angel Canul, Balbina Ancona, and more than six other persons helped in the field too. I am also deeply indebt with my personal, old maya friends Chak Mool and Alux Ob because of their help in the field.

As my Advisor, Prof. Dr. Gerhard Gerold provided me all the academic and logistic advantages he supplies to his students. Before my arrival to Prof. Gerold's Laboratory, my research was consuming all my energy, and advancing too slow. Once there, the job continued to consume my energy, but proceeded very fast and was as fun as the field work itself thanks to the efficiency of the crew of the department. An emergent reputable botanist, Prof. Dr. Michael Kessler, filtered the final quality of this work, Rebecca Benez reviewed the language and made important comments. For identifying plants, I was helped by some taxonomers of the Centro de Investigación Científica de Yucatán (Mexico): José Luis Tapia, Filogonio May-Pat and Paulino Simá. The criticisms and friendship that Dr. Juan Manuel Dupuy gave me during the whole project were not less important. Colleagues of him supplied valuable criticisms too: Doctors José Luis Andrade, Rafael Durán, Víctor Parra, Luz María Calvo, and Roger Orellana. A world wide famous liana expert, Prof. Stefan Schnitzer (University of Winscosin) made valuable comments. Many pictures were kindly supplied or borrowec from K.Fletcher and C. Baylis (http://www.wildsidephotography.ca/), Gabriel Araújo dos Santos and Cecilia Costa, John Stone, Arthur Gibson, Center for Tropical Forest Sciences (Smithsonian Institution), Vrindavana foundation and National Oceanic 
Atmospheric Administration (NOAA). Winfried Pahl and his wife Annegreth supplied important logistic and moral help during the writing of the report. Anne le Mellec and all Students of Prof. Gerold honoured me with their friendship and exchange of ideas. Some sponsors were: the Organization of American States (OAS), the Mexican National Council for Science and Technology (CONACYT), and the German Service of Academic Exchange (DAAD). Last but by no means less important is my debt with Kathrin Pahl. Since August 2005 Kathrin became the only sponsor of this research. She tolerated me to transform our small apartment into a noisy, nocturnal office. She even accepted to marry me and to have a baby (Paulina). The best prize after a hard, but always fun work. 


\section{CONTENTS}

$\begin{array}{lc}\text { Summary } & 8\end{array}$

Chapter 1: General Introduction $\quad 13$

1.1. Justification 14

1.2. General Objectives and General Question $\quad 15$

1.3. General Hypothesis and works supporting it 15

$\begin{array}{ll}\text { 1.4. Limitations of the Hypothesis } & 17\end{array}$

The paradigm of lianas as competitors of trees 17

Lianas as structural parasites of trees: another paradigm

1.5. Study site and reconstruction of its Land Use History: from Traditions to Satellites $\quad 21$

1.6. General Methods $\quad 27$

Selection of forest stands for plots $\quad 27$

1.7. Chapters of this Dissertation, their specific objectives

Chapter 2: Growth of co-existing tree species in response to hosted lianas in Northern Quintana Roo, Mexico 33

2.1. Introduction 34

2.2. Materials and Methods

Study site and settlement of plots $\quad 35$

Field work $\quad 36$

$\begin{array}{ll}\text { Data analysis } & 39\end{array}$

Averaged effect of lianas on different tree species $\quad 41$

2.3. Results 42

2.4. Discussion 53

Chapter 3: Growth of saplings after cutting lianas in Semi-Evergreen

Tropical Forests of different ages and Land Use Histories 60

3.1. Introduction $\quad 61$

3.2. Materials and Methods 63

$\begin{array}{ll}\text { Study site } & 63\end{array}$

Field work $\quad 63$

$\begin{array}{ll}\text { Data analysis } & 64\end{array}$

a) Comparing and grouping plots 66

b) Growth of saplings 67

3.3. Results 68

3.4. Discussion 78 
Chapter 4: Structural Effects of Lianas and Hurricane Wilma on Trees in a Semi-Evergreen Tropical Forest in Quintana Roo, Mexico

4.1. Introduction $\quad 85$

4.2. Materials and Methods $\quad 87$

Study site, location and land use history of the plots $\quad 87$

Field work $\quad 87$

Data analysis $\quad 91$

$\begin{array}{ll}\text { 4.3. Results } & 91\end{array}$

Damages according to girth of trees and their numbers
of hosted lianas

Liana-cutting and other causes of damage 99

4.4. Discussion 102

Structural damages within forest stands: when the lianas
play no-role

Where are lianas harmful, where they protect trees, and how 103

Structural damages between stands: what lianas are

Tree-size and other risk factors $\quad 104$

Hurricanes, gap dynamics and the role of lianas in forest dynamics 106

Chapter 5: General Discussion and General Conclusions 108

5.1. Neither do Lianas generally delay the growth of trees nor do Lianas generally enhance hurricane damage $\quad 109$

5.2. Studies on liana-tree interactions require larger spatio-temporal scales $\quad 109$

5.3. Lianas affect succession in North-Eastern Yucatan Peninsula 110

5.4. Do lianas influence tree species turnover within functional groups of trees? 110

5.5. Do lianas drive tree-species turn-over within guilds?: an Evolutioinary point of view 112

5.6. To cut or not to cut: where and when? 113

5.7. General Conclusions 115

References $\quad 116$

APPENDIX I: Species list and numbers of individuals per species per plot 15 months after liana-cutting ( 2 months before Hurricane Wilma)

APPENDIX II: Indexes of liana-effect $(\Omega)$ on the growth of different tree species after a liana-cut experiment

APPENDIX III: Fallen debris (leaf-litter and woody debris) in liana-cut and liana-un-cut plots

APPENDIX IV: Contingency tables exploring the effects of tree location (forest stand), lianas, and tree-sloping on risks of trees to get damaged during Hurricane Wilma 


\section{SUMMARY}

Lianas are woody vines that reach the canopy by climbing trees. Their vascular tissues are able to conduct more water than those of trees. Consequently lianas are considered to be competitors for water and soil resources delaying the growth of trees, which was demonstrated by many studies. Other studies suggest that lianas are structural parasites reducing the reproduction of trees. Some tree species have been reported to be more affected than others. Therefore ecologists propose that lianas are a driving force in detremining the relative abundance of tree-species through time. According to different reports, lianas represent about $25 \%$ of the tropical forests flora, where $33 \%$ to $79 \%$ of all trees host lianas. The ecological relevance of lianas in the tropics may even increase since lianas colonize gaps and open areas rapidly. The abundance of gaps may increase in the future of the tropics due to increasing logging activities. Also, secondary areas covered by secondary forests are increasing due to the abandonment of crops because of economic reasons. Additionally, in the course of global change it is predicted that the frequency of hurricanes may increase, opening more gaps in forests. Even the rising atmospheric $\mathrm{CO}_{2}$ concentration is suggested to enhance tree-fall dynamics by stimulating trees to grow faster which in result is making them fall faster. In a nutshell, the relative abundance of lianas with respect to trees in tropical forest will most likely increase and current evidences suggest that lianas are harmful to the growth and structure of trees. Furthermore, fallen trees are proposed to pull down other trees connected to them by lianas. In this research I determined the effects of lianas on the growth of different co-existing species of trees and saplings. They were located in semi-evergreen tropical forest stands in Mexico representing different successional age and land-use history. Moreover, during this research, the most powerful hurricane registered to date in the history of the Caribbean (Hurricane Wilma) hit the study site. This helped to determine the effects of lianas on tree-damaging by strong winds. 
The study site is the peasants and Maya Community of Ejido Solferino, northeastern Yucatán Península, México. There, I made two, four, and six 20 m x 20 m plots in forests stands having the following successional ages respectively: ten, eighteen, and $\geq$ fifty five years old. Then I made a survey of all trees $\geq 10 \mathrm{~cm}$ circumference and lianas $\geq 1 \mathrm{~cm}$ diameter. Trees and lianas were identified and tagged with unique codes. I recorded the number of lianas hosted per tree, and estimated the $\%$ of the woody area of each tree that was covered by lianas, and classified it into four liana-cover categories: $(0)=$ no lianas, $(1)=1$ $25 \%,(2)=25-75 \%$, and $(3)>75 \%$. Six litter traps per plot were installed. All saplings between $30 \mathrm{~cm}$ height and $10 \mathrm{~cm}$ circumference were counted, identified and measured on ten $2 \mathrm{~m}^{2}$ subplots per plot. Saplings's lower size-limits are heights and upper limits are widths but this is used by foresters, eco-physiologists and ecologist for many studies on saplings (more details in Box 2, Chapter 1). Notice that the upper limit of the size of saplings is the lower limit of the size of trees (and did not overlap) making this study more comprehensive by including a wide range of sizes of plants and helping to avoid confusions while studying plants in the field. In May 2004, I cut all lianas and vines (without pulling down their fragments from the canopy in order to do not harm trees) in half of the plots of each stand. The few liana re-sprouts were cut again every 2,5 to 3 months. Trees and saplings were remeasured fifteen months after liana-cutting, Hurricane Wilma hit the study site two months after such re-measurements.

In spite of the short time after liana-cutting, clear trends on the growth of trees arose. In the $\geq 55 y r-o l d$ stand, Pouteria campechiana, Zygia stevensonii, and Lonchocarpus xuul grew less when hosting larger liana-coverages and this is consistent to other studies. In the same stand, the growth of Bursera simaruba, P. campechiana, Metopium brownei and Vitex gaumeri was hindered when lianas where not cut and this is also consistent to other studies. But contrary to other studies, one species (Dendropanax arboreus) grew faster in the 10-yr and 18-yr old liana-uncut stands, and three species grew faster when hosting larger liana 
coverages (Coccoloba spicata, V. gaumeri and B. simaruba). A legume liana (Dalbergia glabra, Papilionoideae) was dominant there and I propose that it helped trees by contributing to nitrogen fixation or, at least did not avoid high incidence of sunlight to reach trees there.

Results from saplings were also uneven. In the $\geq 55 \mathrm{yr}$-old stand, Chrysophyllum cainito and Malmea depressa grew less where lianas were not cut. In contrast, lianas favoured Eugenia axillaris and Lonchocarpus rugosus in the 10yr- and 18yr old stands. For many species, liana-cutting had no effects on both forest ages. Though being pioneers, the mentioned sapling species have different wood-densities (when adults), suggesting that reported liana-effects may apply for a wide gradient of light-demands (and life histories) within the guild of the pioneers. Also, after pooling saplings of all species, saplings grew faster in liana-uncut plots of the 10yr- and 18yr old stands. It occurred even where litter input was lower compared to liana-cut plots, while larger inputs of litter are expected to enhance the growth of saplings because of a larger input of nutrients. Also, soil moisture was decoupled to saplings growth; for example, there were locations with high soil moisture but saplings grew less there compared to plots with dryer soil. All this suggests that soil moisture and litter input did not affect the results during the study, being the intact lianas a potential factor favoring saplings. These results indicate that lianas may stimulate better growth of many saplings in younger forest stands. However, further studies with more subplots and more measurments of litter and abiotic factors are needed to test this hypothesis and to determine for which sapling species this may apply.

Hurricanes themselves are amazing and results of Hurricane Wilma related to lianas were amazing too. Trunk snapping and Tree uprooting, the two most severe damages of trees producing larger tree-fall gaps, occurred independently of: liana-cutting, number of lianas per tree, and liana-coverage per tree. This applied for all forest stands. A less severe damage, namely Crown removal, was more frequent in the 10-18yr-old stand, dominated by D.glabra. For the $\geq 55 y r$-old stands, Crown removal affected larger-vertical (emergent) trees, the ones 
more exposed to strong winds. Also in the $\geq 55 \mathrm{yr}$-old stand, individuals hosting larger lianacoverages suffered more crown removal. In contrast, trees hosting more lianas suffered less crown removals in the $10 \mathrm{yr}$ - and $18 \mathrm{yr}$-old stands where the canopy is more homogeneous compared to the rough canopy of the $\geq 55 y$ r-old stand. Since liana-cutting did not have any effect on crown removal, it may not be proposed that lianas pulled or fixed trees to the ground. Instead, I propose that lianas: a) contributed to remove crowns in the $\geq 55 \mathrm{yr}$-old forest by displacing the gravity center of the crowns, and b) reduced crown removal in the 10yr and 18yr old stands by binding crowns (both are hypotheses of Putz, 1984a). I propose that just heavy and rigid lianas like D. glabra played such a role and that many lianas rarely enhance structural damages on trees in the study site.

In total, the results confirm previous studies showing that lianas have a speeciesspecific effect on co-existing tree species. However, it does not imply that lianas are a driving force determining tree species turn-over throughout time. The growth of many tree and some sapling species of my study were negatively affected in some stands, but positively affected in other, close-by stands. At a landscape level, given the short distance among stands, both, negatively- and positively affected trees may belong to the same populations, so liana-induced reduction of some individuals may be compensated by the enhancement of others, avoiding local extinction. It may also occur in patches of different successional ages within a single forest. Indeed, no tree species may tend to local extinction due to lianas. Also, speciesspecific liana-tree engagements should occur in order to lianas to alter tree species compositions in a temporally consistent way. There are studies suggesting that there are no species specific liana-tree associations in different forests. Moreover, fundamental theories on plant evolution and liana biogeography suggest that they evolved in environments where tree diversity was already high. Indeed species-specific interactions and driving effects of lianas on trees of the same functional group (e.g. pioneers) have always been poorly likely. All these 
suggest that the role of lianas on tree-species relative abundance is less important than normally assumed.

I also discuss what role lianas might play in a habitat where hurricanes are so common (semi-evergreen tropical forests of northeastern Yucatan Peninsula). The literature suggests that lianas may proliferate since hurricanes produce gaps and large open areas. However, although it can imply that a certain number of trees will grow less due to "liana-competition", colonizing lianas will rarely make trees to suffer more structural collapses during hurricanes.

Cutting lianas is a common practice in forest management in order to enhance the growth and avoid damages of trees. However, this research and the amount of literature consulted indicate that there is no general rule for saying when and where lianas should be cut. Liana-cutting seems only profitable for trees hosting larger liana-coverage of some target species (e.g. Pouteria campechiana at my $\geq 55 \mathrm{yr}$-old forests and Spondias mombin and other species at my 10-18yr-old forest). But since the growth of no species seemed to be significantly hindered by lianas in every of my studied stands, there is no reason to take such results as a general rule: Ecologists still have not enough evidences.

Moreover, hurricanes must be taken into account for tree-protection aspects in North Eastern Yucatán Peninsula. For avoiding trunk snapping and tree up-rooting, cutting lianas is not particulary helpful because such damages occurred independently of liana-cutting. Crown removal by hurricanes also represents severe damage by potentially reducing further wood production of affected trees. But lianas were not related to such damages in my $\geq 55 \mathrm{yr}$-old stand, suggesting that cutting there is not necessary. Moreover, although heavy-bodied lianas (especially Dalbergia glabra) may have caused pronounced damages where it dominates (my 10yr- and 18yr-old forests), cutting it there was even worse; in D.glabra "saturated" areas, the Hurricane removed more crowns of trees hosting lower numbers of lianas. Finally, because in the 10yr-and 18yr-old stands trees grew better when D. glabra was not cut and while having larger liana-coverage, further studies on the role of this liana species are recommended. 


\section{Chapter 1}

\section{GENERAL INTRODUCTION}

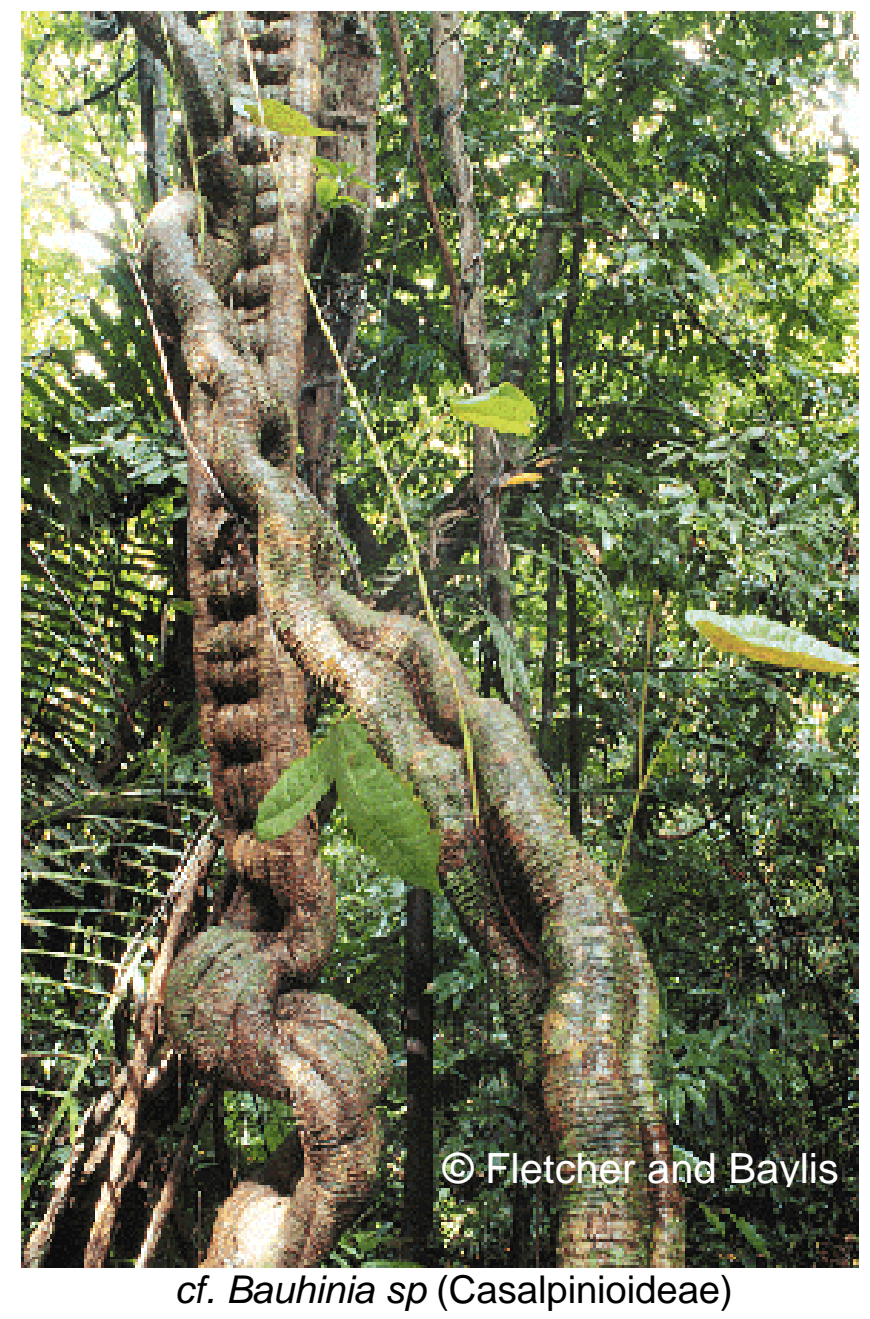

Watching the curved, arched, contorted, spirally wound and triumphantly vertical stems and trunks of trees and lianas(...) it often occurred to me that modern art has missed a most bountiful source of inspiration. The variety of lines and forms in tropical forests surely exceeds what all surrealists together have been able to dream of...

Theodosius Dobzhansky (1900-1966). 


\subsection{Justification}

Lianas (woody vines) compose about $25 \%$ of the flora of tropical forests, where 33 79\% of trees host lianas (Putz, 1984a; Gentry, 1991; Pinard and Putz, 1994; Campbell and Newberry, 1993). Lianas increase their densities in natural and tree-felling gaps by lateral branching, delaying the gap-phase and affecting tree regeneration (Schnitzer et al, 2000; Parren, 2003). As well as logging, hurricanes and global increase in atmospheric $\mathrm{CO}_{2}$ can enhance tree-fall dynamics by making trees grow and fall faster, and thereby increase the relative abundance of lianas with respect to trees in tropical forests (Gerwing, 2001; Gerwing and Vidal, 2002; Phillips et al, 2002; Granados and Körner, 2002; Wright et al, 2004). Lianas are also abundant in young secondary forests and forest edges. Consequently, liana abundance is also expected to increase as a result of both, forest fragmentation, and deforestation followed by land abandonment (Cramer et al, in press; De Walt et al, 2000; Gerold, 1994; Guariguata and Ostertag, 2002; Laurance et al, 2001). Concomitant to the increase in liana abundance, there should be an increase in their role in tropical forests, which is not well understood. This research was made in order to contribute to the understanding of such a role.

There are evidences suggesting that lianas reduce the growth and reproduction of certain tree and tree-sapling species (Putz, 1984a; Whigham, 1984; Stevens, 1987; Clark and Clark, 1990; Dillenburg et al, 1993a; Barker and Pérez-Salicrup, 2000; Gerwing, 2001; Vidal et al, 2002; Pérez-Salicrup, 2001; Grauel and Putz, 2004; Schnitzer et al, 2005; Kainer et al, 2006). Lianas can also break the trunks and branches of trees by pulling them when another, liana-connected tree falls down (Putz, 1984a; 1991; Schnitzer and Bongers, 2002; but see Parren et al, 2001). However, it has been also suggested that lianas avoid falling trees to pull down others by binding canopies together and stabilizing trees there (Putz, 1984a). This possibility is mainly neglected so lianas are mainly considered to break trees. Indeed, cutting lianas is a common practice not only to avoid trees to break, but also to avoid liana-induced reduction of tree growth and reproduction (Putz, 1991; but see Schnitzer and Bongers, 2002; 
Pérez-Salicrup et al, 2001a; Parren and Bongers, 2001). Lianas are also proposed to play a driving role structuring tree communities by favoring some species more than others (PérezSalicrup, 2001; Schnitzer and Bongers, 2002). Understanding it requires to study the effects of lianas on co-existing trees in forests. There is a paucity of such studies and this research seeks to contribute to fill this gap.

\subsection{General Objectives and General Questions}

The general objectives were:

1. To contribute to the understanding whether lianas generally reduce the growth of trees and saplings and of some species of them in forest stands of different land use histories and successional ages.

2. To determine if- and how lianas can produce different mechanical damages to trees during strong winds.

The general questions guiding this research were: Do lianas hinder the growth of trees and saplings and for what species? Do lianas contribute to break trees?

\subsection{General Hypothesis and works supporting it}

The general hypothesis of this dissertation is that lianas do reduce the growth of trees and saplings and enhance mechanical damages of trees. It is supported by the fact that lianas have wider vascular vessels than trees (fig. 1.1), putting forward the expectation that trees will be out-competed in the search of water and soil resources (Ewers et al, 1990, Ewers et al, 1991; Fitchner and Schultze, 1990; Gartner et al, 1990; Phillips et al, 1999; Dillenburg et al, 1993a-b; Pérez-Salicrup and Barker, 2000; Gerwing, 2001; Vidal et al, 2002; Pérez-Salicrup, 2001; Grauel and Putz, 2004; Schnitzer et al, 2005, but see Barker and Pérez-Salicrup, 2000). Competition as a driving force structuring tree communities and determining the evolution of plants has been long argued (Begon et al, 1996). Indeed, the hypothesis that lianas hinder the 
growth of trees and tree saplings can be transformed into a more holistic hypothesis that lianas are a driving force of tree communities, delaying the growth of some species more than others (Pérez-Salicrup, 2001; Schnitzer and Bongers, 2002). As the conceptual guideline to this dissertation, I adopt the hypothesis that lianas reduce the growth of some tree and treesapling species than others, and also contribute to tree-structure damages.
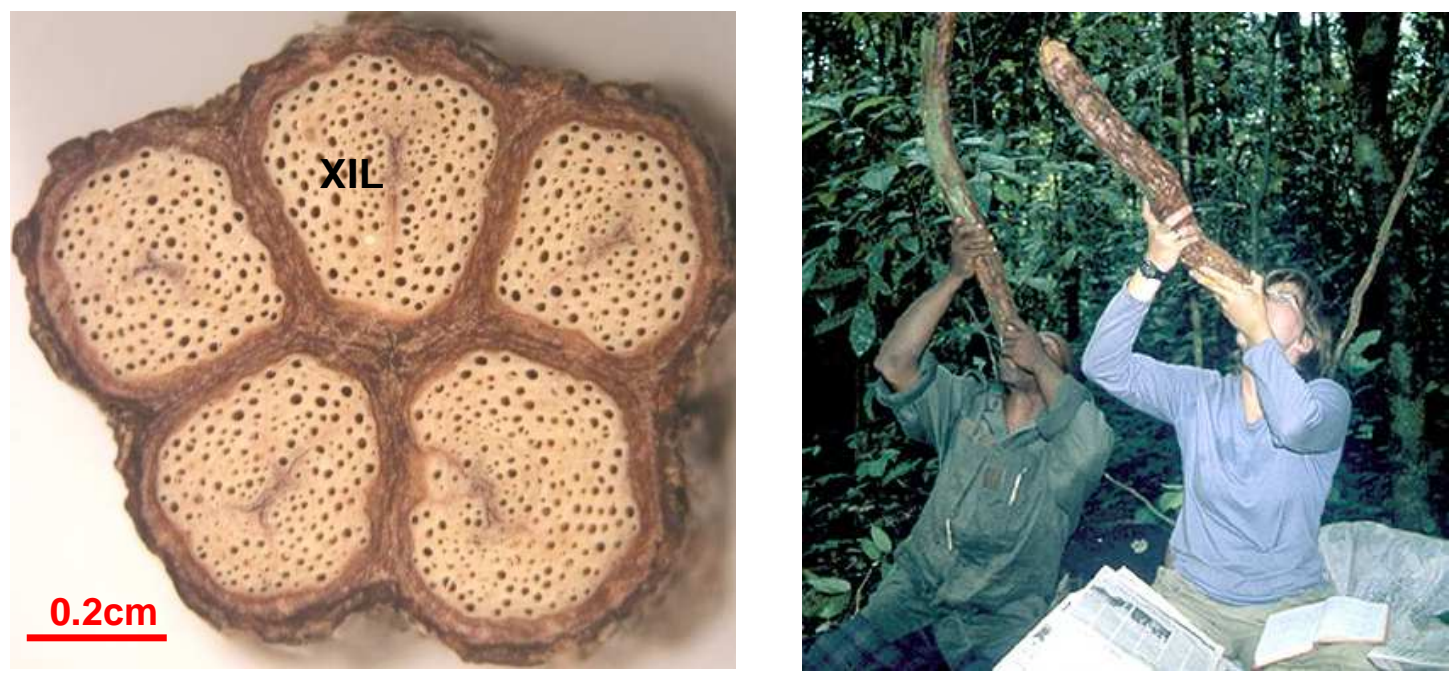

Figure 1.1. Why lianas conduct so much water? Notice the wide vascular vessels of Serjania (Sapindaceae) arranged in xylem masses (XIL, left). Wide xylem vessels aloud lianas to conduct large amounts of water, outcompeting trees below ground according to many studies. For some liana-taxa like Tetracera (Dilleniaceae, right) such amounts of water are even available for humans. Copyrights: G.U.C. Araújo and C.G. Costa (left) and John Stone, Missouri Botanical Garden (right).

The Natural History of Lianas supports that they are harmful for trees. Let us have a look into such a Natural History: Lianas are unable to grow more than $2 \mathrm{~m}$ tall in a selfstanding way, so they must climb trees to reach the canopy (Putz, 1984a; Gentry, 1991). Once in the canopy lianas produce large branches which generally host on several trees (Putz, 1984a). By doing so, they are capable of expanding their area of photosynthesis and dispersal of pollen and seeds without spending as much energy in the construction of trunks as trees have to (see also Putz and Holbrook, 1986). Furthermore, it has been suggested that liana anchoring organs can constrain tree ramets during their radial growth reducing the allocation of photosyntates and provoking the breakage of tree sections (Stevens, 1987; Kainer et al, 2006). By doing so, lianas reduce the production of leaves, flowers and, consequently, fruits of trees (Stevens, 1987; Kainer et al, 2006) potentially affecting tree populations. Also, 
because lianas do not invest in a self-standing trunk, they produce deep roots and wide xylem vessels. This enables them to reach and transport large amounts of water and soil resources as indicated above (see also Restom and Nepstad, 2004; Andrade et al, 2005). This gives many lianas the opportunity to keep their leaves during the dry season of many tropical forests and has been proposed as a competitive advantage of lianas compared to trees (Schnitzer, 2005). Lianas are also faster than trees in colonizing gaps by lateral growth (Putz, 1984a; Schnitzer et al, 2000) having a better capacity to expand horizontally with respect to trees. On the other hand, trees to do not seem to receive any advantage from their relation to lianas.

\subsection{Limitations of the Hypothesis}

The paradigm of lianas as competitors of trees

Some of the studies supporting the idea that lianas affect trees negatively discovered cases where lianas did not. For example, when lianas colonize gaps, pioneer trees are favored with respect to slow-growing species (Schnitzer et al, 2000). Also the native vine Parthenocissus quiquifolia did not affect the growth of Liquidambar styraciflua, but only an introduced vine did it (Dillenburg et al, 1993b). Also, higher occupation of tree canopies by lianas was not a good estimator of the effects of lianas on Prioria copaifera in Darién, Panama (Grauel and Putz, 2004) and Bertholletia excelsa in Acre, Brasil (Kainer et al, 2006). It suggests that liana-tangles are not necessarily related to reduced tree growth (Grauel and Putz, 2004) and reproduction (Kainer et al, 2006).

Some methodological constrains also weaken the hypothesis. For example, many tree species have few individuals per area unit in the Tropics, and therefore studies were obligated to focus on effects of lianas on trees in general instead of assessing species-specific effects (Putz, 1984a; Gerwing, 2001; Vidal et al, 2002). Such obligated practice (including to some extend this dissertation) reveals patterns of effects of lianas on trees, but does not indicate which trees species follow these patterns. Other studies have been evocated as evidences 
suggesting that lianas out-compete trees in a species-specific way. But such studies only tested if such a competition occurs above- or below ground (Dillenburg et al, 1993b; Schnitzer et al, 2005). Indeed, they induced competition artificially instead of testing how oft it occurs in the wild and for which tree-species.

Lianas are a polyphyletic group of plants (Gentry, 1991), so it is justified to ask: Do all lianas affect trees negatively and in a species-specific way, or only some liana taxa do that? Unfortunately, identifying lianas in the field is very difficult (Gerwing et al, 2006). This partly explains why lianas in general, and not certain taxa, have been considered deleterious for trees. "Backpack" liana-taxonomy books like the one of Acevedo-Rodríguez (2003), and the rise of on-line guides (e g Raes and Ek, 2002; The Field Museum, 2005) are becoming excellent tools to improve liana-studies in the future, but they did not exist or were just incipient during the realization of the great majority of the studies on liana-tree interactions. In fact, such documents are only starting to be generated. Even researchers who made big efforts in managing the identification of lianas in their study sites (Stevens, 1987; PérezSalicrup et al, 2001b) only gave a clue, but did not explicitly test what lianas reduced the growth and reproduction of trees and saplings in their studied sites (Stevens, 1987; PérezSalicrup and Barker, 2000; Pérez-Salicrup, 2001).

In spite of its limitations, increasing evidences support the paradigm of lianas as outcompetitors of trees. For this dissertation I found a strong trend that lianas delay the growth of trees and saplings. But I also report cases where they seemed to favor the growth of trees and saplings, or did not outbalance the positive effect of other factors (e. g. incident sunlight).

\section{Lianas as structural parasites of trees: another paradigm and its limitations}

The second general goal of this dissertation was to determine if lianas can produce different mechanical damages to trees during strong winds and, if so, how lianas do that. The hypothesis that lianas are structural parasites of trees (Stevens, 1987; Kainer et al, 2006) 
guides this part of the research. Because no root of lianas penetrates the body of trees, lianas are not considered true parasites of trees as misteltoes are (e.g. Benzing 1990). But because lianas are not able to grow and survive without climibing upon trees (taking structural advantage of them), they have been considered structural parasites, especially because they reduce the reproduction of some tree species (Stevens, 1987, Kainer et al. 2006). Many authors assume that lianas engage to trees in such a parasitic way (see revision in Schnitzer and Bongers, 2002). Since parasitism is better studied by epidemiologists and agronomers, it may be illustrative to compare knoledges from animal parasitology and liana-tree studies in order to porject to what degree the concept of parasitism can help to learn more from lianatree interactions. High infestations with parasites (e.g. nematodes) make plants and animals prone to die and reduce their reproductive success (Chermin, 2000). Similarly, lianas may contribute to break trees during strong winds. Because parasitism is better demonstrated with long-term studies, the paradigm of lianas as structural parasites of trees remains poorly explored. As Stevens (1987) pointed out, it opens wide avenues for studying liana-tree interactions. A deeper comparison between animal parasitology and Liana-tree interaction studies is exposed in Box 1. 


\section{Box-1. Lianas as "structural parasites" of trees: wide avenues for studying liana-tree interactions.}

Only two studies demonstrated that lianas reduce the reproduction of Bursera simarouba (Stevens, 1987) and Bertholletia excelsa (Kainer et al, 2006). Stevens (1987) observed the fruiting of more than 105 B.simarouba individuals per 8 years, and then removed the lianas above ground, but not below ground, from five female individuals having $100 \%$ of their crowns covered by lianas. Then he counted the produced fruits per two successive years and compared it to other 100 individuals. Liana-removed individuals twelve-folded their fruit production. However, the effects of smaller tree-crown coverage by lianas were not tested. After Stevens, Kainer et al (2006) studied B.excelsa trees being: fully infested, trees hosting no lianas, and trees having low, and moderate liana-loads. Then, they quantified the production of fruits and nuts during two years (in total, they studied 140 fertile individuals, no lianaload category had less than 20 individuals). They found that B.excelsa trees having more than $25 \%$ of their crown areas covered by lianas reproduce less. Both studies are part of a "parasitological approach" in the study of liana-tree relations. But, what lianas are such parasites? Stevens (1987) includes a list of 14 liana species hosted on his trees, but nobody tested what lianas are "guilties". Also, Kainer et al (2006) found that trees with the higher liana-infestations had lost about $50 \%$ of their crowns respect to trees without lianas (a possible "pathological" result of lianas on their studied trees).

The parasitological approach to liana-tree relations includes more studies, like the ones determining if certain taxa of trees are more prone to host lianas. Emergent Dypterocarpaceae are less prone than non-emergent Euphorbiaceae to host lianas (Campbell and Newberry 1993). The same authors found emergent Euphorbiaceae hosting less lianas, suggesting that being "emergent", more than the taxon itself, makes trees to "escape" from lianas in the canopy. Other studies suggest that species-specific liana-tree associations are very rare (Pérez-Salicrup et al, 2001b; Malizia and Grau, 2006). Pinard and Putz (1994) report that trees hosting one liana are more prone to host other lianas because the first liana facilitates others to climb upon the same tree (see also Putz, 1984a). For seven longliving, non-pioneer species, Clark and Clark (1990) demonstrated that wider trees host more lianas perhaps because they had more time living in a place (more time to get "infected"). Pérez-Salicrup and de Meijere (2005), and Malizia and Grau (2006) found similar patterns. Other studies indicate that the chances of trees to host lianas decrease according to their distance to each liana (Kainer et al, 2006).

Lianas reach their sexual maturity on their hosts, and have evolved mechanisms to keep attached, and to "escape" from their hosts (tendrils, hooks, seeds, asexual reproduction (e g Hegarthy, 1991). Parasites do the same (Chermin, 2000). Parasites migrate in the body of their hosts, affecting some organs more than others (Chermin, 2000, both are features in common to lianas). Also, there are very few vertebrate individuals free of parasites (Chermin, 2000), and very few trees in the tropic lowlands are free of lianas as well (Lex et al, 1998 and Schnitzer and Bongers, 2002 published just two revisions of literature confirming this). Moreover, Epidemiological studies on animal parasites require the same information than many liana-tree interaction studies: host density, environmental moisture, distance respect to infected individuals or free-living stages of the parasites, relative abundance of different parasite and host species, seasonal and other habitat changes that potentially enhance the growth and reproduction of parasite's populations, historical information about previous diseases and previous habitat conditions, topography, among others (Chermin, 2000). Some studies taking such aspects into account are the ones of De Walt et al (2000) and Caballé and Martin (2001); Schnitzer et al (2000) and Babweteera et al (2000); Gentry (1991), and Balfour and Bond (1993). They consider the abundance of lianas related to forest age and gaps, biogeography, soil type and seasonality, and height of tree branches; that is, places where it is "epidemiologically possible" for lianas and trees to get related (see also Kainer et al (2006) for liana-tree distance as a "risk factor" ).

Because lianas share many analogies with other parasites, it was suggested that trees and palms may have mechanisms to avoid and shed lianas (Putz, 1984b; Rich et al, 1987). This is analogous to the immune responses of vertebrates. Thus, large, composed leaves, smooth barks, flexible trunks, rapid growth rate and the fall of branches and and leaves of trees and palms have been suggested as mechanisms to avoid and shed lianas and vines (Putz, 1984b; Rich et al, 1987). It has been insinuated that such mechanisms evolved in response to the negative effect of lianas on different tree species (Schnitzer and Bongers, 2002). However, studies demonstrating that lianas do not associate to trees in a species-specific way (Pérez-Salicrup et al, 2001b; Pérez-Salicrup and de Meijere, 2005; Malizia and Grau, 2006) suggest that the rise of the mentioned characteristics during the evolution of trees was difficultly due to directional natural selection imposed by lianas. Indeed, different to animal parasites, lianas-tree species-specific coevolution seems to do not occur. In spite of this conceptual limitation, the parasitological approach to the study of lianas have supplied Tropical Ecology with valuable information about the biology of lianas and their interactions with trees, like the quoted above. This approach still promises many new information. For example, it has been well demonstrated that certain trees host more lianas than others, but this "infestation" does not necessarily mean that such trees will reproduce less than others. Also, it remains unstudied if such a parasitism is effectively a driving force in structuring tree communities: perhaps the populations of co-existing trees are evenly affected by lianas so tree species turn-over depends entirely on other factors. More studies with the parasitological approach are needed to test these possibilities. Meanwhile, I used such approach to study the effects of lianas on trees during Hurricane Wilma. For example, for determining the risks of trees to suffer crown removal, trunk snapping, and other damages according to the liana tangles they host. 
I warn that in this research I did not test if lianas are structural parasites or competitors reducing the fitness of trees. For example, I compared tree growths in liana-cut vs liana-uncut plots, but it is not enough for testing if lianas are competitors (Connell, 1990). Plant cutting and exclusion experiments have been evocated as testing competition but, according to Connell (1990), the enhanced vigor of some tree species after liana-cutting may also be due to positive interactions (with other trees) that were interrupted by lianas. On another hand, I did not test if lianas are actual parasites of trees because it requires many years of repeated measurements on trees. I just determined how many trees were broken by lianas during hurricane Wilma, but I did not measure the effects of that on tree reproduction, and I even did not test if snapped trees were effectively dead. Nevertheless, assuming that lianas outcompete and parasite trees structurally, helped immensely during this research.

\subsection{Study site and reconstruction of its Land Use History: from Traditions to Satellites}

The peasant's community of Ejido Solferino, Quintana Roo, Mexico, is close to the Yum Balam Reserve of Flora and Fauna $\left(21^{\circ} 26^{\prime} \mathrm{N}, 8^{\circ} 28^{\prime} \mathrm{W}\right.$; 10m above see level; INEGI, 1993; fig.1.2).

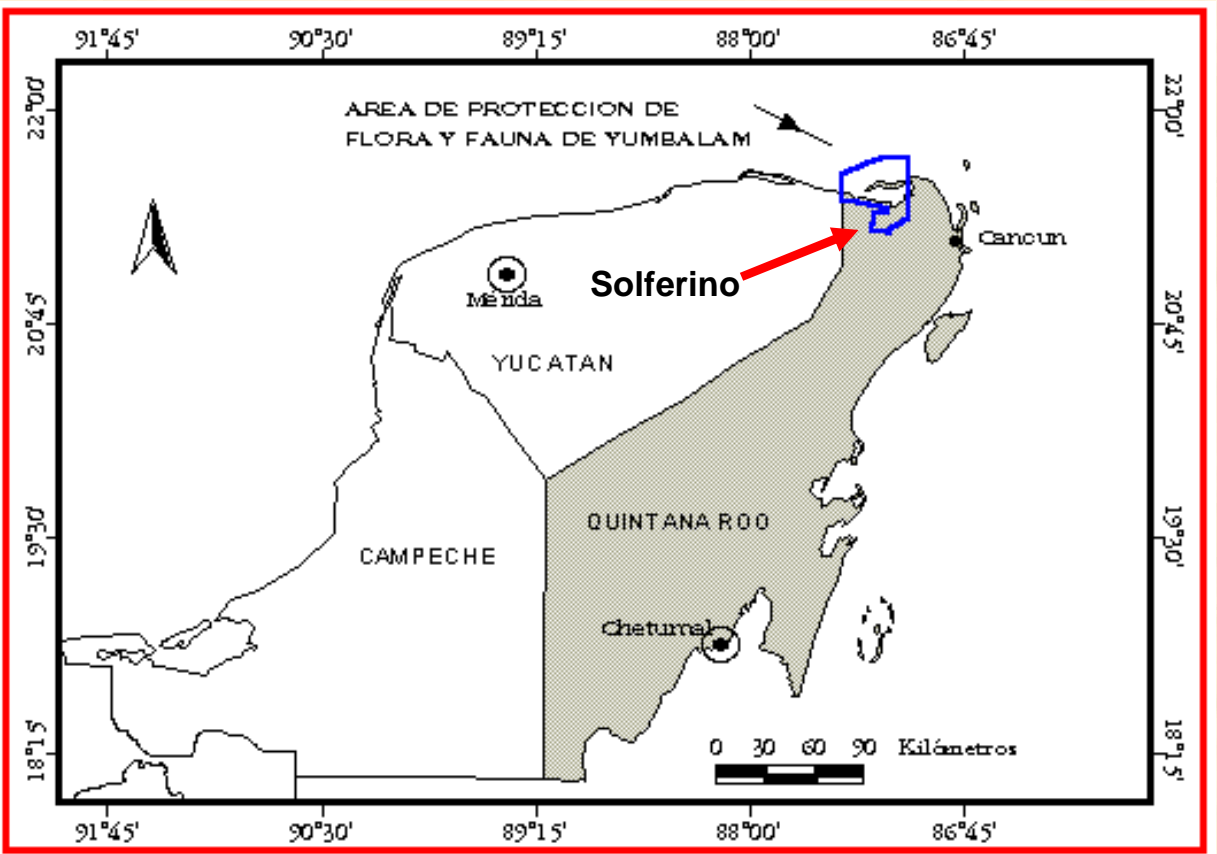

Fig. 1.2. Location of the Study Site (Ejido Solferino). Figure from the Centro de Investigacion Cientifica de Yucatán, México. 
I settled six pairs of $20 \mathrm{~m} \times 20 \mathrm{~m}$ plots in the following locations (first names of land owners, approximated forest age and UTM locations are in brackets): R. Antonio Lara (Antonio A and B, $\geq 55$ yr-old, Q11455139E, 2356216N); Mario Ucan (Mario A and B; $\geq 55$ yr-old, Q1145511E; 2357371N); Rosendo Can (Rosendo A and B; $\geq 55$ yr-old, Q11458200E, 2358807N); José “ Pepe” Quintal (Pepe A and C; approx. 10yr-old, Q11455596E, 2357889N); and two pairs of plots in Saúl Ancona (Saúl A, B, and Saúl C, and D, approx.18yr-old, Q11454708E, 2362311N; see also fig.1.3). All forest ages were estimated respect to year 2003, when I started exploring the area. Distance between plots of the same pair ranged from 5 to $20 \mathrm{~m}$, distance among pairs of plots ranged from 100m (pairs of plots Saúl A, B respect to Saúl C, D), to approx. $3 \mathrm{~km}$. I had no access to replications for the 10 and 18yr-old stands.

Soils are poorly developed Luvisols, Rendzines and Vertisols on a calcareous bedrock emerged after Pleistocene; groundwater is approximately 2-8 m depth for the whole peninsula, sometimes 1-2 m depth in the study site (Personal observation; FAO soil classification before 2006 used in Municipio de Lázaro Cárdenas, 1987; Olmsted et al, 2000; Bautista-Zúñiga et al, 2003; fig.1.4). 


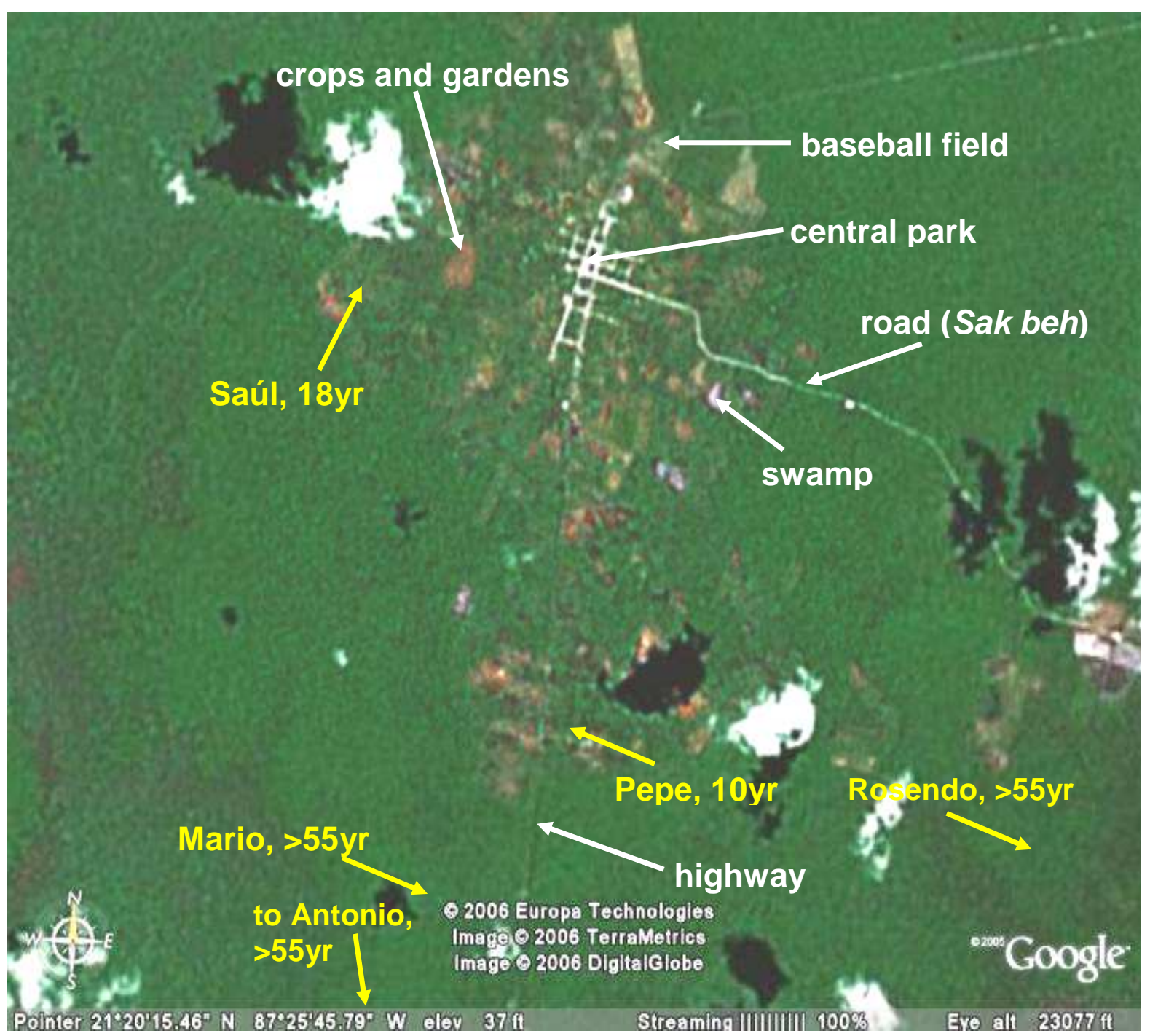

Fig. 1.3. Solferino: a mosaic of Semi-Evergreen Tropical Forest succesional stages (after satellite images of 2005). Yellow arrows indicate the approximate locations of the studied stands and their successional ages (Antonio's stand does not appear in the picture). Black spots are shadows of clouds, the baseball field is shown as a reference on how "green" do grasslands look like in the picture. Crops are mainly survivorship, small scale slash-and-burn poly-cultures (milpas), and back-yard gardens with spices and ornamental plants. However, the one in front of Pepe place is a large papaya plantation started in 2004. Squared spot toward the middle of the right margin of the picture is a remnant cattle after a more than $20 \mathrm{yr}$ process of decline of meadow areas in Solferino. Notice the different tones of green (representing different, very early successional stages of the forest) alternating with milpas. The highway is asphalted while the "white road" (in Mayan Sak beh) consists mainly of calcium stones that dominate the whole area, resulting in a more clear satellite image for the road. (Picture downloaded from (OGoogle Earth). 


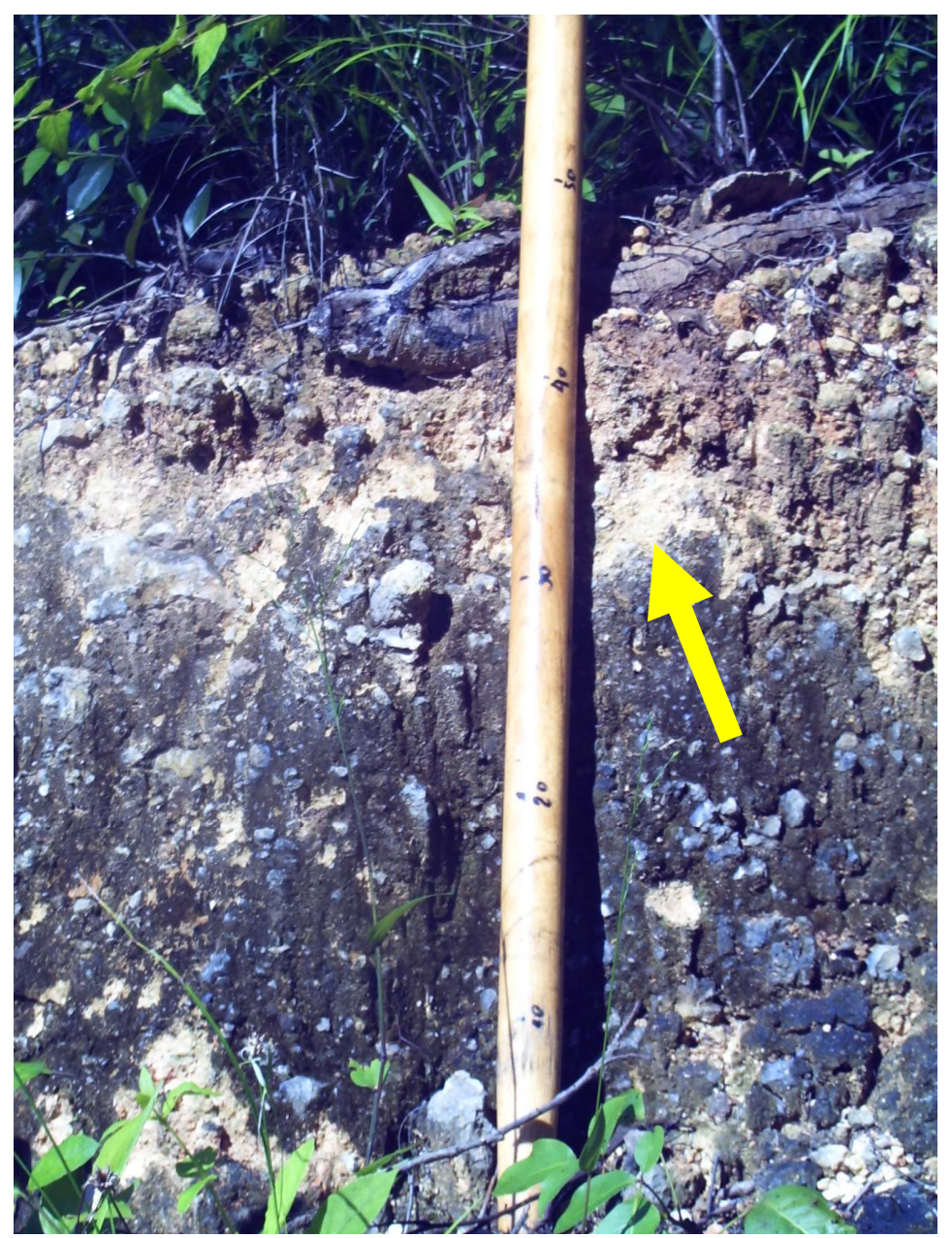

Fig. 1.4. Soil profile of a stone-extraction place near studied plots in Solferino. The arrow shows the calcium bedrock after removing the fungi and micro-algae originated dark cover resulting from rainfall and air moisture on the exposed bedrock.

The study site has a mainly flat topography and belongs to a Semi-Evergreen Tropical Forest (Selva Mediana Subperennifolia, sensu Miranda and Hernández, 1963; Tropical Dry Forest, sensu Holdridge et al, 1971). Mean annual precipitation is $1250 \mathrm{~mm}$, the dry season lasts from February to April and the wet season from May to January and includes strong winds and frequently hurricanes, especially from September to October (Orellana et al, 1999; 2003). Selective manual logging lacking machinery is the main source of income for approximately 800 inhabitants. 
Besides selective logging, Mayan and Mestizo inhabitants practice shifting, survivorship slash-and-burn agriculture, cattle (areas to do so declining since 1983), hunting, and extraction of non-woody wild plant resources. Latter is mainly latex from Manilkara zapota (chewing gum) trees, palm leaves for housing, and lianas for making baskets (Municipio de Lázaro Cárdenas, 1987; INEGI, 1993, 2002; Kiernan, 2000; Dupuy et al, 2007). Mayan-made survival crops (also called milpas) are poly-cultures usually including corn, beans, hot chili, tomatoes and other products mainly cultivated in less than one hectare and rarely per longer than three years. Milpas are made by clearing forest stands which successional ages usually oscillate between twelve and twenty years.

Latex extraction from each $M$. zapota tree (the process is called "chicleo") requires to climb the tree. Before climbing each man (or "Chiclero") cuts lianas and tree saplings around M. zapota individuals to avoid entangling himself (several Mayan Chicleros, pers. com). This practice, combined with selective logging and hurricanes generates gaps of different sizes within the forest and lianas colonize many of such gaps (Schnitzer et al, 2000). In the study site these lianas typically belong to the genera Cydista, Arrabidaea, Melloa (Bignoniaceae), and Serjania (Sapindaceae). Some of these genera have been demonstrated to perform better than other lianas under intense light entrance (Avalos and Mulkey, 1999). The mentioned information on the intensiveness of logging and chicleo and their consequences was available for me only after three years working and living in the area and -unfortunately not before starting my research. Logging and chicleo leads to a very irregular canopy, with patches of hardly detectable young vegetation embeded into older vegetation matrixes. Also, there is a high variation of land use between- and within farmer families. Hence, it was very difficult to locate replicated (similar) forest stands sharing the same plant species compositions.

Well documented history helped to estimate the forest age. There are Post-Classic Mayan-Style pyramids covered by a secondary forest (I saw them guided by Mr. Alfredo Dorantes, field Assitant of the Centro de Investigacion Cientifica de Yucatan) about $15 \mathrm{~km}$ 
away. It suggests that the area was populated not later than when the Spanish arrived in the first quarter of the 16th century and milpa was the dominant agricultural system. At the end of the 19th century, the area was politically linked to the rebelled Cruzob Mayans toward the end of the "War of Castes of Yucatan" and milpa and selective logging were very common (deduced from Reed, 1971). From 1902 to 1920, the Labnah village (today's Solferino) was the center of the Compañía Agrícola, which controlled almost all of the North Eastern Yucatan Peninsula. They produced sugar, hot chili, cotton, cacao and bananas in a very large scale, co-existing with the milpas of the natives (Careaga, 1994). Further abandonment of such areas may have produced the large areas of forest older than 55 years shown in fig.1.3.

Besides logging, intensive latex extraction from M. zapota trees during the 1930's, 50's and 60's (Reed, 1971; Careaga, 1994, also part of the oral tradition) produced clearings in the forest. The last two sources also suggest that larger gaps were open inside the forest where chicleros were camping per many months a year; each chiclero group was composed by an average of 14 men and one cooker. Old chicleros relate they were sleeping in personal, self-made beds (in Mayan "hatos") with roofs made out of treelets and palm leaves tied by Bignoniaceae lianas (Mr. David Morales, pers. com.). It suggests there was an intense clearing within the forest but avoiding total devastation in the studied $\geq 55 \mathrm{yr}$-old forest. To date, low-scale latex extraction for local markets remains an activity of the Mayans, but by individuals who do not camp into the forest, implying a lower level of disturbance.

In 1970, concomitant to the construction of Cancun City (about $90 \mathrm{~km}$ from Solferino), cattle breeding was sponsored. The trembling of large cattle feet destroyed (degraded) the shallow soil coverage. Cattle farming implies that the forest cannot recover, which is very important for the local religion. Indeed, many Mayans (e g Rosendo Can, pers. com.) do not accept cattle and prefer to combine milpa, hunting and many other sources of food and income (see also Jiménez-Osornio et al, 2003). Consequently, the meadow areas are reduced to less than $50 \%$ of its original size since the early 1980's (deduced from aerial 
pictures, see also Dupuy et al, 2007). All the mentioned activities generate disturbances producing forest margins, gaps, and a mosaic of secondary-growth stands favoring lianaproliferation (Laurance et al, 2001; Schnitzer and Bongers, 2002; fig.1.3).

I estimated the age of the forest stands by combining these information, aerial pictures from 1979, 1985, and 2001, and satellite images from 1997 and 2005, and thorough conversations with local farmers. Conclusions were that the ages and land use histories of the studied forest stands are: a) stand of José "Pepe" Quintal: 10yr-old, used 20 years for cattle farming and for four years for milpa with fertilizer; b) Saúl Ancona stand: 18yr-old, used just one year for milpa without fertilizer. c) The stands $\geq 55 \mathrm{yr}$-old belonged to: R. Antonio Lara, Mario Ucan, and Rosendo Can, now used mainly for extraction of latex, selective logging and hunting (ages respect to 2003).

One liana species (Dalbergia glabra, Papilionoideae) is very common in some stands 10-18yr-old. Because it proliferates in wetlands, the patchy distribution of poorly drained soils in the area may have promoted this species (Carnevali et al, 2003; Orellana et al, 2003). D.glabra is also common in areas previously exposed to fire (J.M.Dupuy, pers. com.), also contributing to explain its high abundance in the studied 10yr- and 18yr-old plots. In contrast, lianas from the Bignoniaceae family typify the $\geq 55 y r-o l d$ stands, suggesting that selective logging, chicleo and trees fallen due to hurricanes (e g Hurricane Gilbert, 1988) abet such lianas there by increasing incident light, that has been demonstrated to favor lianas of the Bignoniaceae in mature secondary forests of similar age in Panama (Avalos and Mulkey, 1999).

\subsection{General Methods}

Selection of forest stands for plots

After exhaustive walk, the forests stands for this study were preliminary chosen according to their: a) similar successional age and land-use history, b) visually high 
abundance of lianas, c) location in seasonally dry soils and outside wetlands, and d) visually similar composition of tree species. Six transects of approximately $25 \mathrm{~m}$ length were installed at each stand for identifying and measuring the bole and length of trees, their diameters at breast height, and the diameter of lianas at ground level, as well as determining the number of lianas per tree. Comparisons among transects (e.g. histograms of tree sizes) were made to create a basis for the decision on where to locate the plots with a maximum chance of being similar to each other. Approximately 15 plots were delimited by this procedure, but only six in the 10 and 18yr-old stands combined, and six in the $\geq 55 y$ r-old stands were finally chosen in terms of similarity. Even the effort of building plots helped to choose the stands to reform the studies. For example, during plot-delimitation, non-regular abundances of Randia truncata and other spiny plants suggested that some plots had incident light, stem densities and plant species compositions too different to the others. The small areas cleared by Mayans for milpa-agriculture, combined with the high efforts of the field work (all trees $\geq 10 \mathrm{~cm}$ girth at breast height, all lianas $\geq 1 \mathrm{~cm}$ diameter at ground level, see for example Materials and Methods in Chapter 2) among massive tangles of spiny lianas (specially D.glabra), suggested that it was unrealistic to study plots bigger than $20 \mathrm{~m} \times 20 \mathrm{~m}$.

\subsection{Chapters of this Dissertation, their specific objectives and specific hypotheses}

In Chapters 2, 3, and 4, I report the results form this research. The objective of Chapter 2 was to determine if lianas reduce the growth of co-existing trees located in forest stands of $\geq$ 55yr- vs 10-18yr-old forests. The hypothesis: If lianas are competitors of trees, then trees should grow less when hosting more lianas, when their liana-coverages are larger, and when lianas are not cut. In order to test such hypothesis, I measured and identified all trees $\geq 10 \mathrm{~cm}$ circumference in 12 plots $20 \mathrm{~m} \times 20 \mathrm{~m}$, and all lianas $\geq 1 \mathrm{~cm}$ diameter at ground level with the help of very competent field assistants. The number of lianas per tree was also determined and trees were classified into categories according to the percentage of their woody areas being 
covered by lianas. Lianas were cut in six of the 12 plots and tree circumferences were remeasured 15 months later. The results include trees that were negatively, and positively affected by liana cuttings or when hosting larger liana coverage. I propose that one liana species (Dalbergia glabra, Papilionoideae) enhanced the growth of trees by fixing nitrogen or, at least, did not outbalance the effect of other factors favoring trees (e.g. incident light). Specific objective of Chapter 3 was to test if liana-cutting enhances the growth of saplings in the same plots described above. The hypothesis: If lianas out-compete saplings for soil resources, liana-cutting should enhance the growth of saplings. In each of the 12 plots, 10 subplots of $2 \mathrm{~m}^{2}$ were installed and the lengths of all saplings $\geq 30 \mathrm{~cm}$ length but $<10 \mathrm{~cm}$ circmference were measured. Box 2 explains why a minimum length size but a maximum width size were used and why it is a common practice in Ecology and Forestry.

Fifteen months after liana-cutting, saplings were re-measured. In the plots where Bignoniaceae lianas dominated, liana-cutting enhanced the growth of the saplings. However, in three plots dominated by far by D.glabra, liana-cutting had no species-specific effect and enhanced the growth of saplings when all species were pooled. Factors like accumulated leaflitter per hectare, basal area of trees and soil moisture differences among plots seemed to do not cause such results. More studies are necessary to test if lianas, and not other factors like the quantity and quality of light, determined the results. However, as pointed out in Chapter 2, these results encourage reconsidering the idea that lianas cannot favor saplings (e.g. Clark and Clark, 1990; Ewel and Hiremath, 2005). 


\section{Box 2. What are saplings and how Ecologists decide which saplings to study?}
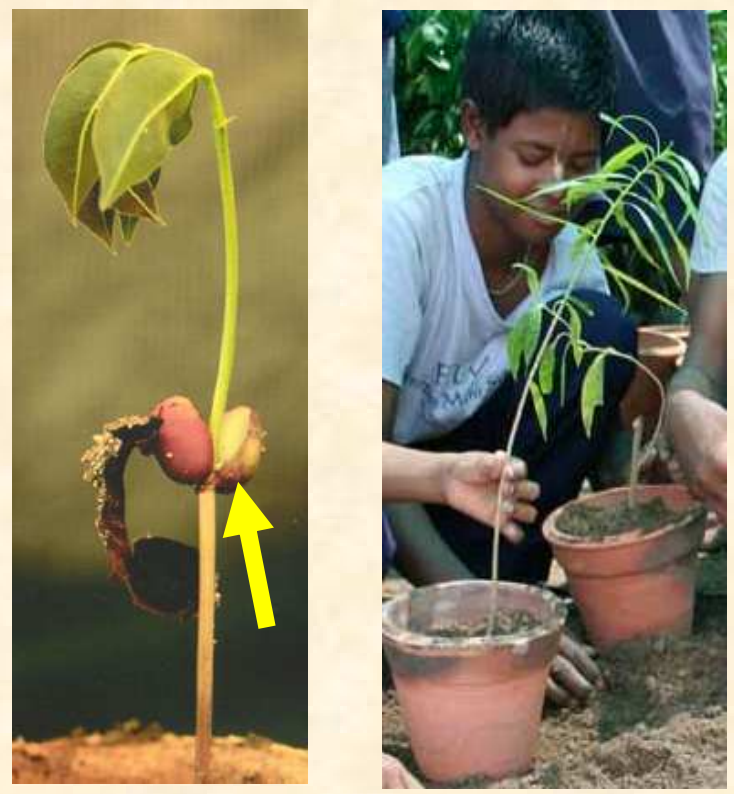

Trees are too large to scientist to measure their primary (length) growth and that is why scientist measure the change of their widths (secondary growth). In contrast, the growth of seedlings (left) and saplings (right) is mainly primary, so to study their growth implies to measure their lengths. Respect to trees, seedlings and saplings are more handreachable, making easier to measure their elongation. However, because plants grow very gradually, it is not easy for fast surveys to define if many "saplings" are already subadults or adult trees. Adults produce flowers and this occurs also to many small, hand reachable individuals, but many surveys have no time to wait for flowering. It also changes among species, but many studies include too many species for assessing the real stage for each individual, especially because there is also intra-specific variation due to genetic and microenvironmental factors like light,

soil moisture and nutrients. Because of this, Ecologists and Foresters study the "saplings" and mention minimum and maximum sizes for plants considered under this name. But because the length of smaller saplings is a more informaive measure than their width, the lower size limit is usually reported as a length (30 cm length, for the proposes of this dissertation). For many studies, the upper size limit is usually a width (10cm circumference for this dissertation), when secondary growth is alredy detectable. This inconsistence of measured dimensions also makes sense if, besides saplings, trees and other large individuals are studied in the same place. For example, in this dissertation, the upper size limit of studied saplings (10cm circumference) is also the lower limit of studied trees, implying that a wide range of plant development stages is included in the whole study. Finally, saplings must not be confused with an earlier stage of plant development, namely the seedlings (left hand figure). Dislike saplings, seedlings have seed-originated cotyledons (see the arrow), which are organs supplying them nutrients that were originally produced by the "mother" tree . Because such nutrients, and not necessarily lianacutting, may affect this growth, seedlings were not studied in this dissertation (more information in Begon et al. 1996, credits to figures are: Center for Tropical Forest Science -left, and Vrindavana foundation -right).

The objective of Chapter 4 was to test if the presence of living lianas increases the chance of trees to suffer structural damage when strong winds pull down other trees. Two alternative hypotheses were tested: 1) lianas may cause more damage by pulling more trees, and 2) lianas may tie canopies together providing more stability and thus there will be less damaged trees (Putz, 1984a). Hurricane Wilma enabled this study to test the hypotheses. Before the hurricane, and when I measured the trees as described in Chapter 2, I also determined if they were bowed by lianas and by causes different to lianas, and even if they 
grew sloped (in a diagonal position in spite of their straight trunks). Seventeen months after cutting lianas, the hurricane hit the study site. Trees were re-visited and classified into categories of structural damages. Trunk snapping and tree uprooting (the two most severe damages) occurred independently of liana-cutting, number of lianas per tree, and lianacoverage per tree. Larger trees and trees hosting larger liana coverage had more chances of suffering crown removal in the $\geq 55 \mathrm{yr}-$ old stand. In contrast, trees hosting more lianas suffered less crown removals in the 10-18yr-old stand. Because liana-cutting did not have any effect, I propose that lianas: a) contributed to crown removal in the $\geq 55 y$ r-old forest by displacing the gravity center of crowns, and b) reduced crown removal in the 10-18yr-old forest by binding canopies together. I also propose that just heavy-and-rigid-bodied lianas like D.glabra played such a role, and that many lianas rarely enhance structural damages on trees in the study site.

Chapter 5 integrates the main results and conclusions of chapters 2, 3, and 4. Essentially, results confirm the classically accepted idea that lianas affect the growth of coexisting trees and sapling species differently. However, some species tended to grow less in some stands while growing more in others. At a landscape level, liana-effects of some individuals in one area may be compensated by liana-effects -or lack of effects on others, avoiding lianas to reduce substantially the populations of trees. Something similar may occur in patches of different successional ages within a single forest. That is why I propose that lianas could not be a driving force in tree species turnover throughout time. At the same time, my results challenge the idea that lianas cannot enhance the growth of trees in a consistent, predictable fashion and avoid structural damages of trees in North Eastern Quintana Roo. Consequently, cutting lianas for protecting trees is not always necessary and there is no single rule to decide when to do it.

Finally, I want to warn readers about the repetition of some information in chapters 2 , 3, and 4 (e.g. description of the study site and classification of trees into liana-coverage 
categories). I am trying to publish each chapter as an article in a different journal and it remains unclear which one will be accepted first so it was necessary to repeat such information in this text. The advantage is that each chapter is understandable without reading the others. Also, although I am the only and original responsible of this dissertation, no serious modern scientist works without the deep interaction with colleagues (in this case, my advisors and one field collaborator). Indeed, in order to my further publications to honor such a valuable help, the mentioned chapters are written in first person plural ("we cut the lianas", instead of "I cut the lianas"). I would appreciate you to enjoy reading this document as I enjoyed generating it in the field and on the paper. 


\section{Chapter 2}

\section{GROWTH OF CO-EXISTING TREE SPECIES IN RESPONSE TO HOSTED LIANAS IN NORTHERN QUINTANA ROO, MEXICO}

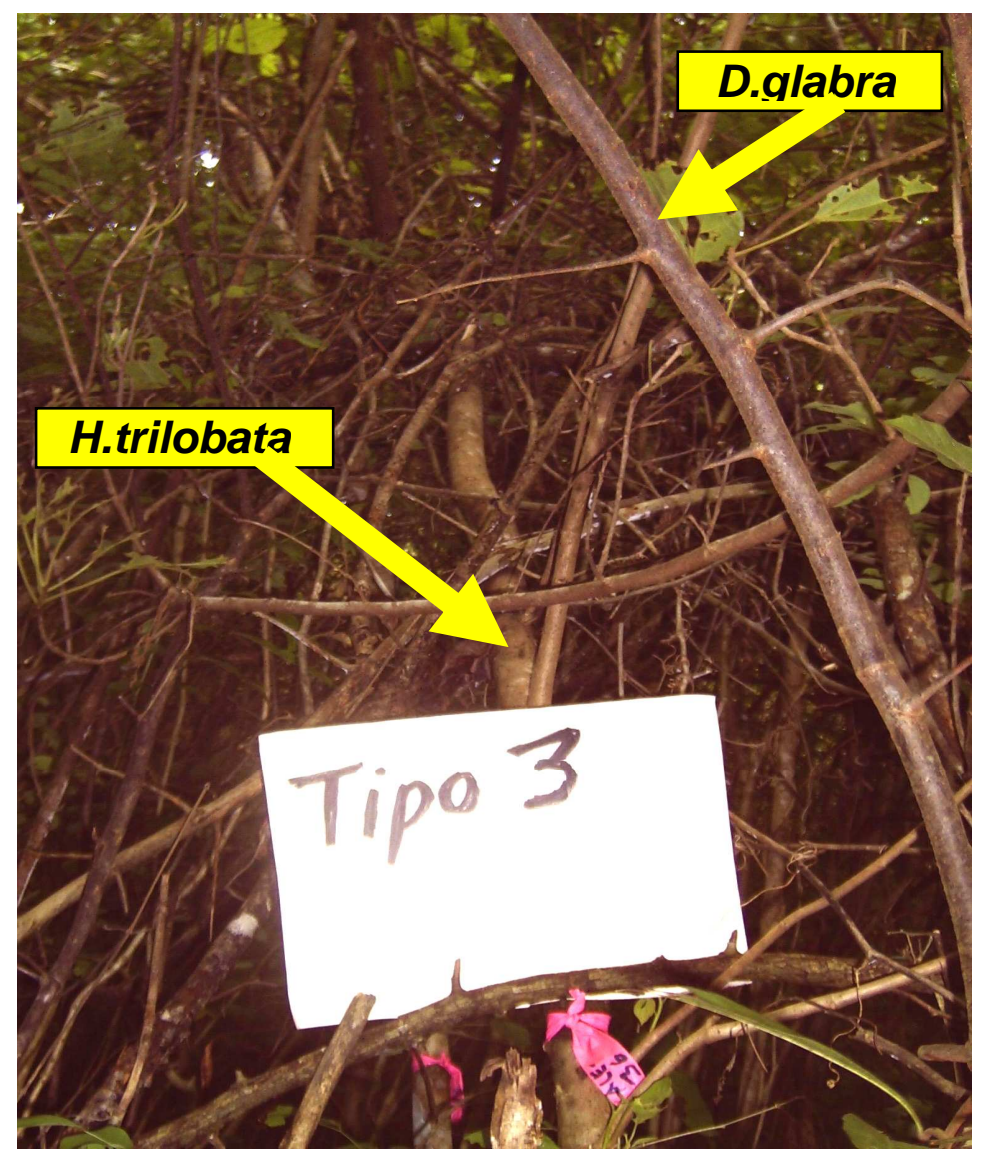

This figure shows a Hampea trilobata (Malvaceae) tree with the highest liana-coverage category (in Spanish "tipo") recorded in this study. The liana species is Dalbergia glabra (Papilionoideae). In spite of the hughe abundance of D.glabra and other lianas, some tree species tended to grow better when it was not cut. Picture by E. I. Garrido-Pérez (August, 2005). 


\subsection{Introduction}

Lianas (woody vines) compose about $25 \%$ of the flora of tropical forests, where 33 79\% of trees host lianas (Putz, 1984a; Gentry, 1991; Pinard and Putz, 1994; Campbell and Newberry, 1993). Lianas increase their densities in natural and tree-felling gaps by lateral branching, delaying the gap-phase and affecting tree regeneration (Schnitzer et al, 2000; Parren, 2003). Global increase in atmospheric $\mathrm{CO}_{2}$ can enhance tree-fall dynamics by making trees grow and fall faster, and thereby increase the relative abundance of lianas with respect to trees in tropical forests (Phillips et al, 2002; Granados and Körner, 2002; Wright et al, 2004). Lianas are also abundant in young secondary forests and forest edges. Consequently, liana abundance is also expected to increase as a result of both, forest fragmentation, and deforestation followed by land abandonment (Guariguata and Ostertag, 2002; Gerold, 1994; De Walt et al, 2000; Laurance et al, 2001).

Several studies indicate that lianas reduce the growth and reproduction of certain tree species (Putz, 1984a; Whigham, 1984; Stevens, 1987; Clark and Clark, 1990; Pérez-Salicrup, 2001; Schnitzer et al, 2005). Because their xylem vessels are wider than those of trees, lianas can outcompete trees for water and soil resources (Ewers et al, 1990, Ewers et al, 1991; Fitchner and Schultze, 1990; Gartner et al, 1990; Phillips et al, 1999; Dillenburg et al, 1993a, b; Pérez-Salicrup and Barker, 2000; Schnitzer et al, 2005, but see Barker and Pérez-Salicrup, 2000). Studies demonstrating deleterious effects of lianas on trees have been the basis of the hypothesized role of lianas in tree species regeneration and forest dynamics, assuming that competition with lianas differentially affects co-existing tree species (Barker and PérezSalicrup, 2000; Clark and Clark, 1990; Pérez-Salicrup, 2001; Pérez-Salicrup and Barker, 2000; Laurance et al, 2001; Schnitzer and Bongers, 2002; Parren, 2003).

Compared to trees, however, lianas can extract water from deeper layers of the ground thereby potentially avoiding root competition (Andrade et al, 2005). While studies supporting the assertion that lianas differentially reduce tree growth and reproduction focus on individual 
trees of one or two species (Putz, 1984a; Clark and Clark, 1990; Barker and Pérez-Salicrup, 2000; Pérez-Salicrup and Barker, 2000; Schnitzer and Bongers, 2002; Parren, 2003; Schnitzer et al, 2005; but see Pérez-Salicrup, 2001); there is a paucity of studies on liana effects on assemblages of co-existing trees of different species. Since liana abundance and species composition changes during secondary forest succession (Caballé and Martin, 2001; De-Walt et al, 2000; Laurance et al, 2001), effects of lianas on tree communities may vary with successional age. In this study we evaluate the effect of lianas on tree growth at the community level by comparing the growths of trees whith different percentages of their woddy areas covered by lianas, and by experimentally cutting lianas in young (10-18 yr-old) and intermediate ( $\geq 55$ yr-old) secondary semi-evergreen tropical forests in Quintana Roo, Mexico. We also measured the effects of liana load (number of lianas per tree) on the growth of trees. Hypothetically, a) higher numbers of hosted lianas should hinder the growth of trees compared to trees hosting less lianas, b) trees having larger liana-coverages should grow less compared to other trees, and c) liana-cutting in forest plots should enhance the growth of trees. We test these hypothesis for different co-existing tree species and discuss the results according to the potential role of lianas in tropical forests.

\subsection{Materials and Methods}

Study site and settlement of plots

Study site is in the peasants' community of Ejido Solferino, Quintana Roo, Mexico, near Yum Balam Reserve of Flora and Fauna $\left(21^{\circ} 26^{\prime} \mathrm{N}, 87^{\circ} 28^{\prime} \mathrm{W}\right.$; $10 \mathrm{~m}$ above see level; INEGI; 1993). Soils are poorly developed luvisols, rendzines and vertisols upon a calcareous base emerged after Pleistocene, with underground waters c.a. 2-8m depth (Municipio de Lázaro Cárdenas, 1987; Olmsted et al, 2000; Bautista-Zúñiga et al, 2003). Topography is mainly flat; life zone is Semi-Evergreen Tropical Forest (Selva Mediana Subperennifolia, sensu Miranda and Hernández, 1963; Tropical Dry Forest, sensu Holdridge et al, 1971). 
Average annual rainfall is $1250 \mathrm{~mm}$, dry season lasts from February to April, wet season from May to January, including strong winds and some hurricanes, especially in SeptemberOctober (Orellana et al, 1999; 2003). Mayan and Mestizo inhabitants practice: shifting, survivorship slash-and-burn agriculture, cattle (areas to do so declining since 1983) hunting, selective logging, and extraction of non-woody wild plant resources, mainly latex from Manilkara zapota (chewing gum) trees (Municipio de Lázaro Cárdenas, 1987; INEGI, 1993; Kiernan, 2000).

We settled 12 plots $20 \mathrm{~m}$ x 20m described in Table 2.1. Plot selection was biassed to places having high abundance of lianas in order to have more tree individuals with lianas per species, since our aim was to assess the effect of lianas on tree species assemblages. Altogether, the $\geq 55$ yr-old plots averaged a liana-density $=0,41$ ind $\cdot \mathrm{m}^{-2}$ and tree density $=$ 0,36 ind $\cdot \mathrm{m}^{-2}$. The10yr- and 18yr-old plots combined averaged: liana density $=0,375$ ind. $\mathrm{m}^{-2}$, and tree density $=0,39$ ind. $\mathrm{m}^{-2}$. Liana communities are dominated by species of the genera Cydista and Arrabidaea (Bignoniaceae, in the $\geq 55$ yr-old plots), and by Dalbergia glabra (Papilionoidae, plots 10-18 yr-old; see chapters 3, and 4).

\section{Field work}

We identified, marked with a unique code number, measured the girth and painted the measurement point of all the trees $\geq 3,16 \mathrm{~cm}$ dbh (diameter at breast height, that means 1,30 m above ground level; see tree species in Appendix I). We also measured and identified into genera and some species all lianas $\geq 1 \mathrm{~cm}$ diameter at ground level, marking each individual with a unique code number (Appendix I). Diameters were measured with a caliper in nonhunched regions of stem internodes in order to have conservative estimations of liana-basal areas. When liana stems were not transversally round but elliptical, only the smaller diameter was measured. Lianas rooting outside plots but hosting on trees inside them were excluded assuming they do not compete with trees inside plots. We marked all hand reachable stems of 
each liana individual with its respective code number to avoid counting and measuring the same individual more than once. When stems seemed to be branches from underground stems, we excavated c.a. $10 \mathrm{~cm}$ depth around them to find and measure the main stem. When it was not reached, each aerial stem was marked and considered as a different individual. When we reached the main stem but it was impossible to be measured (e.g. stems decomposing or surrounded by big stones), we considered the sum of the basal areas of the branches as the basal area of the individual. Herbaceous vines and juveniles of lianas (mainly Smilax spp, Smilacaceae) having at least one stem $\geq 1 \mathrm{~cm}$ diameter were included as lianas ad honorem. It assumed that their roots are potentially able to compete with the ones of trees and the pressure of their anchoring organs (e g tendrils) can avoid sap flow throuoghout the phloem of their hosting trees as lianas are suggeested to do, potentially reducing allocation of photosynthate for the growth of trees (Dillenburg et al, 1993a; Stevens, 1987; Kainer et al, 2006).

We counted the number of liana individuals hosted by each tree by gently moving with the hand and a pole both, liana and tree branches, while following visually liana branches until the base of their stems on the ground and checking its identification code number. Only lianas anchored (e g by tendrils, spines or hooks), climbing upon the trunks, or having at least one stem horizontally or diagonally contacting any branch of the tree but being upon it were considered as lianas hosted by the target tree. Lianas with branches, stems or leaves above or close to the tree without contacting it at the moment of our visit were not considered as hosted by any target tree, although their may have been hosted by these trees before our visit.

Because lianas may overlap tree leaves and apply forces on trees, liana effects may depend not only on how many lianas hosts a target tree, but also on how large is the coverage of a tree by lianas (= liana-load sensu Kainer et al, 2006). For example, one single liana can be so entangled with one tree, that its effects may be higher than the one of several lianas having fewer contact points with a similar tree. A very good measurment of that is to count how many liana-tree contact points each tree has, but it was logistically not possible in the 
field. Indeed, we visually classified each tree according to the percentage of its woody area covered by lianas into the following liana-cover categories: $(0)=$ no lianas, $(1)=1-25 \%,(2)=$ $25-75 \%$, and (3) $>75 \%$ (fig. 2.1 ).
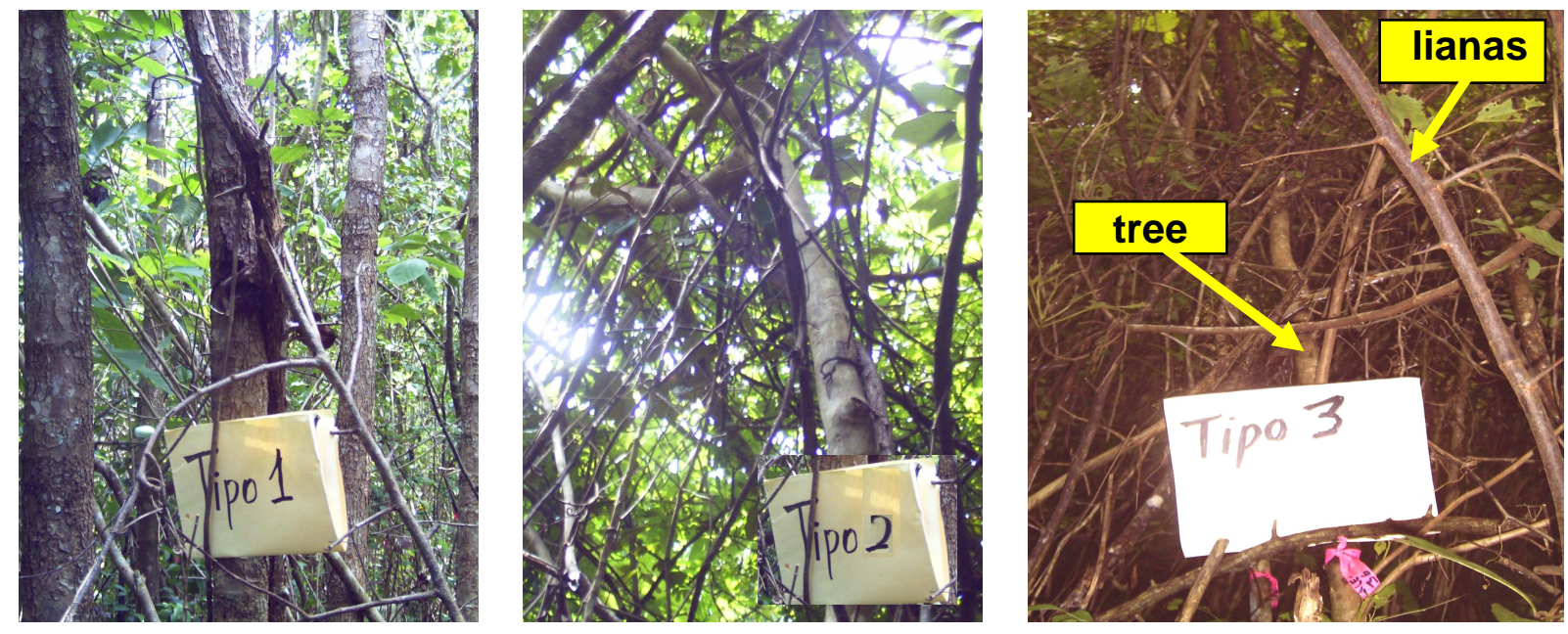

Fig.2.1. Representatives of three categories ("tipos") of liana-coverage per tree. Category 0 (no lianas) is not shown. The number of lianas per category is not necessarily the same that appears in the figure. See text for full explanation. Pictures by: E. I. Garrido-Pérez (August 2005).

This ordination is very similar to the one of Clark and Clark (1990) and Kainer et al (2006), though they used the crown area (not the woody area) of trees as reference. After data-collection we analyzed a random sample of 322 trees from all stands in order to check how many liana individuals and which basal area of lianas corresponded to what lianacoverage categories. Categories (1), (2), and (3) had on average one, two, and six lianas (see results for details). Such relation probably arose because lianas facilitate other lianas to climb upon trees (Putz, 1984a; Pinard and Putz, 1994). However, it does not determine how large are the upcomming lianas, resulting in a lack of consistency between liana-number and lianabasal area per coverage category in our study site (contrary to Kainer et al, 2006). Thus, for avoiding confussions with the literature, we reserved the word "liana-coverage" as an indicator of how liana-entangled a tree is, keeping the term "liana-load" only as a precise categorization of the number and basal area of lianas hosted by a tree.

On May 22-23 2004 we cut the lianas and herbaceous vines in the following plots: $\geq$ 55 yr-old: Mario55 B, Antonio55 B, Rosendo55 A; 10 yr-old: Pepe10 A; 18yr-old: Saúl18 B 
and Saúl18 C; re-cutting them every 2,5 to 3 months to control the few re-sprouting lianas (Apanah and Putz, 1984; De la Torre, 2003; Parren, 2003). We never removed lianafragments suspended in the canopy in order to avoid damages of leaves and small branches of trees due to this manipulation (that potentially reduces the growth of trees). During August 2005 we re-measured the girth of each tree in the painted point it was measured before cutting the lianas. Both, pre- and post cut measurements were made with the same tapes, avoiding bark protuberances. Almost all trees had no buttresses and the few ones having them were measured above the buttresses.

\section{Data analysis}

We used one way ANOVA to compare both, number of lianas and liana-basal areas among liana-coverage categories.

Many tree species had too few individuals per plot to analyze liana-effects on their growths. Indeed, we decided to group the plots according to their similarities in tree species composition and number of individuals per species by using a Cluster Analysis (Weighted Pair-Group Average, WPGA; Appendix I enlists tree species and their numbers of individuals used for WPGA). For such analysis we used Manhattan distances as indicators of similarities among plots. We repeated the method for lianas, but not for trees and lianas together because of potential non-precise liana taxonomic identifications.

For each individual tree we calculated a Relative Growth $\left(R G=\left(X_{f}-X_{i}\right) / X_{i}\right.$, where $\mathrm{X}_{\mathrm{i}}=$ pre-cut girth and $\mathrm{X}_{\mathrm{f}}=$ post-cut girth). In order to our data to fit normality and homogenous variances before analysis, we transformed them as follows: RG and Xi: $\log _{2}$; Number of hosted lianas per tree: $\left(V_{n}+V_{n+1}\right)$, where $n=$ number of lianas.

For each of both plot groups ( $\geq$ 55yr- and 10-18yr-old forests) we used Multiple Regressions for exploring the relation between: number of lianas per tree and pre-cut girth of trees (as explanatory variables) and the RG of trees (response variable). One property of 
regressions is their potential to show non-reliable trends when the sample includes several hundereds of individuals. We used this property of regressions to ensure if our explanatory variables affected our response variable by analyzing all plots of each group together. If after such "exaggerated Regressions"there is no trend in spite of the large sample size, the response variable is not affected by the explanatory ones. For any group showing a trend, we split the group into its indivivual plots, and then we made regressions within plots for detecting in what plots the explanatory variables (number of lianas per tree and pre-cut girth) were related to RG.

Within each group we explored the effect of the liana-coverage on the RG of the different tree species for all species having $\mathrm{n} \geq 3$ individuals in all liana-cover categories. For that we ran two-way fixed effect ANOVA, being liana-cover one factor with four levels, each one corresponding to one liana-cover category, and the tree species the second factor, with as many levels as tree species being analyzed. We also explored the relationship between the following explanatory variables: (a) liana cutting (one factor with two levels: liana-cut and liana- uncut), and (b) species of target tree, (two-way fixed factor ANOVA, where RG was the response variable). We made it only for species having $\mathrm{n} \geq 5$ individuals in both, the liana cut and liana un-cut treatments of each group. We did not use three way ANOVA for testing the effects of liana-coverage and liana-cutting on the growth of tree species because the number of species having enough individuals to be analyzed was too small. Because we ran two ANOVAs per group of plots, we corrected our significance level by Bonferoni method from $\alpha=0,05$ to $\alpha=0,025$. In order to confirm if the results for individual species occur for all trees in general, we tested the effect of liana-cutting (Student's t) and liana-coverage (oneway fixed effect ANOVA) for all trees in each group regarding their species. Bonferoni's corrected $\alpha$ were: 0,016 for liana-cutting, and 0,0125 for liana-coverage.

Altogether, plots had 1826 trees, 56 of them automatically excluded by our Software (Statistica 5) for further analysis (but not for the Cluster Analysis mentioned above). From the 
remaining 1770 trees, there were 1526 individuals increasing their widths, analyzed as previously explained, and 244 trees having $R G \leq 0$. The effects of lianas on trees with $R G \leq 0$ were studied appart of width-increasing trees because it is impossible to transform zeros and negative numbers into logarithms. We converted all negative and zero values into positive ones by summing $0.000001 \mathrm{~cm}$ to each $0 \mathrm{~cm}$ growth in order to our data to stay as realistic as possible. Meanwhile, we multiplied the growth of each negatively grown tree per -1 . Resulting RG were $\log _{2}$ transformed. As well as for trees incresing their widths, no species had enough individuals to study the effects of liana-coverage and liana-cutting among species using three-way ANOVA, and not for analyzing liana-cover and liana-cutting separatedly (two-way ANOVA). Individuals were also too few to perform such analysis in the two forest age categories separately. Indeed, for the particular case of trees with no-positive growth, we pooled the data from all the 12 plots and nested the trees of the four liana-cover categories into the liana-cutting categories (liana-uncut and liana-cut), and tested the effect of lianacover and liana-cutting on the negative growth of such for trees (Nested ANOVA).

\section{Averaged effect of lianas on different tree species}

We calculated one index to assess the effect of lianas on each tree species. Such an index is: $\Omega$ (index of liana effect on tree growth), which is based on the width growth of trees expressed as RG. Within the group of plots $\geq 55 \mathrm{yr}$-old forest, we had plots where lianas were cut and un-cut. We averaged the RG for each species for both, liana-cut and liana-uncut treatments within plot group and calculated $\Omega= \pm / \mathrm{avRG}_{\mathrm{cut}}-\mathrm{avRG}_{\mathrm{un}-\mathrm{cut}} /$; where $a v R G$ is the average relative growth rate for all the individuals of the same species; signs + and - indicate respectively that the species grew more, or less when lianas were intact, and values of 0 indicate trees had the same growth in both, liana-cut and uncut places. All $\Omega$ calculations were made only for species having $\mathrm{n} \geq 5$ individuals in both, cut and uncut treatments, including individuals with null and negative growth. Results are represented as bar graphs 
where each bar represents a species. We repeated the whole procedure for the group of plots in the 10-18yr-old forest.

\subsection{Results}

Four of our six pairs of plots had very uneven basal areas of trees, having one plot generally about 1,8 times higher basal area than the other (Table 2.1). However, it was mainly due to the five bigger trees and, after excluding them, basal areas of trees among plots of the same pair were similar for four of our six pairs of plots (Table 2.1). Plot Antonio55 B had five times smaller tree basal area than Antonio55 A; plot Saúl18 D had almost 1,5 times larger tree basal area than Saúl18 C, Table 2.1.

Our liana-cover categories averaged the following numbers of liana-individuals: cat$1=1,6(\mathrm{SD}=0,93)$, cat $-2=2,3(\mathrm{SD}=1,72)$, and cat $-3=5,6(\mathrm{SD}=3,75)$, being cat $-1<$ cat $-2<$ cat. 3 in terms of numbers of individuals (one way ANOVA, $\mathrm{F}=112,169, \mathrm{P}<0,001 \mathrm{DF}=319$ ). Resulting basal areas in $\mathrm{m}^{2} \mathrm{ha}^{-1}$ averaged: cat- $1=0,02(\mathrm{SD}=0,04)$, cat- $2=0,12(\mathrm{SD}=0,21)$, and cat-3=0,04 $(\mathrm{SD}=0,12)$, being cat $-1 \approx$ cat-3 < cat-2 (one way ANOVA, $\mathrm{F}=15,983$, $\mathrm{P}=0,000001, \mathrm{DF}=319$. For each category, subsampled numbers of individuals (n) were: cat$1=210$, cat $.2=60$, and cat $-3=52)$.

After WPGA both dendrograms suggested there were two broad categories of plots: $\geq$ 55 yr-old and 10-18yr-old (fig.2.2), which is consistent with the similarities of successional ages among plots (Table 2.1). Indeed, for further analysis we collapsed our plots into two categories: $\geq 55 \mathrm{yr}-$ and 10-18yr-old forests. 

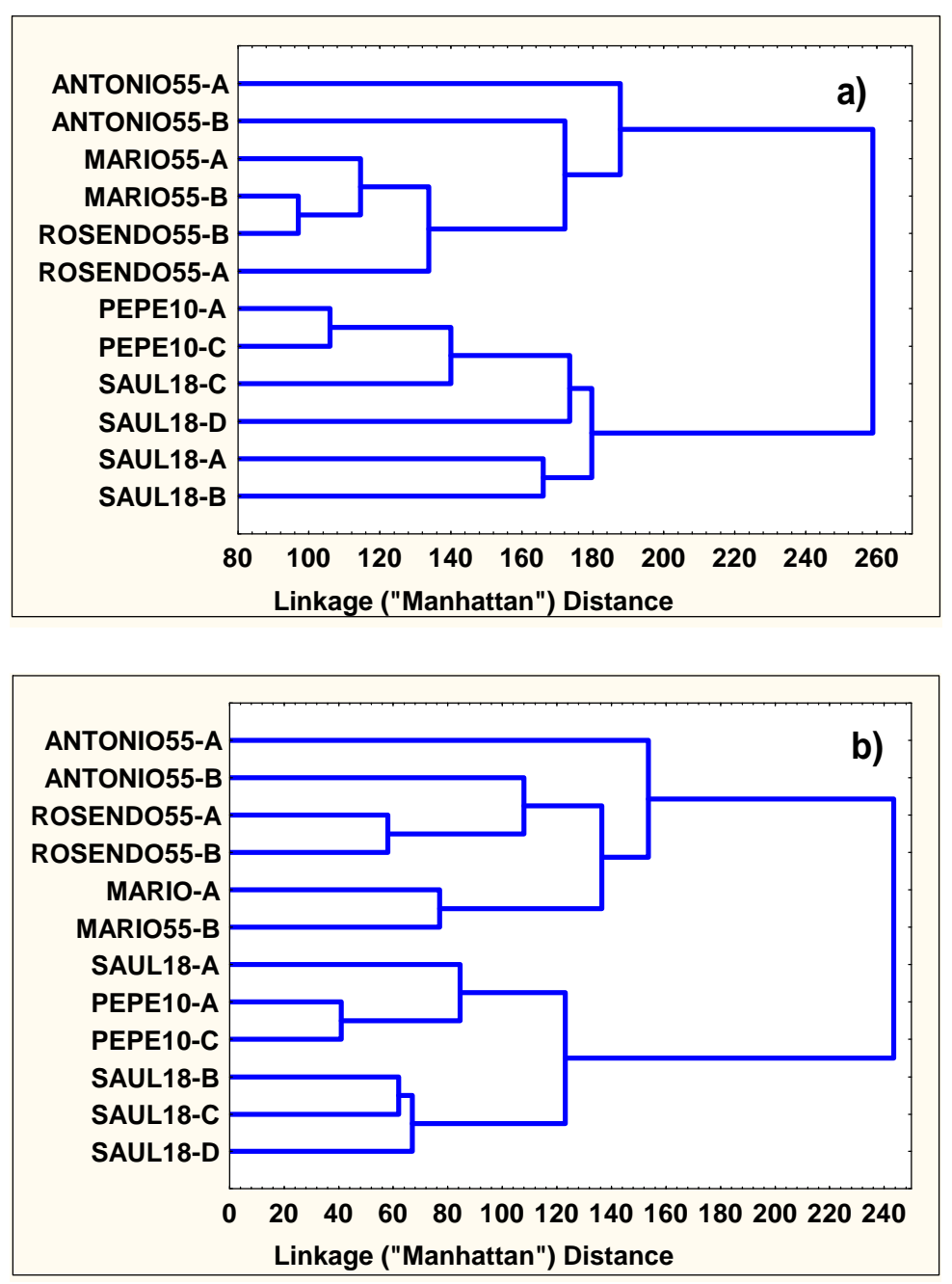

Fig.2.2. Dendrograms clustering plots according to their shared (a) tree species and (b) and liana species after Weighted Pair-group Average (WPGA). Plots separated by smaller Manhattan distances share more species and individuals per species. Notice that the two major groups (main branches) also share more similar successional ages (indicated by numbers besides the name of each plot, e.g. Antonio55-A is a plot in a forest $\geq$ 55 yr-old). Smaller scale in (a) indicates shorter Manhattan distances in tree species compositions, suggesting more similar species compositions for trees than for lianas among plots. It was probably because of a more clumped distribution of lianas due to their mainly vegetative reproduction. 
Table 2.1. Summarized description of twelve $400 \mathrm{~m}^{2}$ plots of Semi-Evergreen Tropical Forest.

\begin{tabular}{|c|c|c|c|c|c|c|}
\hline $\begin{array}{l}\text { Age and Land } \\
\text { use history }\end{array}$ & Plot & $\begin{array}{l}\text { Liana-uncut } \\
\text { or Liana-cut }\end{array}$ & $\begin{array}{l}\text { number } \\
\text { of tree } \\
\text { individuals }\end{array}$ & $\begin{array}{l}\text { number } \\
\text { of liana } \\
\text { individuals }\end{array}$ & $\begin{array}{l}\text { tree-basal } \\
\text { area }\left(\mathrm{m}^{2} \mathrm{ha}^{-1}\right)\end{array}$ & $\begin{array}{l}\text { liana-basal } \\
\text { area }\left(\mathrm{m}^{2} \mathrm{ha}^{1}\right)\end{array}$ \\
\hline $\begin{array}{l}\geq 55 \mathrm{yr} \text {, selective } \\
\text { logging, latex, } \\
\text { hunting to day. }\end{array}$ & $\begin{array}{l}\text { Antonio55 A } \\
\text { Antonio55 B } \\
\text { Mario55 A } \\
\text { Mario55 B } \\
\text { Rosendo55 A } \\
\text { Rosendo55 B }\end{array}$ & $\begin{array}{l}\text { uncut } \\
\text { cut } \\
\text { uncut } \\
\text { cut } \\
\text { cut } \\
\text { uncut }\end{array}$ & $\begin{array}{l}168 \\
153 \\
128 \\
129 \\
159 \\
111\end{array}$ & $\begin{array}{l}179 \\
185 \\
93 \\
184 \\
169 \\
140\end{array}$ & $\begin{array}{l}37,86(21,55) \\
27,27 \\
16,30 \\
28,23(16,75) \\
19.17 \\
25,11(17,20)\end{array}$ & $\begin{array}{l}1,32 \\
1,15 \\
1,03 \\
3,59 \\
1,37 \\
1,65\end{array}$ \\
\hline $\begin{array}{l}18 \mathrm{yr} \text {, slash- } \\
\text { and-burn } \\
\text { agriculture } \\
\text { per one yr. }\end{array}$ & $\begin{array}{l}\text { Saúl18 A } \\
\text { Saúl18 B } \\
\text { Saúl18 C } \\
\text { Saúl18 D }\end{array}$ & $\begin{array}{l}\text { uncut } \\
\text { cut } \\
\text { cut } \\
\text { uncut }\end{array}$ & $\begin{array}{l}195 \\
186 \\
111 \\
172\end{array}$ & $\begin{array}{l}127 \\
82 \\
85 \\
99\end{array}$ & $\begin{array}{l}15,21 \\
16,53 \\
12,88\{\mathbf{1 5}, \mathbf{1 6}\} \\
24,32(22,07)\end{array}$ & $\begin{array}{l}2,12 \\
0,66 \\
2,10 \\
3,37\end{array}$ \\
\hline $\begin{array}{l}10 \mathrm{yr} \text {, cattle } \\
\text { per } 20 \mathrm{yr}, \\
\text { slash-and-burn } \\
\text { agriculture per } \\
\text { four yr. }\end{array}$ & $\begin{array}{l}\text { Pepe10 A } \\
\text { Pepe10 C }\end{array}$ & $\begin{array}{l}\text { cut } \\
\text { uncut }\end{array}$ & $\begin{array}{l}112 \\
146\end{array}$ & $\begin{array}{l}147 \\
196\end{array}$ & $\begin{array}{l}11,10 \\
11,32\end{array}$ & $\begin{array}{l}4,06 \\
3,92\end{array}$ \\
\hline
\end{tabular}

Notes: Forest ages were estimated respect to 2003. Lianas were cut in May 22-23, 2004. Only live trees in the census of August 18-23 2005 are included. Distance between plots of the same pair ranged from 5 to $20 \mathrm{~m}$, distance among pairs of plots ranged from $100 \mathrm{~m}$ (pairs of plots Saúl18 A, B respect to Saúl18 C, D), to approx. $3 \mathrm{~km}$. Digits in brackets are total basal areas of trees excluding the five bigger individual trees (which are, however, included in the rest of our analysis). Highlighted number $\{\mathbf{1 5 , 1 6}\}$ indicates the basal area of trees in plot Saúl18 C before the accidental cut of 17 trees by some farmers, such trees were excluded from any analysis. Notice the very high basal area of trees in Saúl18 D. This plot was approx. 35m away from a leaf-cutter ants (Atta spp) nest (E. Garrido-Pérez, pers.obs.). 
The number of lianas hosted per tree and the initial girth of trees was not related to the Relative Growth of trees in the $\geq 55 \mathrm{yr}$-old forest, even after pooling the data from the 6 plots of such a forest (Multiple Linear Regression, $\mathrm{R}^{2}=0,090$; adjusted $\mathrm{R}^{2}=0,087 ; \mathrm{n}=682$ trees increasing their girths). Only in plots Rosendo55 B, and Antonio55 B, the initial girth had some effect on the growth of trees (adjusted $R^{2}$ are: 0,236 and 0,116 , respectively; other $R^{2}$ are not shown). In the 10-18yr-old forest, the number of lianas hosted per tree and the initial girth of trees were not related to the growth of trees (Multiple Linear Regression, $R^{2}=0,022$, adjusted $\mathrm{R}^{2}=0,019 ; \mathrm{n}=783$ trees increasing their girths).

For five species able to be analyzed in the $\geq 55 \mathrm{yr}$-old forest, the growth changed between species, but not in response to liana-cover per tree, and not in response to tree species $\mathrm{x}$ liana-cover interaction (two-way ANOVA, $\mathrm{F}_{\mathrm{spp}}=5,857, \mathrm{P}_{\mathrm{spp}}=0,007<0,025$ (Bonferoni's corrected $\alpha), \mathrm{DF}_{\mathrm{spp}}=4 ; \mathrm{F}_{\text {cover }}=2,932, \mathrm{P}_{\text {cover }}=0,077, \mathrm{DF}_{\text {cover }}=3 ; \mathrm{F}_{\mathrm{spp} \times \text { cover }}=1,087, \mathrm{P}_{\mathrm{spp} \mathrm{x} \text { cover }}=$ $0,372, \mathrm{DF}_{\mathrm{spp} \mathrm{x} \text { cover }}=12$, fig.2.3, these species summed 249 individuals $(36 \%$ of the sizeincreasing trees in the $\geq 55 \mathrm{yr}$-old stand). However, some species showed a clear trend to grow less when hosting larger liana-coverages. In concrete, Pouteria campechiana grew less when having liana-cover cat.3, and D.arboreus grew less when having liana-cover categories 2 and 3 (fig.2.3; see full species list in Appendix I). 


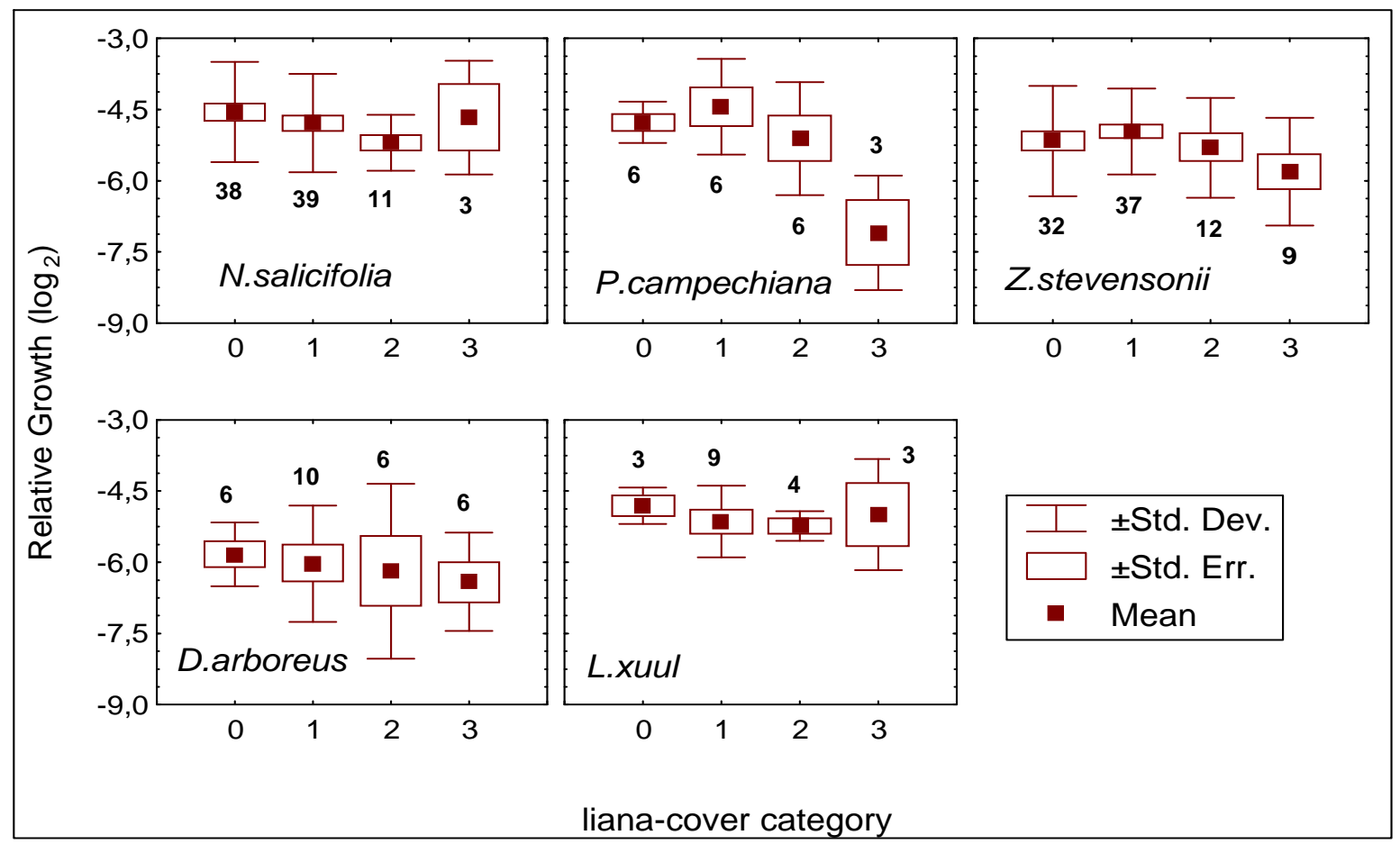

Fig.2.3. Relative Growths (RG) of five tree species according to their liana-coverages (forest $\geq 55 y r-0 l d)$. Digits near boxes are numbers of individuals, see fig. 1 for liana-cover categories. Species: Nectandra salicifolia, Pouteria campechiana, Zygia stevensonii, Dendropanax arboreus, and Lonchocarpus xuul. RG changed between species, but not due to liana-cover and species $x$ liana-cover interaction (two-way ANOVA, $\mathrm{F}_{\mathrm{spp}}=5,857, \mathrm{P}_{\mathrm{spp}}=0,007<0,025$ (Bonferoni's corrected $\alpha$ ), $\left.\mathrm{DF}_{\mathrm{spp}}=4 ; \mathrm{F}_{\text {cover }}=2,932, \mathrm{P}_{\text {cover }}=0,077, \mathrm{DF}_{\text {cover }}=3 ; \mathrm{F}_{\mathrm{spp} \mathrm{x} \text { cover }}=1,087, \mathrm{P}_{\mathrm{spp} \text { x cover }}=0,372, \mathrm{DF}_{\mathrm{spp} \times \text { cover }}=12\right)$.

For eight species able to be analyzed in the 10-18yr-old forest, the relative growth did not change neither between species, nor in response to liana-cover per tree, and nor in response to tree species $\mathrm{x}$ liana-cover interaction (two-way ANOVA, $\mathrm{F}_{\mathrm{spp}}=1,293, \mathrm{P}_{\mathrm{spp}}=0,301$, $\mathrm{DF}_{\mathrm{spp}}=7 ; \mathrm{F}_{\text {cover }}=2,848, \mathrm{P}_{\text {cover }}=0,062, \mathrm{DF}_{\text {cover }}=3 ; \mathrm{F}_{\text {spp x cover }}=1,677, \mathrm{P}_{\text {spp x cover }}=0,042, \mathrm{DF}_{\text {spp } \mathrm{x}}$ cover $=21$; all $\mathrm{P}$-values $>$ Bonferoni's corrected $\mathrm{P}=0,025$; the eight species summed 454 individuals (58\% of the total trees increasing their sizes in the 10-18yr-old forest). However, as a trend, Lonchocarpus yucatanensis grew more with liana-cover category 3 but less with liana-cover category 2; Vitex gaumeri grew more with liana-cover categories 1, 2, and 3, fig.2.4). 


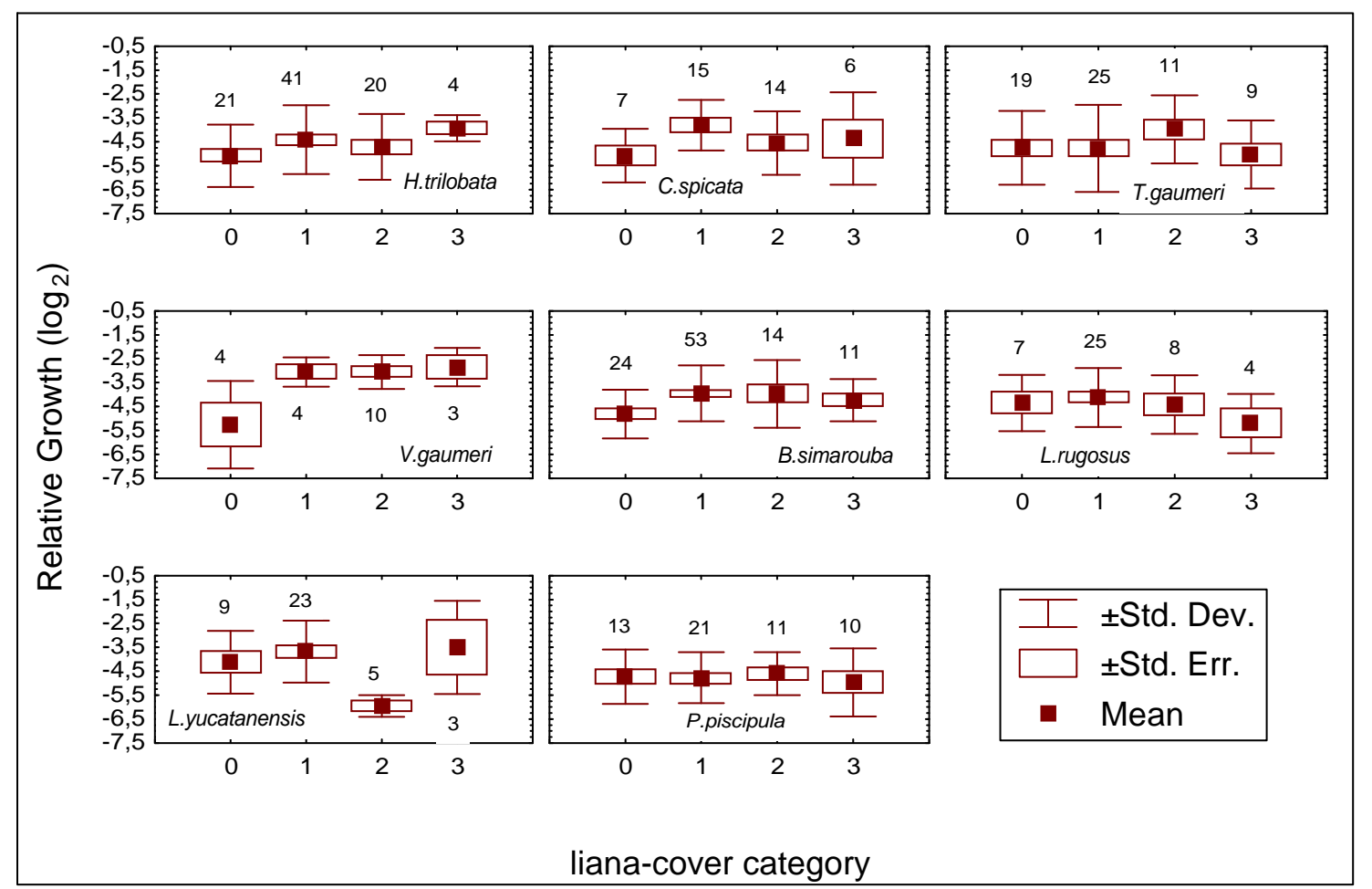

Fig.2.4. Relative Growths of five tree species according to the liana-coverage per individual tree (forest 1018yr-old). Digits near boxes are numbers of individuals, see fig. 1 for liana-cover categories. Species: Hampea trilobata, Coccoloba spicata, Thevetia gaumeri, Vitex gaumeri, Bursera simarouba, Lonchocarpus rugosus, Lonchocarpus yucatanensis, and Piscidia piscipula. Relative Growth did not change according to: liana-cover, species and species $x$ liana-cover interaction (two-way $A N O V A, F_{s p p}=1,293, P_{\text {spp }}=0,301, \mathrm{DF}_{\mathrm{spp}}=7 ; \mathrm{F}_{\text {tangle }}=2,848$, $\mathrm{P}_{\text {cover }}=0,062, \mathrm{DF}_{\text {cover }}=3 ; \mathrm{F}_{\text {spp x cover }}=1,677, \mathrm{P}_{\mathrm{spp} \mathrm{x} \text { cover }}=0,042, \mathrm{DF}_{\mathrm{spp} \mathrm{x} \text { cover }}=21$; all $\mathrm{P}$-values $>$ Bonferoni's corrected $\mathrm{P}=0,025)$.

For 14 species in the $\geq 55 \mathrm{yr}$-old forest, the relative growth of trees did not change among their species, and was not affected by liana-cutting, but by the species $\mathrm{x}$ liana-cutting interaction (two-way ANOVA, $\mathrm{F}_{\mathrm{spp}}=2,197, \mathrm{P}_{\mathrm{spp}}=0,084, \mathrm{DF}_{\mathrm{spp}}=13 ; \mathrm{F}_{\text {cutting }}=3,919, \mathrm{P}_{\text {cutting }}=$ $0,069, \mathrm{DF}_{\text {cutting }}=1 ; \mathrm{F}_{\text {spp x cutting }}=2,116, \mathrm{P}_{\text {spp } \mathrm{x} \text { cutting }}=0,012<$ Bonferoni's corrected $\mathrm{P}=0,025$, $\mathrm{DF}_{\text {spp } \mathrm{x} \text { cutting }}=13$, fig.5; these 14 species totalize 520 individuals $(76 \%$ of all trees increasing their girths in the $\geq 55 \mathrm{yr}$-old forest) ). Nevertheless, there was a clear trend of differences among species: B.simarouba, P.campechiana, M.brownei and V.gaumeri grew less where lianas were not cut; M. zapota and L. xuul tended to grow more where lianas were not cut (fig.2.5). 


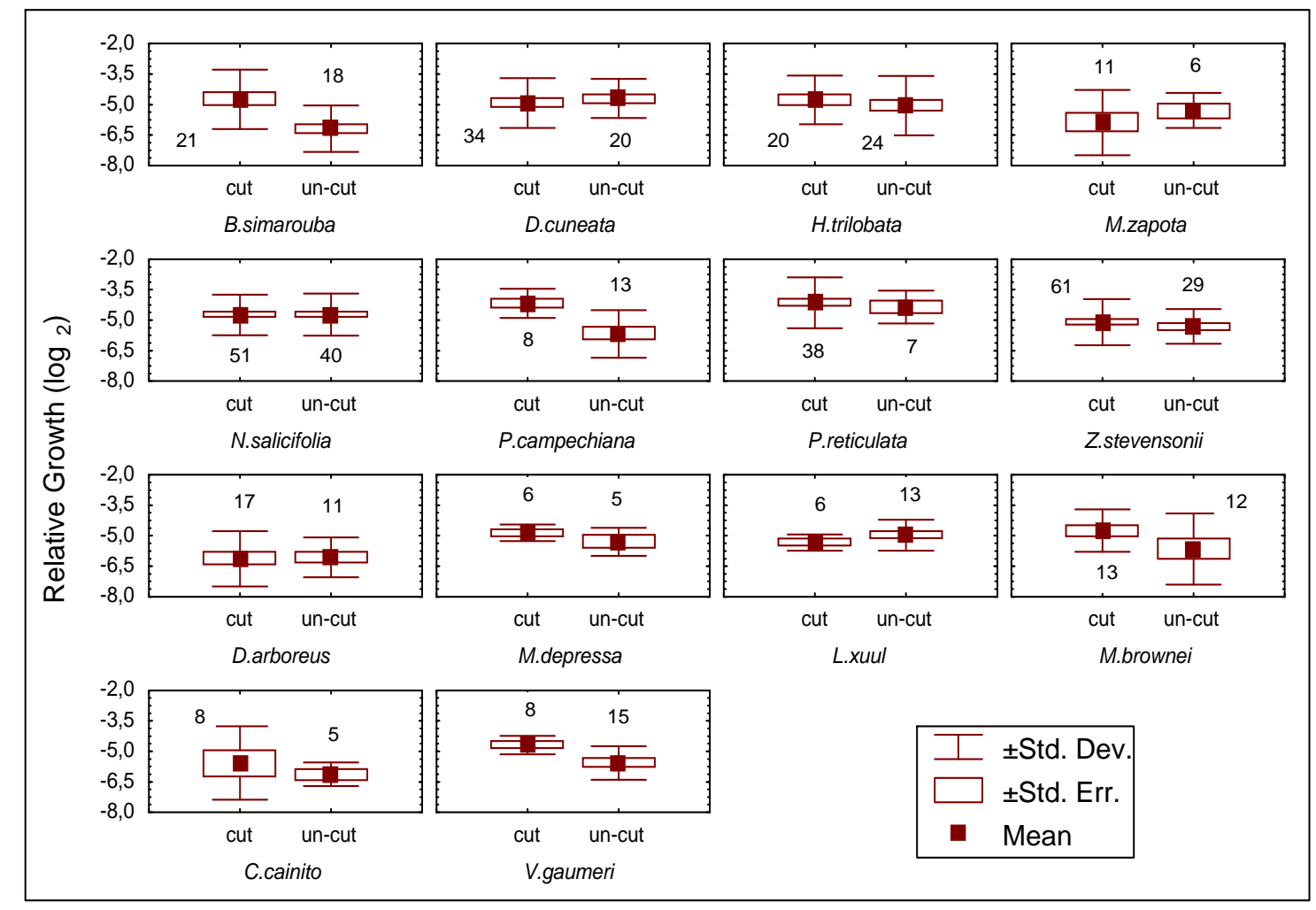

Fig.2.5. Relative Growths of 14 tree species present in liana-cut and liana-uncut plots of $\geq \mathbf{5 5 y r}$-old forest. Digits upon or under boxes are numbers of individuals. Species non mentioned in previous figures are: Diospirus cuneata, Manilkara zapota, Pouteria reticulata, Malmea depressa, Metopium brownei, and Chrysophyllum cainito. Relative Growth Rate of trees did not change among their species, and was not affected by liana-cutting, but by the species $x$ liana-cutting interaction (two-way ANOVA, $\mathrm{F}_{\mathrm{spp}}=2,197, \mathrm{P}_{\mathrm{spp}}=0,084, \mathrm{DF}_{\mathrm{spp}}=13$; $\mathrm{F}_{\text {cutting }}=3,919, \mathrm{P}_{\text {cutting }}=0,069, \mathrm{DF}_{\text {cutting }}=1 ; \mathrm{F}_{\text {spp x cutting }}=2,116, \mathrm{P}_{\text {spp x cutting }}=0,012<$ Bonferoni's corrected $\mathrm{P}=0,025$, $\left.\mathrm{DF}_{\text {spp } \mathrm{x} \text { cutting }}=13\right)$.

For 16 species in the 10-18yr-old forest, the relative growth rate of trees did not change between tree species, and was not affected by: liana-cutting and tree species x liana cutting interaction (two-way ANOVA, $\mathrm{F}_{\mathrm{spp}}=2,817, \mathrm{P}_{\mathrm{spp}}=0,027, \mathrm{DF}_{\mathrm{spp}}=15 ; \mathrm{F}_{\text {cutting }}=0,773$, $\mathrm{P}_{\text {cutting }}=0,393, \mathrm{DF}_{\text {cutting }}=1 ; \mathrm{F}_{\text {spp } \mathrm{x} \text { cutting }}=1,514, \mathrm{P}_{\text {spp } \mathrm{x} \text { cutting }}=0,393, \mathrm{DF}_{\text {spp } \mathrm{x} \text { cutting }}=15$, all $\mathrm{P}$ values $>$ Bonferoni's corrected $\mathrm{P}=0,025)$. Such species represent 671 individuals ( $86 \%$ of all trees increasing their girths in the 10-18yr-old stand fig.2.6). However, Coccoloba spicata, A. caminia and L.rugosus tended to grow more in the liana-un-cut plots (fig.2.6). 


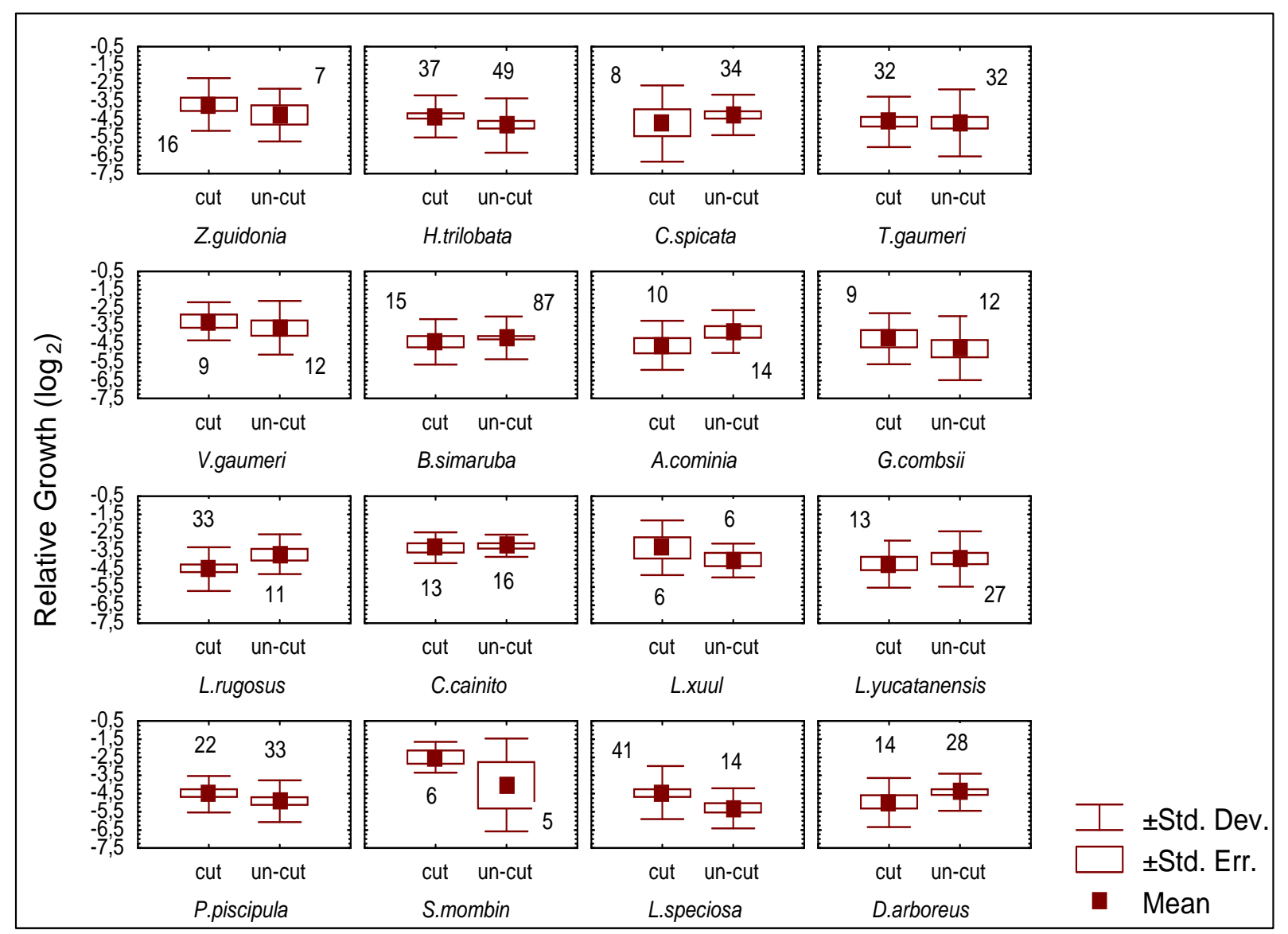

Fig.2.6. Relative Growths of 14 tree species present in liana-cut and liana-uncut plots of 10-18yr-old forest. Digits upon or under boxes are numbers of individuals. Species non mentioned in previous figures are: Zuelania guidonia, Allophylus cominia, Guettarda combsii, Spondias mombin, and Luehea speciosa (Relative Growth Rate of trees did not change between tree species, and was not affected by: liana-cutting and tree species $\mathrm{x}$ liana cutting interaction (two-way ANOVA, $\mathrm{F}_{\mathrm{spp}}=2,817, \mathrm{P}_{\mathrm{spp}}=0,027, \mathrm{DF}_{\mathrm{spp}}=15 ; \mathrm{F}_{\text {cutting }}=0,773, \mathrm{P}_{\text {cutting }}=0,393, \mathrm{DF}$ cutting $=1$; $\mathrm{F}_{\text {spp x cutting }}=1,514, \mathrm{P}_{\text {spp x cutting }}=0,393, \mathrm{DF}_{\text {spp } \mathrm{x} \text { cutting }}=15$, all $\mathrm{P}$-values $>$ Bonferoni's corrected $\left.\mathrm{P}=0,025\right)$. 
In the $\geq 55 \mathrm{yr}$-old forest and after pooling all species, trees grew less when having larger liana-cov erages (one-way ANOVA, $\mathrm{F}=10,354 ; \mathrm{P}=0,000001 ; \mathrm{DF}=678$ ), and while growing more in the liana-cut plots (Student's $\mathrm{t}=8,560 ; \mathrm{P}=0,0035 ; \mathrm{DF}=680$, fig2.7a,b).
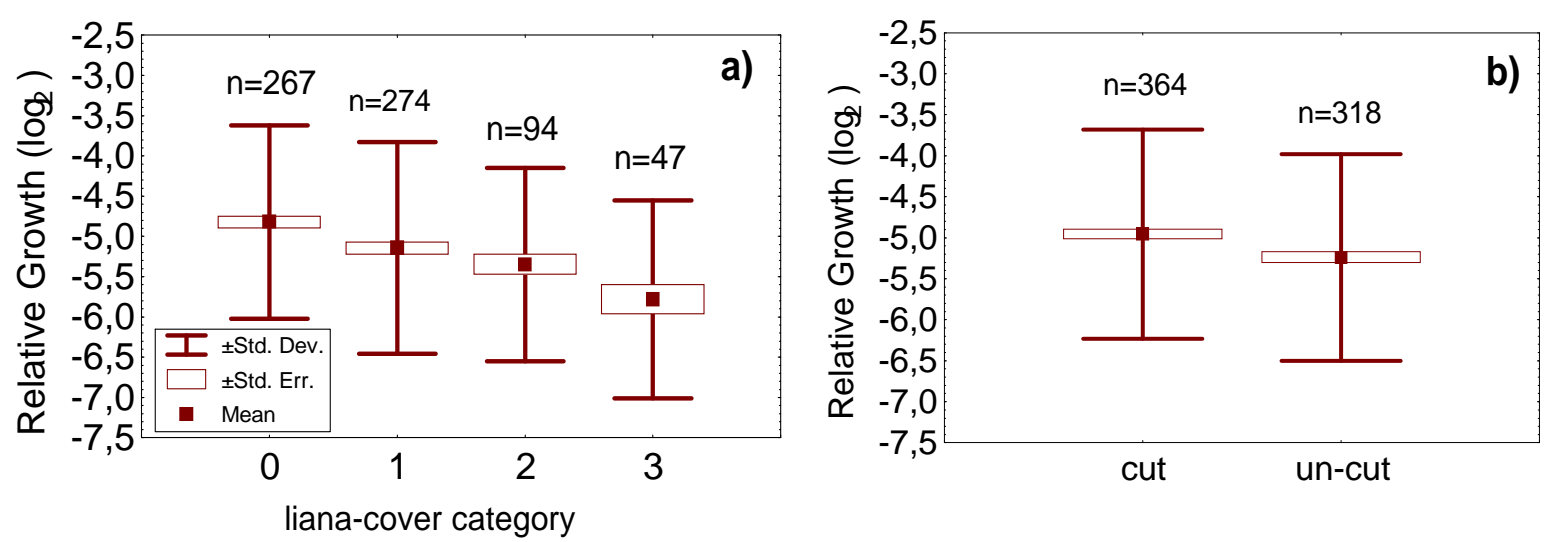

Fig.2.7. Relative Growths of all trees regarding their species ( $\geq 55 y$ r-old forest) according to: a) liana-cover categories, and b) liana-cut vs liana un-cut plots. Notice that the results are similar to the patterns followed by some species in figs. 3 and 5. Results in figs. 3 and 5 are not statistically significant, but the ones here are: trees grew less when having larger liana-tangles (one way ANOVA, $\mathrm{F}=10,354 ; \mathrm{P}=0,000001 ; \mathrm{DF}=678$ ), while growing more in the liana-cut plots (Student's $\mathrm{t}=8,560 ; \mathrm{P}=0,0035 ; \mathrm{DF}=680$ ).

After pooling all trees in the 10-18yr-old forest, individuals having liana-cover categories 1,2, and 3 grew more than the ones having no-lianas (cover cat. 0; one-way ANOVA: $\mathrm{F}=4,358, \mathrm{P}=0,0047 ; \mathrm{DF}=779$ ), while liana-cutting had no-effects on Relative Growth (Student's t=0,0016, $\mathrm{P}=0,968, \mathrm{DF}=781$, fig.2.8a,b).
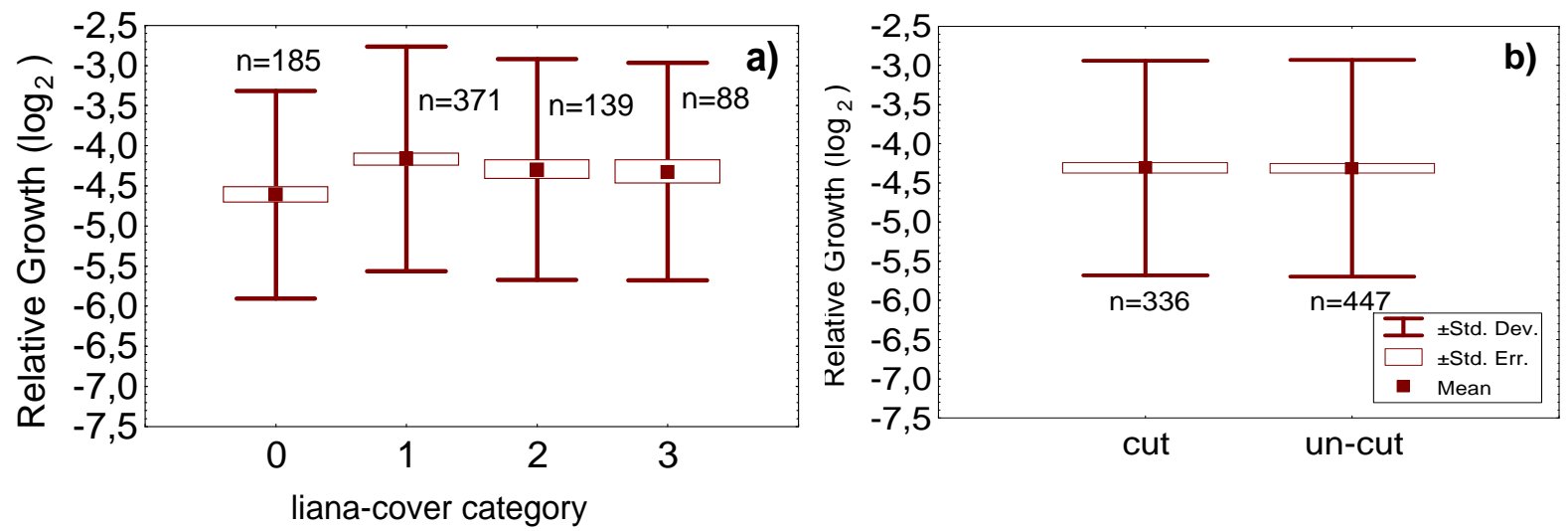

Fig.2.8. Relative Growths of all trees regarding their species (10-18yr-old forest) according to: a) lianacover categories, and b) liana-cut vs liana un-cut plots. Notice that the results are similar to the patterns followed by some species in figs. 4 and 6 . Results in fig. 4 are significant only for species $x$ liana-cover interaction, but here individuals having liana-cover categories 1, 2, and 3 grew more than the ones having hosting no-lianas (cover category 0; one-way ANOVA: $\mathrm{F}=4,358, \mathrm{P}=0,0047 ; \mathrm{DF}=779$ ), while being non affected by liana-cutting (Student's $\mathrm{t}=0,0016, \mathrm{P}=0,968, \mathrm{DF}=781$ ). 
Regardless the species and the forest age in their locations, the 244 trees with $R G \leq 0$ were not affected by their liana-cover and by liana-cutting (Nested ANOVA, $F_{\text {cover }}=1,408$, $\left.P_{\text {cover }}=0,212, D_{\text {cover }}=6 ; F_{\text {cutting }}=0,578 ; P_{\text {cutting }}=0,476, D_{\text {cutting }}=1\right)$.

In the $\geq 55 \mathrm{yr}$-old forest, Coccoloba spicata averaged the highest $\Omega$ compared to all species in all forest ages $(\Omega=0,24$, fig. $2.9 \mathrm{a})$, but the same species had a slightly negative $\Omega$ in the 10-18yr-old forest ( $\Omega=-0,004$, fig.2.9b). Excluding C.spicata in the $\geq 55 \mathrm{yr}$-old forest, trees there had smaller size-changes than in the 10-18yr-old forests suggesting a more remmarked effect of lianas in the younger stand (see scales in fig.2.9a,b). From 17 species in the $\geq 55 \mathrm{yr}$-old forest, $70 \%$ (12 species) had negative values of $\Omega$, and 5 had positive $\Omega$ (fig.2.9a). In contrast, from 15 species in the 10-18yr-old forest, 53\% (eight species) had positive values of $\Omega$, and the rest had negative $\Omega$ (fig. $2.9 \mathrm{~b}$ ). 


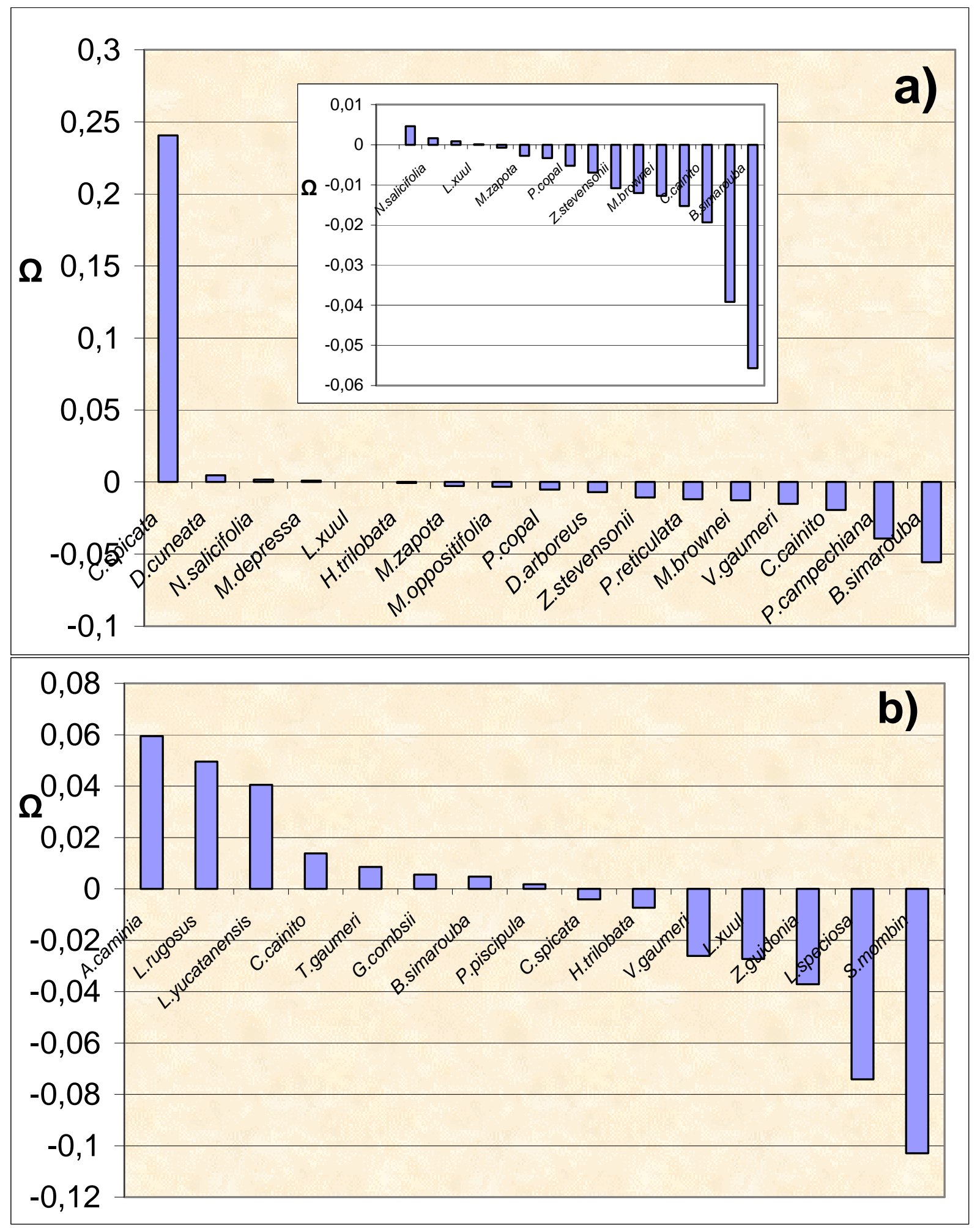

Fig.2.9. Liana-effect index $(\Omega)$ on sampled populations of different tree species. a) $\geq 55 y$-old forest; b) 1018 yr-old forest. For each successional age, Relative Growths (RG) for each species were averaged (av) within both treatments, liana- cut and non-cut. Then, for each species, $\Omega= \pm / a v R G_{\text {cut }}-a v g . R G_{\text {un-cut }} /$. When avRG $G_{\text {un-cut }}>$ avRG $G_{\text {cut }}$, we assumeed the presence of intact lianas favored the species so we used a " + " sign. Negative signs (-) indicate the presence of

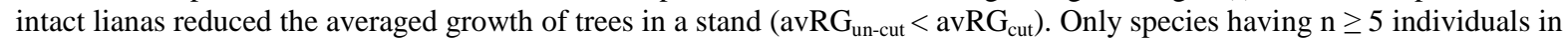
both treatments per forest age were included in $\Omega$ calculations. The small graph within (a) reproduces such a graph but excluding C.spicata in order to illustrate the variation of $\Omega$ in the $\geq 55$ yr-old forest. Appendix II details this graphs. 
We also calculated $\Omega$ for six species occurring in both, $\geq 55 \mathrm{yr}$ - and $10-18 \mathrm{yr}$-old stands (fig.9a,b). From them, V.gaumeri had negative $\Omega$ in both successional ages, while C.spicata, had positive $\Omega$ in the $\geq 55 \mathrm{yr}$-old forest but negative (though almost 0 ) in the 10 -18yr-old forest fig.9a,b). H.trilobata, had $\Omega \approx 0$ in both forest ages, and L.xuul had negative $\Omega$ in the 10-18yr-old forest, but almost 0 in the $\geq 55 \mathrm{yr}$-old forest (fig.2.9a,b). Two species (B.simarouba and C.cainito) had negative $\Omega$ in the $\geq 55 \mathrm{yr}$-old forest, but positive in the 1018yr-old forest, (fig.2.9a,b). Respect to other species, P.campechiana and B.simaruba were the more affected in the $\geq 55 \mathrm{yr}$-old forest, while L.speciosa and S.mombin were the most affected in the 10-18yr-old forest, where A.caminia, L.rugosus and L.yucatanensis were favored (fig.2.9a,b).

\subsection{Discussion}

Contrary to other studies (Kainer et al, 2006; Clark and Clark, 1990; Putz, 1984a), the number of lianas per tree did not affect the growth of trees in our study area. We think it was because our criterion to define a hosted liana included lianas that are not strongly anchored to trees (e.g. by means of just only one tendril or with one branch contacting the tree in the same direction than gravity). It implies, however, that many lianas in nature may only be slightly associated to some trees not reducing their growths. Also the poor and null relation between pre-cut tree circunference with respect to their post-cut growths is non-consistent to other studies (Clark and Clark, 1990). We think it is explainable by two facts: 1) in our study site we had a very high abundance of narrow trees (data not-shown), having basically the same width for the effects of linear regressions; and b) we re-measured trees only 15 months after cutting lianas, which is too short for the growth of trees, although it included two growing seasons.

Other studies lasted one year (Pérez-Salicrup and Barker, 2000), 18 months (PérezSalicrup, 2001); two years (Putz, 1984a; Gerwing, 2001; Grauel and Putz, 2004; Schnitzer et 
al, 2005; Kainer et al, 2006), and three years (Whigham, 1984; Vidal et al, 2002). Only one study is based on data of 10 years (Putz, 1984a for Luehea seemanii). Also Clark and Clark (1990) analyzed long-term growth of trees according to their liana-loads during a nonspecified number of years. Moreover, tree species were poorly represented as in other studies, suggesting that larger samples are necessary.

Despite the short time of our experiment and certain statistically insignificant results figs. 2.3, and 2.4 do show clear trends that higher liana coverage reduces the growth of tree species as P.campechiana, Z.stevensonii, and L.rugosus. Furthermore, the following species grew less in liana-uncut plots compared to liana-cut plots: B.simarouba, P.campechiana, M.brownei, V.gaumeri (fig.2.5), G.combsii, S.mombin, and L.speciosa (fig.2.6). Since liana fragments were not removed from the canopy after cutting, such results suggest that lianas were deleterious for trees by means of below-ground processes. Recall that we had to pool our data from different plots for species comparisons. Local differences among plots may have increased the variation of our data, but further measurements could verify such a trend.

All the above mentioned species (and all species studied here) can be considered pioneer because of their presence in early- and very-early successional stages in the Yucatan Península (Sánchez-Sánchez and Islebe, 2002). Indeed, the trends we found apply only for this guild of trees and support the assertion that lianas reduce the growth of many, but not all tree species (Putz, 1984a; Whigham, 1984; Clark and Clark, 1990; Pérez-Salicrup, 2001; Laurance et al, 2001; Schnitzer and Bongers, 2002; Schnitzer et al, 2005). Some mechanisms suggested for these effects are: out competition for water and soil resources (Ewers et al, 1990; Ewers et al, 1991; Fitchner and Schultze, 1990; Gartner et al, 1990; Phillips et al, 1999; Dillenburg et al, 1993b; Pérez-Salicrup and Barker, 2000; Pérez-Salicrup, 2001; Grauel and Putz, 2004; Schnitzer et al, 2005), and structural parasitism (Stevens, 1987; Kainer et al, 2006). Our study did not test such mechanisms, for example, we did not determine the existence of limited resources below ground and the liana-tree fine-roots co-existence (see 
also Connell, 1990). Groundwater uses to be 1-2m depth in our study site (E. Garrido-Pérez, pers. obs), so competition for nutrients may be more plausible.

The existence of numerous studies demonstrating negative effects of lianas suggest that lianas never favor trees (Ewel and Hiremath, 2005; Clark and Clark, 1990). However, some of our results give reason to re-consider such a generalization. For example, C. spicata, A. cominia and L. rugosus tended to grow more in the liana-uncut plots of the $10-18 \mathrm{yr}-\mathrm{old}$ stands (fig.2.6). Also in our 10-18yr-old stands, trees in general grew more when hosting all liana-coverage categories compared to trees hosting no-lianas (category 0, fig.2.8a). $\mathrm{V}$. gaumeri is one species which tended to follow this pattern (fig.2.4). Just the opposite occurred to V.gaumeri in the $\geq 55 \mathrm{yr}$-old stand (fig.2.7a), suggesting that liana-effects on single species changes on space and probably during succession.

Our 10-18yr-old plots are dominated by the legume D. glabra (Papilionoidae), and we think it contributes to nitrogen fixation in the soil and making it available to trees. Alternatively, since lianas grow better in areas exposed to sunlight (e g Laurance et al, 2001; Schnitzer et al, 2000), lianas may be associated to a higher sunlight incidence in the 10-18yrold forest for the trees hosting them. This does not necessarily mean that they are enhancing sunlight availability for trees which are growing more there. Both, lianas and trees hosting them in the 10-18yr-old stand, may be exploiting the abundant sunlight typifying early successional forests. The canopy was closer in our $\geq 55 \mathrm{yr}$-old stands, but lianas did not seeme to overlap the leaves of their hosting trees (E.Garrido-Pérez, pers. obs). It suggests that those lianas, being mainly wide-xylem Bignoniacee, may have affected their hosting trees by below-ground competition when forming higher liana-coverage (fig.7a, b); since Kainer et al (2006) indicate that higher liana coverage is due to shorter liana-tree distances making competition feasible (but see Andrade et al, 2005). In contrast, lianas seem to help some species in our younger stands or, at least, did not outbalance the effects of factors favoring them. We warn that our study indicates the relative effect of lianas on the growth of some tree 
species, not the mechanisms underlying these effects (e.g. competition, association to incident light, structural parasitism or nitrogen fixation). Independently of the mechanisms, our data suggest that lianas are not always harmful to trees.

Additional evidence rejecting the general statement that lianas are always harmful to trees arises from our trees decreasing their circumferences (assuming that they are dying). If lianas would be deleterious for them, trees having higher liana-coverage or located in lianauncut plots should decrease faster in width. But trees decreased in width independently of liana-coverage or liana-cutting.

Our results are not the first ones reporting non-deleterious effects of lianas on trees. For example, individuals of Prioria copaifera being 4-15 cm dbh had similar growths in liana-cut and liana un-cut plots in Darien, Panama (Grauel and Putz, 2004). Furthermore, the introduced vine Lonicera japonica, but not the native Parthenocissus quinquifolia, hindered the growth of Liquidambar styraciflua in Maryland, USA (Dillenburg et al, 1993b). Water uptake of Switenia macrohylla in a dry forest of Bolivia did not change after lianas had been cut (Barker and Pérez-Salicrup, 2000). In a nutshell, this and other studies confirm that the effects of lianas on trees are different between tree species (Pérez-Salicrup, 2001; Schnitzer and Bongers, 2002; see also Clark and Clark, 1990), but not that lianas are mainly harmful for trees.

The trends of diverse liana-effects on our sampled tree populations (indicated by $\Omega$ ) across successional ages were consistent with the results for liana-coverage regarding tree species (figs. 2.7a and 2.8a). Where high liana-coverage reduced the growth of trees $(\geq 55 \mathrm{yr}-$ old forest), most of the analyzed species had a negative $\Omega$. Accordingly, if high lianacoverage favored the growth of trees (10-18yr-old forest), more species had a positive $\Omega$ (fig.2.9a,b). We remark that $\Omega$ only describes the trends of liana-effects on tree species. It does not imply that "favored" tree species (e.g., C. spicata in the $\geq 55 \mathrm{yr}$-old forest) will become dominant during succession. Other factors (e.g. fungi, Gilbert, 2005) may be 
important too. In our study site, trees with fungi in their trunks grew better than trees not hosting fungi in some plots, less in others, and had similar growths in others (data not shown). This illustrates that considering lianas as driving forces in communities requires measuring their effects on trees respect to fungi, herbivores and other factors.

For the pioneers trees of this study, liana-induced specific effects on tree species are not always uniform but change at least in space. Some species tending to be affected by lianas in a certain way in $\geq 55 \mathrm{yr}$-old areas were affected in different fashion in the 10-18yr-old areas. Thus, $C$. cainito, $B$. simarouba, and $D$. arboreus had negative $\Omega$ in the $\geq 55 \mathrm{yr}-\mathrm{old}$ stands, but positive in the 10-18yr-old stand (fig.2.9a,b). Something similar seemed to occur with $C$. spicata: it had positive $\Omega$ in the $\geq 55 \mathrm{yr}$-old forest, but slightly negative in the $10-18 \mathrm{yr}-$ old forest. The spatial variation of liana-effects on applied also for L. xuul: this species was basically not affected in the $\geq 55 \mathrm{yr}$-old forest, but had a negative $\Omega$ in the $10-18 \mathrm{yr}$-old forest. These landscape-level evidences challenge the suggested role of lianas as driving forces structuring tree-communities and tree-evolution within the guild of the pionners (see Schnitzer and Bongers, 2002). For playing such a role, lianas need to be deleterious for the same tree species everywhere, thereby reducing their population size. Based on Hubbell and Foster (1986) and Hubbell (2001), we propose that lianas may affect individual trees "only if the wrong tree is in the wrong place surrounded by the wrong lianas", which depends on seed dispersal, history and random processes.

Notice also that $H$. trilobata was almost not affected in both forest ages (though negatively affected), suggesting that some species may be poorly influenced by lianas even in different microhabitats. Finally, V. gaumeri had salient negative $\Omega$ values in both forests $(\geq$ 55yr-and 10-18yr-old). It suggests that, besides microenvironments, the taxonomic identity, which is linked to life history strategies (Begon et al, 1996, Martínez-Ramos, 1994; Dalling and Burslem, 2005; see also Uriarte et al, 2005), and not only lianas, may play an driving role 
in the growth of trees in our study site, with respect to the sometimes null, sometimes deleterious, and sometimes beneficial effect of lianas on tree growth.

Even within the guild of the pioneers, life history strategies change in a continuum for all species (Grime, 1974). Wood density is related to life history strategies of trees since, -for instance, slow-growing pioneers (and shade tolerants) have denser woods. Because life history strategies are strongly inherited, they are also related to phylogeny and taxonomic identity. In order to explore a possible role of phylogeny as determinant of our results, we plotted the averaged relative growths of 24 tree genera in our study site (fig.2.10) against their wood densities enlisted in Reyes et al (1992). Not all of our genera appear in such a list. Almost all the data we used from the table of Reyes et al. (1992) come from Tropical American species. No one of the specimens reported in Reyes et al (1992) came from our study site and many belonged to different species -althoug to the same genera respect to ours. Reyes et al (1992) warn also on sampling limitations of their compiled studies, and also treegrowth is subjected to phenotipic plasticity. In spite of all these limitations, there is a significant trend in fig.2.10, being dense-wood trees proner to grow slower. This is consistent to the theory of life-history strategies (fig.2.8; Begon et al, 1996, Martínez-Ramos, 1992; Dalling and Burslem, 2005), goes beyond the effects of lianas, and should be taken into account before indicating that lianas affect tree-species turnover significantly. In other words, further experiments should elucidate the effect of lianas respect to phylogeny and other factors.

Lianas are proposed to increase their abundance in the Neotropics due to the increment of disturbance and atmospheric $\mathrm{CO}_{2}$ (Phillips et al, 2002; Wright et al, 2004; Schnitzer, 2005), frest fragmentation and crop abandonment (e.g. De Walt et al, 2000; Laurance et al, 2001). Our results suggest that this may be less dangerous for trees than previously suggested. 


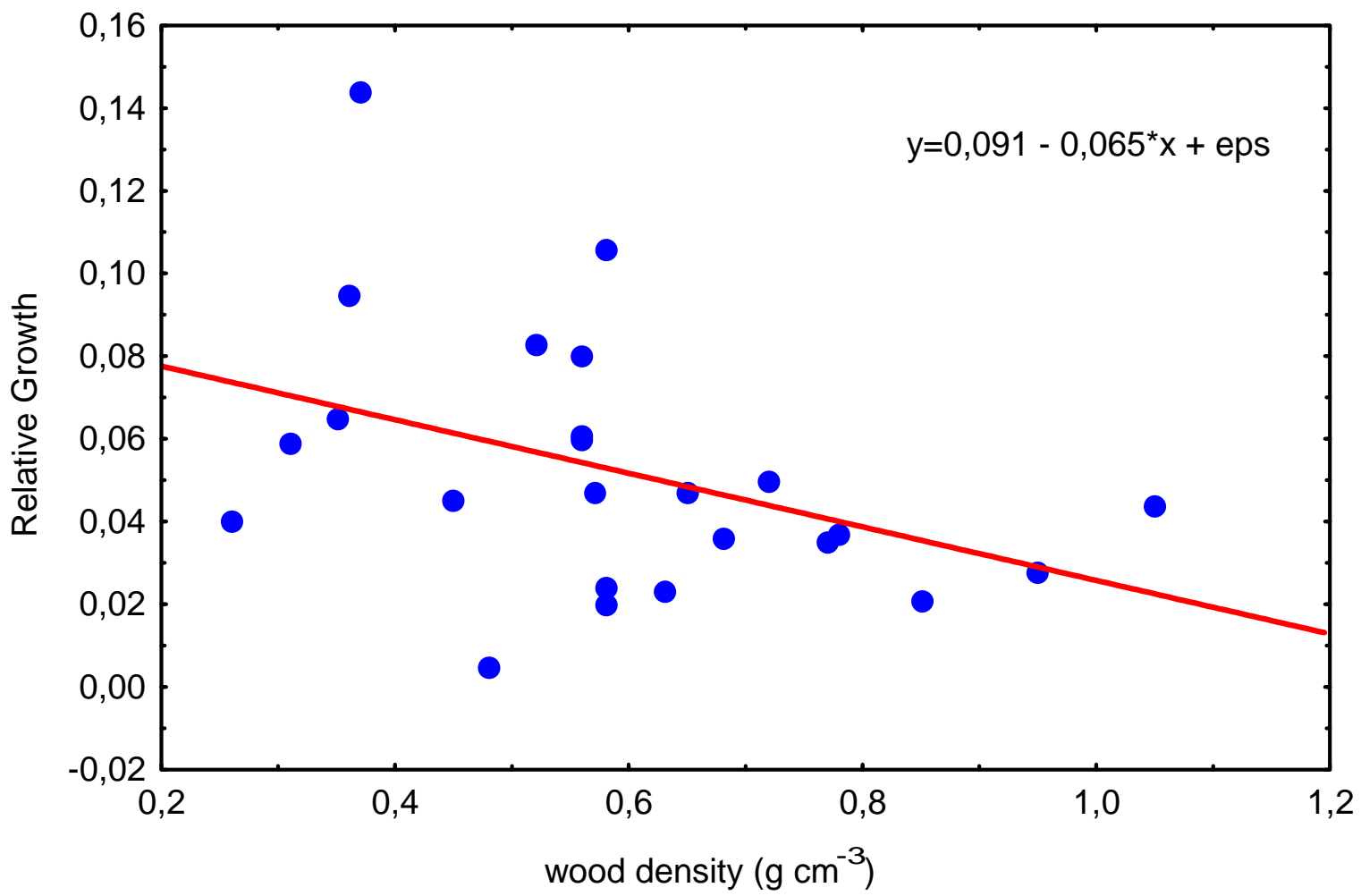

Fig.2.8. Relative Growths of 24 tree genera present in Solferino plotted against averaged wood densities of con-generic species worldwide enlisted in Reyes et al (1992). Wood density is assumed as an indicator of life history strategy, being shade tolerant tree genera denser respect to pioneer genera. There is a slight, but significant trend of tree density to be related to slower growths $\left(\mathrm{R}^{2}=0,16, \mathrm{R}^{2}\right.$ adjusted $\left.=0,13, \mathrm{P}=0,049\right)$. It occurs even in spite of: a) the taxonomic and geographic distance between the species enlisted in Reyes et al. (1992) respect to ours, b) the paucity of wood density measurements worldwide (Reyes et al, 1992), c) the small number of genera (24) tested in this regression, and d) The fact that we measured growth in relatively young trees (from forest between 10 and approx. 55yr-old) while wood density uses to be measured in commercially mature individuals from older forests. In spite of all that, denser tree genera had slower Growths respect to less dense trees. It suggests that the growths of trees in our study area are (at least partially) constrained by phylogeny. 


\section{Chapter 3}

\section{GROWTH OF SAPLINGS AFTER CUTTING LIANAS IN SEMI- EVERGREEN TROPICAL FORESTS OF DIFFERENT AGES AND LAND USE HISTORIES}

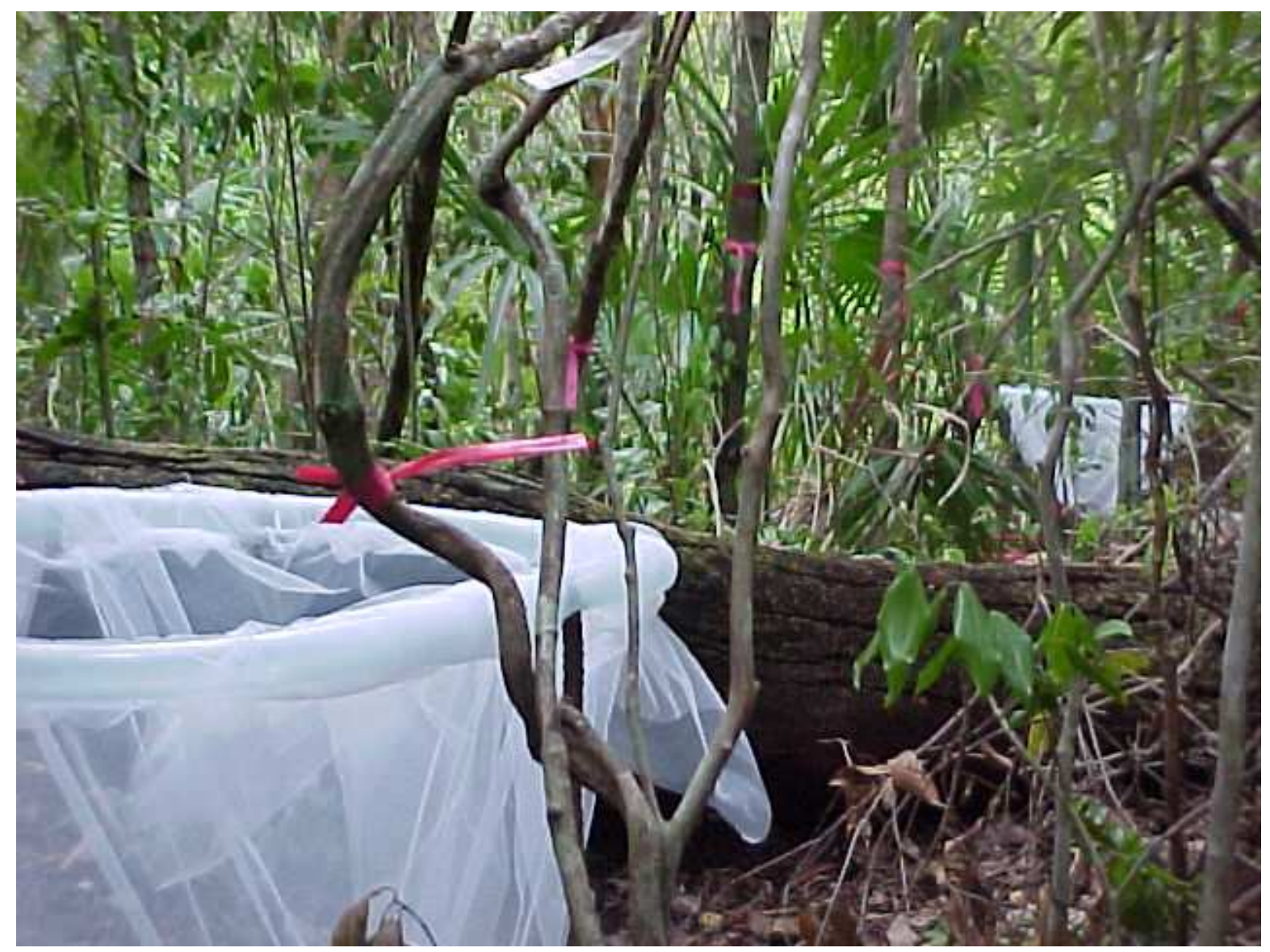

Figure showing how some forest plots of this research looked like. Lianas and trees were measured, marked and identified. Litter-traps were installed, plots having one fallen tree were paired to others having a similar fallen tree, but mostly of the plots had no-fallen trees. Each plot had sub-plots where saplings were studied. Lianas and vines were cut in one plot of each pair and, after 15 months, saplings were re-measured and I report the results of them in this chapter. Picture by E. I. Garrido-Pérez (August 2005). 


\subsection{Introduction}

Lianas (woody vines) are increasing their abundance in the Neotropics respect to trees, probably in response to the increment of atmospheric $\mathrm{CO}_{2}$, which is thought to enhance the forming of gaps that are occupied by lianas (Phillips et al, 2002; Schnitzer et al, 2000). Another cause is the increase of the areas of secondary forests (Gerold, 1994; Guariguata and Ostertag, 2002) because lianas are more abundant there than in the "primary" ones (DeWalt et al, 2000; Schnitzer and Bongers, 2002; Schnitzer, 2005). Lianas compose about $25 \%$ of the flora of tropical forests, where 33- 79\% of trees host lianas (Putz, 1984a; Gentry, 1991; Pinard and Putz, 1994; Campbell and Newberry, 1993). Lianas also reduce the growth of some sapling species (Pérez-Salicrup, 2001); although there is a paucity of such studies. Since many saplings become trees, testing if lianas affect saplings will contribute to a better understanding to forests recovery and other functions and this research contributes to this.

Many studies suggest that lianas not only reduce the reproduction of adult trees (Stevens, 1987; Kainer et al, 2006), but also the growth of seedlings, saplings and juveniles of trees, affecting some species more than others (Putz, 1984a, Whigham, 1984; Clark and Clark, 1990; Pérez-Salicrup and Barker, 2000; Barker and Pérez-Salicrup, 2000; PérezSalicrup, 2001, Grauel and Putz, 2004). In this ways, lianas are hypothesized to contribute to change the abundance of some tree species respect to others, becoming a driving force in structuring tree communities (Pérez-Salicrup, 2001; Schnitzer and Bongers, 2002).

Below ground competition per water and minerals has been suggested as a mechanism for the mentioned role of lianas (Pérez-Salicrup, 2001; Schnitzer and Bongers, 2002). Because xylem vessels of lianas are wider than the ones of trees, they are expected to out-compete saplings below ground (Ewers et al, 1990, 1991; Gartner et al, 1990) and that is consistent to many experimental studies (Dillenburg et al, 1993a,b; Pérez-Salicrup and Barker, 2000; Grauel and Putz, 2004; Schnitzer et al, 2005). 
As well as seedlings, saplings are a vulnerable ontogenic stage of tree populations (Moles and Westoby, 2004), and the relative survivorship and growth of sapling-species determines further tree-species composition of the forest (Martínez-Ramos, 1992). Indeed, the effect of lianas on saplings should be determinant in further structuring of tree communities (Pérez-Salicrup, 2001). Cutting lianas is a way of testing if they reduce the growth of saplings (Pérez-Salicrup, 2001; Schnitzer et al, 2005), and trees (Pérez-Salicrup and Barker, 2000; Barker and Pérez-Salicrup, 2000; Grauel and Putz, 2004), although it does not confirm if such a reduction is due to competition (Connell, 1990).

Some studies have shown null and positive effects of lianas on trees. For example, the water uptake of some tree species does not change after cutting surrounding lianas (Barker and Pérez-Salicrup, 2000), or when they host lianas being native of their habitats (Dillenburg et al, 1993b). Also, incident light in liana-dominated gaps favor pioneer trees (Schnitzer et al, 2000). Before these evidences, some authors considered poorly possible lianas to have null or favoring effects on trees (Clark and Clark, 1990; see also Ewel and Hiremath, 2005), and this may apply for saplings too.

Here we test the hypothesis that lianas reduce the growth of saplings, not if competition is the mechanism for that. Just to use below-ground proceses as an example, postulating competition as a mechanism of liana negative effects on saplings implies to assume that: a) lianas play no-role in tree-tree competitions, b) resources like water and Nitrogen are scarce in the soil, c) fine roots of lianas co-exist with the ones of saplings and trees, for example, mixing with each other, d) physiologically required water and nutrients of lianas are more than the required by saplings and trees, and e) lianas exhaust the resources faster than saplings or produce alelopathic substances harming saplings and trees (Connell, 1990). If cases where such conditions do not occur are common in nature, lianas do not necessarily out-compete saplings below-ground and liana-cutting should not favor saplings. In this study we compared the growth of saplings between liana-cut and liana-uncut forest plots. 
Besides lianas, other factors can affect saplings; for example: pathogens, herbivores, light in the understory, soil moisture, land use history and forest successional stage, as well as the availability and chemical nature of nutrients comming from litter decomposition (Moles and Westoby, 2004; Denslow et al, 1998; Dalling and Hubbell, 2002; Dalling et al, 1998; Makana and Thomas, 2005; Laurance and Foster, 2002). Trying to control such factors, we compared the growth of saplings located in plots sharing similar successional ages and land use histories. Our plots also shared similar basal areas and species compositions of lianas (and relatively similar in the case of trees). That assumed that trees in each plot could also compete against saplings, and produce litter quantities and qualities able to affect the nutrients available for the saplings.

As well as helping to test the effects of lianas on saplings and trees, liana-cutting is used in sylviculture to protect trees. Such practice is partially fed by evidences suggesting that lianas out-compete trees and saplings (Putz, 1991; Schnitzer and Bongers, 2002; Schnitzer et al, 2005). However, cutting lianas is expensive and not always necessary (Pérez-Salicrup et al, 2001a; Parren and Bongers, 2001), and is dangerous for the insects and vertebrates depending on lianas (Vidal et al, 1997; Gerwing and Vidal, 2002). Indeed, our results not only help to determine wheather or not lianas affect saplings, they also seek to contribute to give criteria for deciding if lianas may be cut.

\subsection{Materials and Methods}

Study site

Study site is in the peasants' community of Ejido Solferino, Quintana Roo, Mexico, near Yum Balam Reserve of Flora and Fauna $\left(21^{\circ} 26^{\prime} \mathrm{N}, 87^{\circ} 28^{\prime} \mathrm{W}\right.$; $10 \mathrm{~m}$ above see level; INEGI; 1993). Soils are poorly developed luvisols, rendzines and vertisols upon a calcareous base emerged after Pleistocene, with underground waters c.a.2-8m depth (Municipio de Lázaro Cárdenas, 1987; Olmsted et al, 2000; Bautista-Zúñiga et al, 2003) and even 1 - 2m 
depth (E. Garrido.Pérez, pers. obs). Topography is mainly flat; life zone is Semi-Evergreen Tropical Forest (Selva Mediana Subperennifolia, sensu Miranda and Hernández, 1963; Tropical Dry Forest, sensu Holdridge et al, 1971). Average annual rainfall is $1250 \mathrm{~mm}$, dry season lasts from February to April, wet season from May to January, including strong winds and some hurricanes, specially in September-October (Orellana et al, 1999; 2003). As part of a wider study, we settled 12 plots $20 \mathrm{~m}$ x 20m each (described in Table 3.2).

\section{Field work}

We measured all trees $\geq 3,16 \mathrm{~cm}$ dbh (diameter at $1,30 \mathrm{~m}$ above ground level). We also identified, marked and measured the diameter at ground level of every liana putative genet (sensu Schnitzer et al, 2000). We calculated the total basal area of trees and lianas within each plot in order to confirm if they were similar among plots, assuming lianas and trees as potential competitors against saplings per soil resources.

We located 10 sampling points within each plot as described in fig.1. There we measured the moisture of the Ah-horizon of the soil (the organic phase of the soil) in the first $6 \mathrm{~cm}$ of the soil, but under the leaf-litter layer. We made such measurements using a soil moisture meter type HH1 (Delta T-Devices). All measurements were made in June 7th, 8th, and $9^{\text {th }} 2004$ in the beginning of the afternoon, and the same day for the plots being closer to each other (indicated by similar names in Table 3.2), and within no more than 2 hours of difference between plots of the same pair. Days of measurements were partially cloudy; there was a strong rainfall in June $5^{\text {th }}$, but it never rained during the days of our measurements. Because we did not manage to measure soil moisture more than once, this results are only an approximation to the similarities of soil moisture among plots, and do not indicate any effect of liana cutting in soil water content.

Each one of the 10 points were soil moisture was measured in each plot was also the center of a $2 \mathrm{~m}^{2}$ subplot ( $\mathrm{n}=10$ subplots for each $20 \mathrm{~m} \times 20 \mathrm{~m}$ plot). There we counted, 
identified into species and registered the length of all saplings between $30 \mathrm{~cm}$ legth and $3,16 \mathrm{~cm}$ diameter (10 cm circumference, see Box 2 in Chapter 1 for a deeper explanation). Sapling legths were measured with a flexometer from the stem-ground contact point of each sapling to the base of the apical meristem of the largest branch of such sapling, but not including the meristem because it is still growing. We made the flexometer to follow the shape of the stem and branches in order to avoid size overestimations. We made this measurements between May $19^{\text {th }}$ and June $26^{\text {th }} 2004$.

In each $20 \mathrm{~m}$ x $20 \mathrm{~m}$ plot we also installed six litter- traps $1 \mathrm{~m}^{2}$ each. All traps were $1 \mathrm{~m}$ above ground height and the location of the traps was the same for all plots (fig3.1). The asymetric position of the traps in the plot shown in fig.3.1 is the one we noticed as more able to catch the falling litter, representing both, trees at the edge and in the interior of the plot, while catching less litter from outside the plot (fig.3.1).

From each plot being closer to another, we randomly choose one. Then, on May 22th23th, 2004, we cut all lianas and vines there. However, liana fragments were not removed from the canopy in order to do not affect another experiment. Lianas and vines were cut $5 \mathrm{~m}$ around such plots as well. Re-srpouting lianas were cut every 2,5- to 3 months. Between June 2004 and July 2005, we extracted the litter from the traps once per month, always during the first six days of each month and in the same visit for both plots of each pair. All extractions lasted only one or two days. We packaged and dried the litter at $68^{\circ} \mathrm{C}$ until stable weight and registered such a weight as the dry weight of litter in grams. However, when no-balance was available, we kept the litter at $45^{\circ} \mathrm{C}$ and moved it to the Laboratories of the Centro de Investigacion Cientifica de Yucatan, where we dried it again at $70^{\circ} \mathrm{C}$ before weighting it again. Finally, between August $18^{\text {th }}$ and $20^{\text {th }} 2005$ (15mo after liana-cutting), saplings were re-measured in order to estimate their legth growth. 


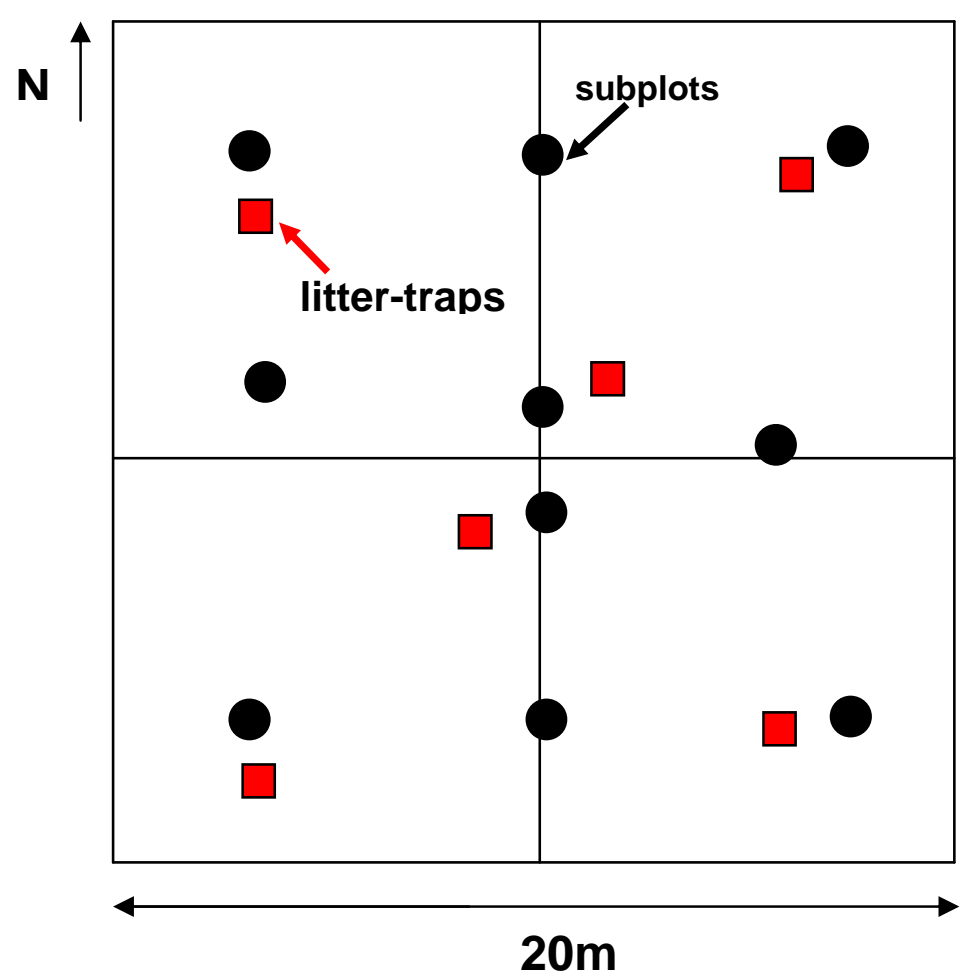

Fig. 3.1. Scale diagram of a plot. Circles represent $2 \mathrm{~m}^{2}$ subplots where we measured both, soil moisture and growth of saplings $\geq 30 \mathrm{~cm}$ length $<3,16 \mathrm{~cm}$ diameter. Red squares represent $1 \mathrm{~m}^{2}$ leaf-litter baskets that also caught woody debris. The arrow upper left indicates the North. We made 12 plots following this figure (see text for details).

\section{Data analysis}

\section{a) Comparing and grouping plots}

In order to determine what plots had similar species compositions to get a criterion for grouping plots, we ran two Cluster Analysis (WPGA, using Manhattan distances to assess similarities): one for the trees and the other for lianas. Such a grouping was necessary because of the very few individuals per sapling species, making plot-paired comparisons non viable. Some plots shared similar liana species composition, but were diffrent to other plots in their tree species composition. When that occurred, plots were grouped according to their lianaspecies composition similarities because we made the experiment to test the effect of lianas on saplings. However, plots in locations with similar forest ages were roughly similar in their species compositions of both, trees and lianas, simultaneously. Based on WPGA results, plots were grouped as follows: each plot in the $\geq 55 \mathrm{yr}$-old forest remained paired to its closer neighboring plot; three plots in the 18yr-old stand (Saúl18 B, C, and D) were collapsed in one 
group (trio), and plots Pepe10A, C, and Saúl18 A, were collapsed in a third group. Within each pair or trio of plots, soil moistures were compared (Student t-tests and one-way ANOVAs).

Using repeated measurement ANOVAs we tested if the fallen litter was similar between liana-cut and un-cut plots throughout the 12 months of litter collection. Natural logarithm of the dry weight of the litter was our dependent variable, otherwise data followed no-normal distribution and had no-homogeneous variances. Because liana-cut treatments had almost allways similar litter falls respect to un-cut ones, we continued comparing the growth of the saplings within each pair or trio of plots.

\section{b) Growth of saplings}

For each sapling we calculated a Relative Growth $(\mathrm{RG})$ as follows $\mathrm{RG}=\left(\mathrm{L}_{\mathrm{f}}-\mathrm{L}_{\mathrm{i}} / \mathrm{L}_{\mathrm{i}}\right)$, where $L_{i}$ and $L_{f}$ are the pre- and post-liana-cutting lengths of the sapling in cm, respectively (but see Pérez-Salicrup, 2001). Results included neagative values having a minimum of 0,93798. We summed to each value a positive number having an absolute value slightly larger than the mentioned one $(0,93799)$ in order to transform all results into positive numbers. Then we transformed each value into its cubic root in order to reach normality and variance homogeneity, but such transformations were not needed to analyze the data of some groups.

Two-way ANOVA is the best way to test the influence of liana-cutting on the growth of different sapling species for each pair or trio of plots, but no species had enough individuals for such analysis. Due to that we first compared the growth of saplings in general (disregarding their species) between liana-cut and un-cut plots of each group or trio (Student's t-test). Afterwards, we re-organized all plots in two groups according to their forest ages: $\geq$ 55yr- and 10-18yr-old. Then we tested the effects ofliana-cutting for all species having $\mathrm{n} \geq 3$ individuals in both, liana-cut and liana-uncut treatments (two-way ANOVA), within such successional ages. 


\subsection{Results}

a) Comparing and grouping plots

In the $\geq 55 \mathrm{yr}$-old forest, plots physically closer to each other shared similar tree species compositions (except plots Mario55 B and Rosendo55 B, fig.3.2a). It tends to be similar to plot similarities according to their liana-species compositions (fig.3.2b).

Dendrograms also confirm that there are two great groups of plots: the ones in the $\geq 55$ - and the ones in the 10-18yr-old forests (see the two main branches in fig.3.2a,b).

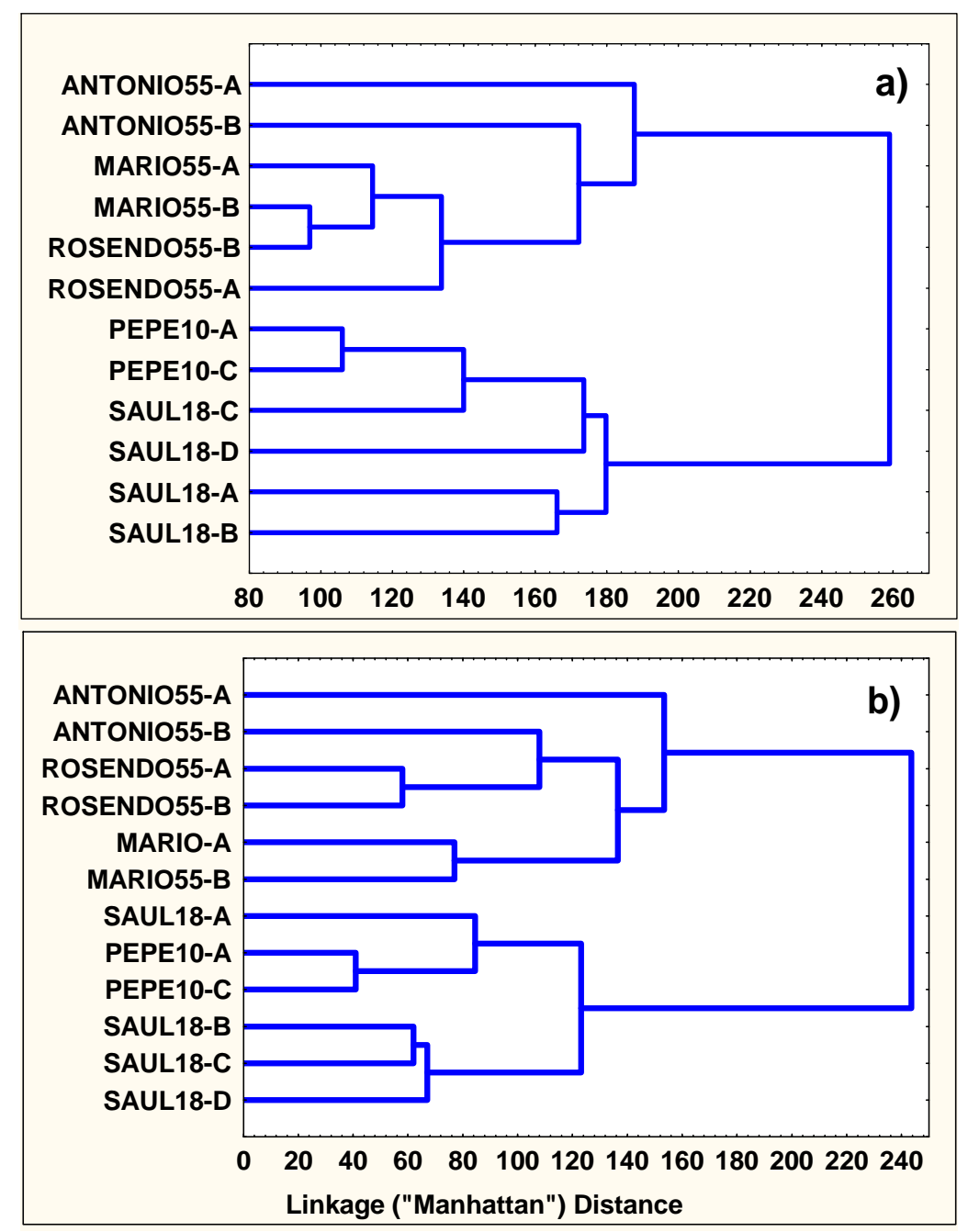

Fig. 3.2. Dendrograms clustering plots according to their shared tree (a) and liana (b) species, and to the numbers of individuals per species after Weighted Pair-group Average (WPGA). Plots separated by smaller Manhattan distances share more species and individuals per species. Notice that the two major groups (main branches) also share more similar successional ages (indicated by numbers besides the name of each plot, e.g. Antonio55-A is a plot in a forest $\geq 55 \mathrm{yr}$-old). (a) was taken from Chapter 2 of this dissertation, see fig.3.3 for liana taxa and their relative abundances.

Liana genera Arrabidaea and Cydista (Bignoniaceae) had more individuals and larger basal areas than other lianas in the $\geq 55 \mathrm{yr}$-old forest, while Dalbergia glabra (Leguminosae, 
Papilionoideae) dominated in the 10-18yr-old forest (fig.3.3; see possible reasons at the end of the discussion).
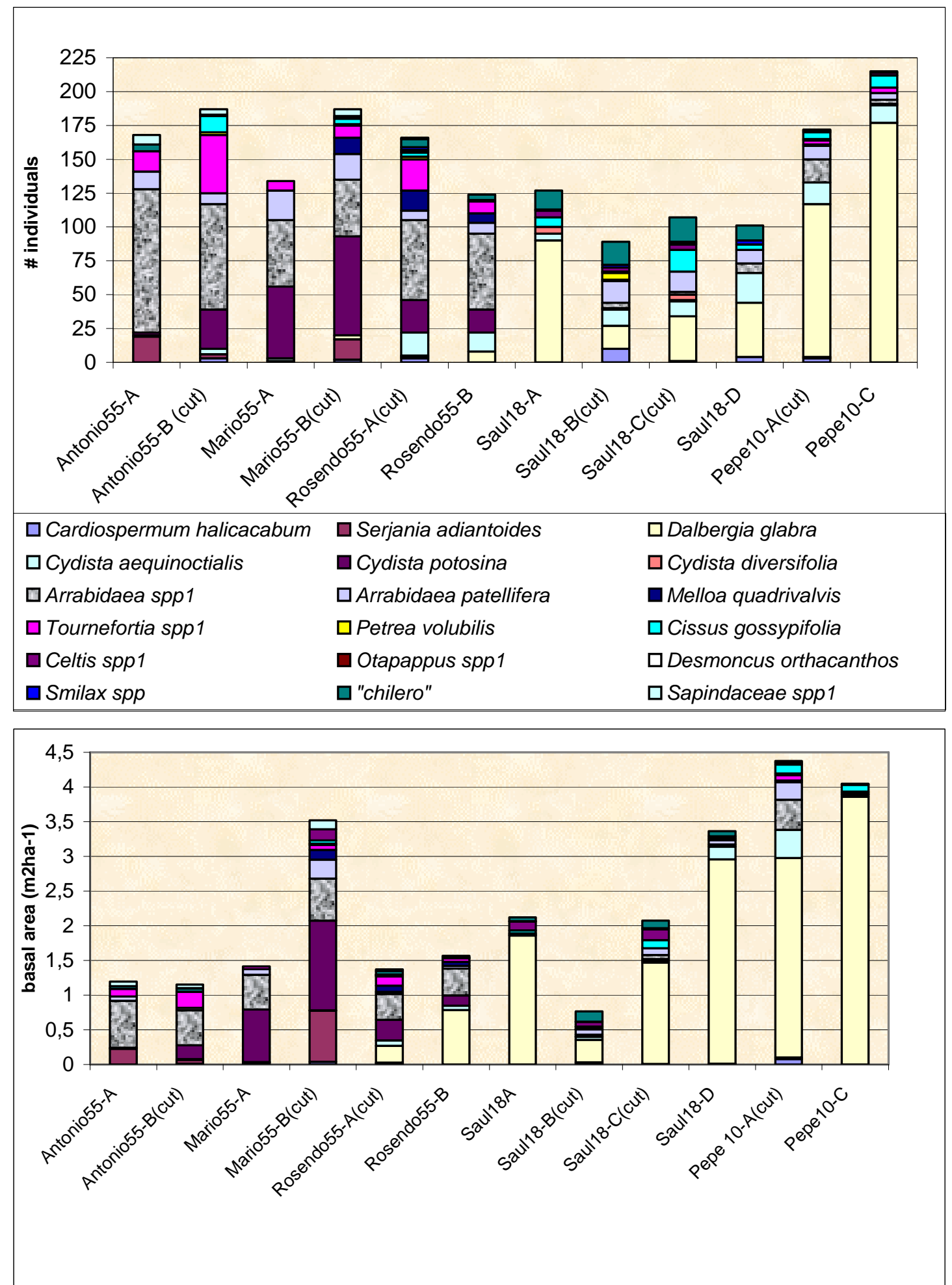

Fig.3.3. Liana numbers of individuals (upper graph) and basal area (lower graph) per species per plot.

Notice that the genera Arrabidaea and Cydista (Bignoniaceae) dominated the $\geq 55$ yr-old forest plots, while Dalbergia glabra (Papilionoideae) dominated the 18- and 10yr-old forest plots. According to the relative abundances of all of these species, dendrogram in fig3.2-b was made. "Chilero" is the common name of one non-identified Leguminosae having very small basal area (see lower graph). The word "cut" indicates liana-cut plots. 
Within each pair or trio of plots, litter fall was similar in liana-cut vs un-cut plots for the 12 months it was measured, except for the trio of plots Pepe10 A-C + Saúl18-A (Repeated measurements ANOVAs, Table 3.1, fig. 3.4; detailed values are in Appendix III). Litter accumulated during the year was about $2500 \mathrm{~kg} \cdot \mathrm{ha}^{-1} \mathrm{y}^{-1}$, very low compared to a $>500 \mathrm{yr}$-old forest in Barro Colorado, Panama (12 $390 \mathrm{~kg} \cdot \mathrm{ha}^{-1} \mathrm{y}^{-1}$, Wieder and Wright, 1995) and secondary forests in Guatemala with similar successional ages to ours (between $8000 \mathrm{~kg} \cdot \mathrm{ha}^{-1} \mathrm{y}^{-}$ ${ }^{1}$ and $9000 \mathrm{~kg} \cdot \mathrm{ha}^{-1} \mathrm{y}^{-1}$, Ewel, 1974), probably because the higher rainfall and has an older successional age in both places supports a larger standing biomass compared to our study site. Table 3.2 summarizes the densities and basal areas of both, trees and lianas, in each plot and soil moistures of plots as well.

Table 3.1. P-values after comparing the dry weight (in grams) of fallen litter per month between liana-cut vs liana-uncut plots belonging to the same pair or group of plots.

\begin{tabular}{llll} 
Pair or group & $\mathrm{P}_{\text {(cutting) }}$ & $\mathrm{P}_{\text {(month) }}$ & $\mathrm{P}_{\text {(cutting x m }}$ \\
& & & \\
Antonio55 A-B & 0,28190 & 0,00001 & 0,18180 \\
Mario55 A-B & 0,26190 & $<0,00000$ & 0,76260 \\
Rosendo55 A-B & 0,19790 & 0,00003 & 0,17430 \\
Saúl18 B-C-D & 0,47550 & 0,000002 & 0,61310 \\
Pepe10 A-C + Saúl18-A & 0,49060 & $\mathbf{0 , 0 0 0 5 8 0}$ & $\mathbf{0 , 0 0 1 2 8}$ \\
\hline
\end{tabular}

Notes: $\mathrm{n}=6$ traps per plot. P-values were obtained after Repeated Measurements ANOVA in a monthly basis during 12 months. Notice that for almost all plot pairs or trios, the time in months, but not the liana-cutting influenced the litter fall (but for the trio "Pepe10 A-C + Saúl18-A", the interaction between liana-cutting and time in months also influenced the litter production, Fig.3.4). Analysis were ran after transforming dry weights into their natural logarithms. Highlighted values indicate where both treatments, liana-un-cut vs liana-cut had different litter falls. 


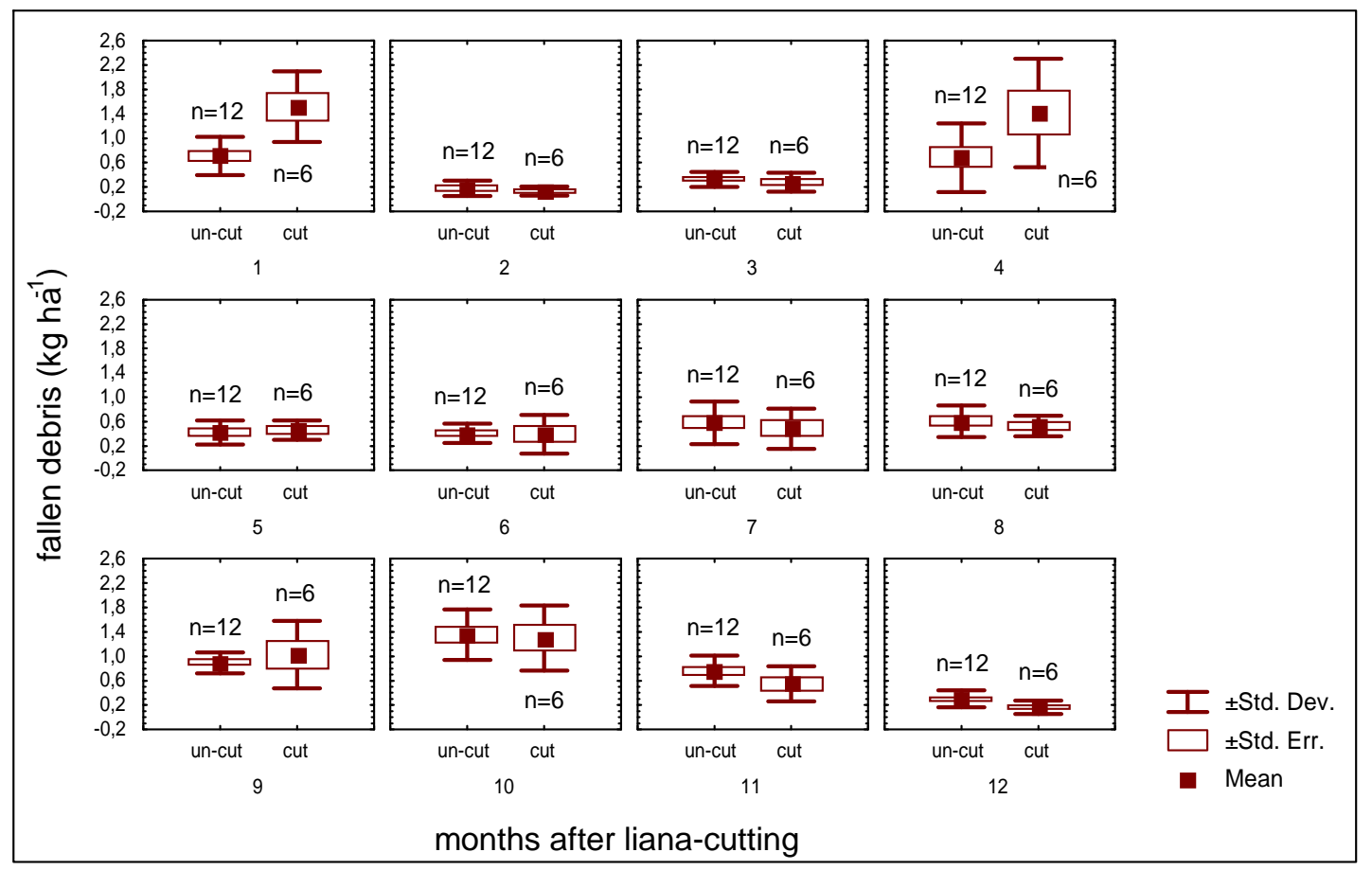

Fig. 3.4. Fallen debris per month in liana-uncut and liana-cut plots in plot-trio Pepe10A-C + Saúl18. $n=$ number of traps collecting debris. Notice that in months 1 and 4 liana-cut plots produced more debris, probably due to a massive fall of liana-fragments from Dalbergia glabra which did not occur for the other plot groups (see also Table 3.1). 

Table 3.2. Summarized description of twelve $400 \mathrm{~m}^{2}$ plots of Semi-Evergreen Tropical Forest.

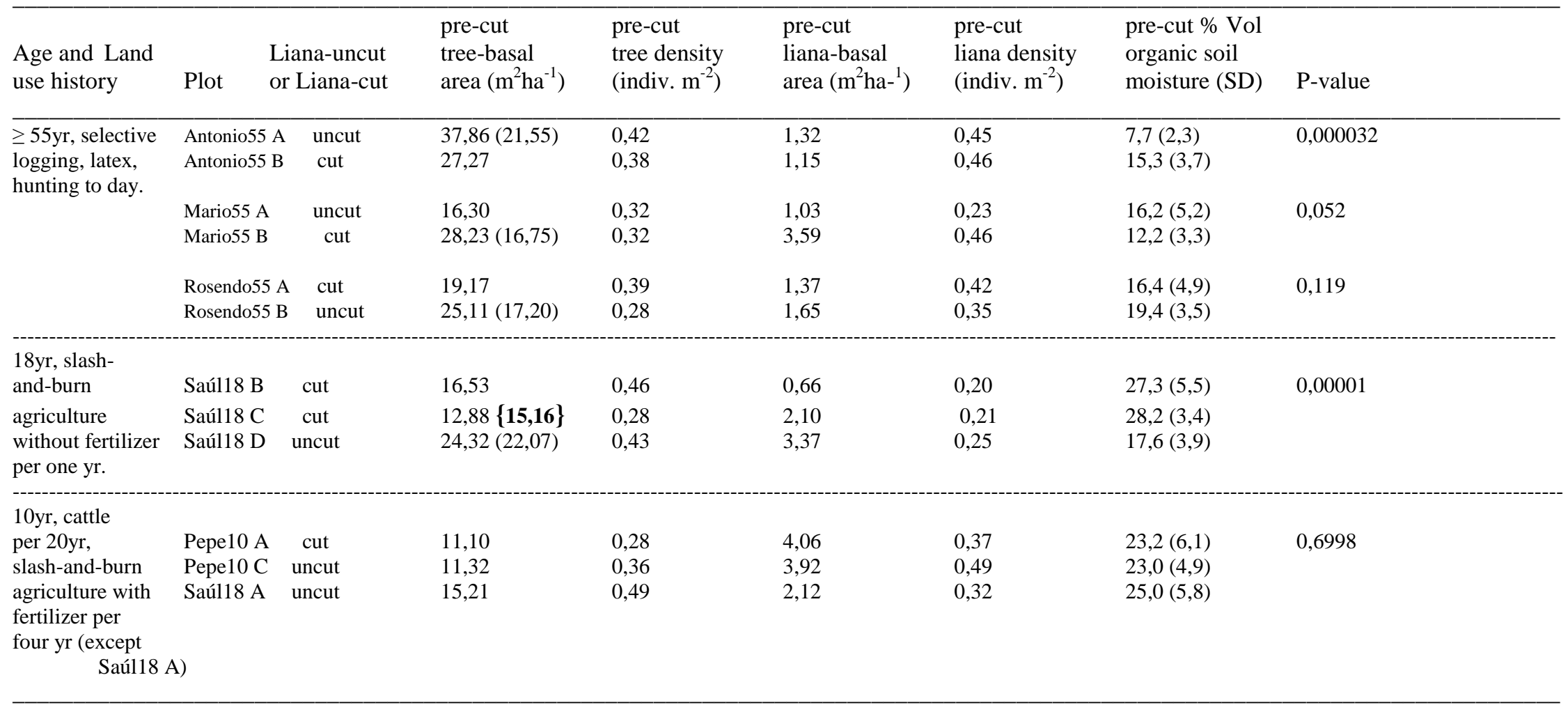

Notes: Forest ages were estimated respect to 2003. Lianas were cut in May 22nd-23rd 2004. Only live trees in the census of August 18-20 2005 are included. Liana-basal area comprises all lianas rooted in each plot, including the ones climbing upon trees outside each plot. Plots in the $\geq 55 \mathrm{yr}$-old forest were settled in pairs indicated by the same

name (eg Antonio), and kept paired because of their similar liana species compositions (fig.1 $1 \mathrm{a}-\mathrm{b}$ ). Distance between such paired plots ranged from 5 to $20 \mathrm{~m}$. Plots

in the 18- and 10yr-old (Saúl and Pepe) were grouped according to their similar liana-species compositions (fig.1b, relative abundances of liana species are shown in fig.2).

Plots are named according to the land owners: Antonio Lara, Mario Ucan, Rosendo Can, Saúl Ancona and José "Pepe" Quintal. Digits in brackets besides tree basal areas indicate basal areas excluding the five biggest trees of their respective plots. Highlighted tree basal area digits $\{\mathbf{1 5 , 1 6}\}$ indicate tree basal area before the accidental cut of some trees in plot Saúl18 C by some farmers. Soil moistures were measured for the organic section of the soil with a Soil moisture meter type HH1, (Delta T-Devices). Such measurements were made in 10 sample points per plot, except for plots Saúl18 B and Pepe10 A (8 and 5 sampling points, respectively). P-values were calculated for Student't t tests comparing moistures for each pair of plots, and ANOVA-I for the groups of three plots. Land Use History was re-constructed by formal and non-formal interviews with land owners and elder inhabitants of the study site, aerial pictures from 1979, 1985, 2001, satellite images from 2005 and historical information about Quintana Roo State and Solferino Village (Reed, 1971; Careaga, 1994; Kiernan, 2000). 


\section{b) Growth of saplings}

From 733 registered saplings, 384 were in the $\geq 55 \mathrm{yr}$-old forest plots and 349 in the 10-18yr-old forest plots. Also from such 733 saplings, 408 were in liana-uncut plots and 325 in the liana-cut plots. In two of the three pairs of plots in the $\geq 55 \mathrm{yr}$-old forest the saplings grew more where lianas were cut, suggesting a negative effect of lianas (Plot pairs Antonio55A-B and Mario55A-B, Table 3.3). For the 18yr-old plot trio (Saúl B, C, and D), saplings grew more where lianas were not cut, suggesting a favoring effect of lianas there (Table 3.3). Liana-cutting had no effects on the growth of saplings in: Plot-pair Rosendo55AB, and plot trio Pepe10A-C-Saúl18-A (Table 3.3).

After pooling data in all plots of the $\geq 55 \mathrm{yr}$-old forest, seven species had $\mathrm{n} \geq 3$ individuals in both, liana-cut and liana-uncut sites. That summed 327 saplings ( $85 \%$ of all saplings in such a forest). The species were: Eugenia axillaris, Chrysophyllum cainito, Dendropanax arboreus, Diospyros cuneata, Nectandra salicifolia, Zygia stevensonii and Malmea depressa. Where we cut lianas, C.cainito and M.depressa grew more, suggesting that lianas hinder their growth. However, the other species were not affected (two-way ANOVA, fig. 3.5a).

After pooling data in the $10-18 \mathrm{yr}-$ old forest plots, eight species represented $71 \%$ of all saplings there: Guettarda elliptica, Chrysophyllum cainito, Eugenia axillaris, Guettarda combsii, Lonchocarpus rugosus, Swartzia cubensis, Lonchocarpus xuul and Randia truncata. Two species, E.axillaris and L.rugosus, grew more where lianas were not cut. It suggests that lianas enhanced the growth of this species, or at least did not outbalanced factor favoring them (e.g. incident light, fig.3.5b). Meanwhile, liana cutting did not affect the other six species and they also had no species-specific differences on their growths (two-way ANOVA, fig.3.5b). 
Table 3.3. Growth of saplings in liana un-cut and liana cut plots 15 months after cutting lianas.

\begin{tabular}{|c|c|c|c|c|c|c|}
\hline $\begin{array}{l}\text { Pair or trio } \\
\text { of plots }\end{array}$ & $\mathrm{n}_{\text {(un-cut) }}$ & $\mathrm{n}_{\text {(cut) }}$ & $\mathrm{RG}_{\text {(un-cut) }}(\mathrm{SD})$ & $\mathrm{RG}_{\text {(cut) }}(\mathrm{SD})$ & Student's t & P-values \\
\hline Antonio55 A-B & 50 & 93 & $-0,133(0,240)$ & $0,004(0,299)$ & 7,905 & 0,006 \\
\hline Mario55 A-B & 100 & 52 & $-0,026(0,205)$ & $0,045(0,213)$ & 4,064 & 0,046 \\
\hline Rosendo55 A-B & 40 & 49 & $0,227(0,195)$ & $0,138(0,697)$ & 0,603 & 0,439 \\
\hline Saúl18 B-C-D & 53 & 67 & $0,130(0,300)$ & $-0,002(0,288)$ & 5,960 & 0,016 \\
\hline Pepe10 A-C-Saúl18 A & 165 & 64 & $0,171(0,467)$ & $0,102(0,972)$ & 0,070 & 0,791 \\
\hline
\end{tabular}

Notes: $\mathrm{RG}=$ Relative Growth $=\left(\mathrm{L}_{\mathrm{f}}-\mathrm{L}_{\mathrm{i}} / \mathrm{L}_{\mathrm{i}}\right)$, where $\mathrm{L}_{\mathrm{i}} \mathrm{y} \mathrm{L}_{\mathrm{f}}=$ pre-cut and post-cut lengths, respectively. $\mathrm{n}=$ number of individual saplings. Negative values indicate length decrease. 

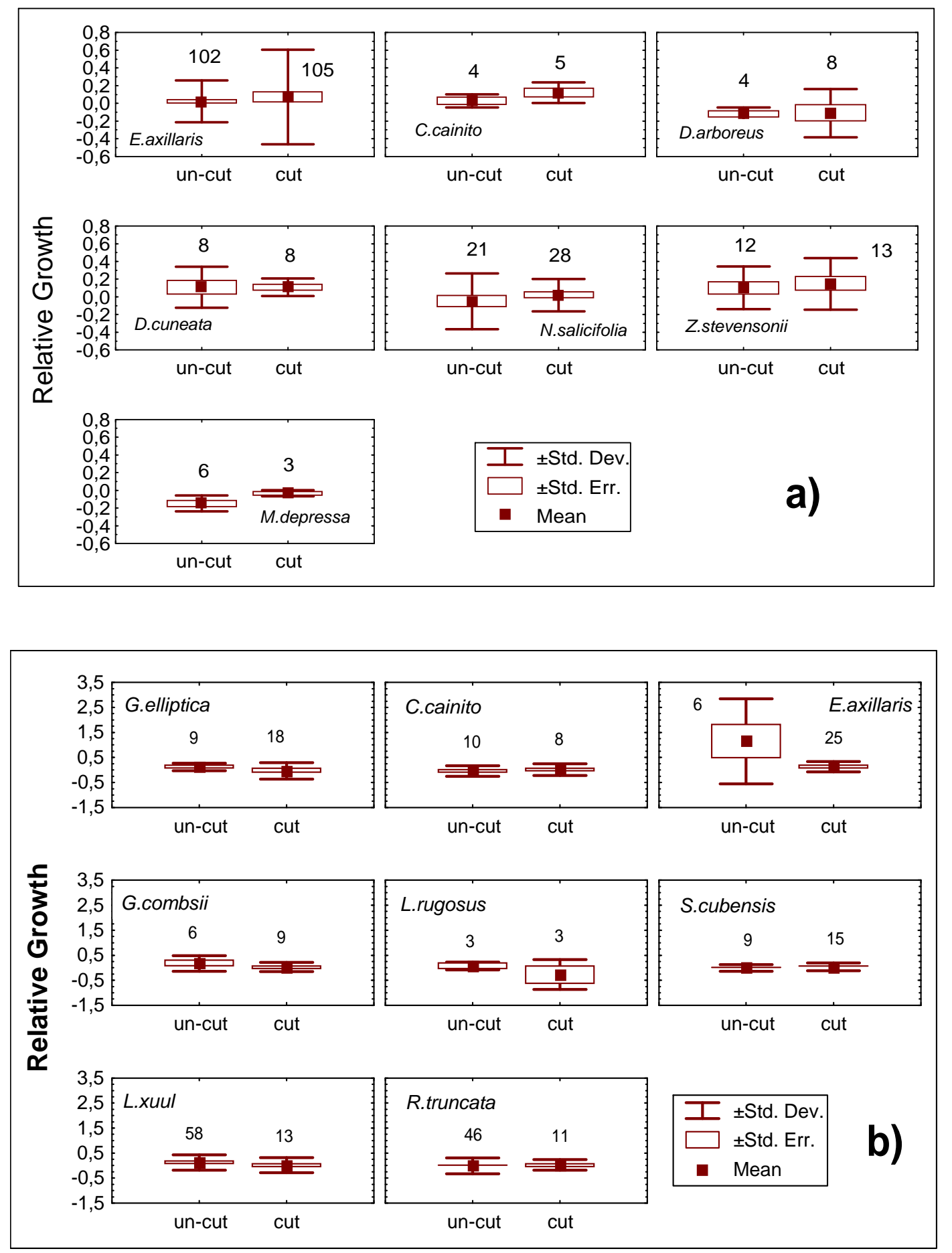

Fig. 3.5. Relative Growth of saplings after cutting lianas in: a) $\geq 55 \mathrm{yr}$-old forest, and b) 10 -18yr-old forest, for species having $\mathbf{n} \geq \mathbf{3}$ individuals in both, liana cut and liana un-cut plots. In the $\geq 55 \mathrm{yr}$-old forest both, sapling species and liana-cutting, but not their interaction altered the growth of saplings. There C.cainito and M.depressa grew better when lianas were cut; the other species were not affected (two-way ANOVA:

$\left.\mathrm{F}_{\text {spp }}=10,962, \mathrm{P}_{\text {spp }}=0,00513 ; \mathrm{F}_{\text {cutting }}=6,408, \mathrm{P}_{\text {cutting }}=0,0446, \mathrm{~F}_{\text {spp } x \text { cutting }}=0,1210, \mathrm{P}_{\text {spp x cutting }}=0,9938\right)$. In the 10-18yrold forest, only the interaction between sapling species and liana-cutting affected the growth of saplings. There E.axilaris and L.rugosus grew more where lianas were not cut, the other species were not affected (two-way ANOVA: $\mathrm{F}_{\text {spp }}=1,7090, \mathrm{P}_{\mathrm{spp}}=0,248 ; \mathrm{F}_{\text {cutting }}=3,7908, \mathrm{P}_{\text {cutting }}=0,0926 ; \mathrm{F}_{\mathrm{spp} x}$ cutting $\left.=2,7718, \mathrm{P}_{\mathrm{spp} \mathrm{x} \text { cutting }}=0,0087\right)$. Digits upon boxes are numbers of individuals. See text for full names of species. 
Notice also that E.axillaris was non-affected on the $\geq 55$ yr-old stand whiole being growing more on the liana-uncut plots of the 10-18yr-old forest. Meanwhile, C.cainito was negatively affected by lianas on the older stand, but non-affected on the younger stand (fig.3.5a-b). 


\subsection{Discussion}

There is a general lack of studies on the effect of lianas on saplings. The three studies reported to date lasted 18 months (Pérez-Salicrup, 2001), two years (Schnitzer et al, 2005), and three years (Whigham, 1984). Our study lasted even less (15 months) and probably mostly of our sapling species would not respond to liana-cutting after such time. But despite the short study time, four sapling species changed their growths according to liana-cutting. They were C. cainito and M. depressa ( $\geq 55 \mathrm{yr}-\mathrm{old}$ stands), and E. axillaris and L. rugosus (10-18yr-old stands, fig.3.5a-b). This is true even by using the same formula for annual growth rate than Pérez-Salicrup (2001, data not shown). Additionally, similar results were obtained when analyzing length-increasing and length-decreasing saplings separately (fig.3.5a). Consistent to other studies our results for the $\geq 55 y$ r-old stands show that lianas are related to slower growth of saplings and trees (Putz, 1984a; Whigham, 1984; Clark and Clark, 1990; Dillenburg et al, 1993a; Pérez-Salicrup and Barker, 2000; Pérez-Salicrup, 2001; Grauel and Putz, 2004; Schnitzer et al, 2005; Kainer et al, 2006). Liana-cutting may not necessarily have reduced below ground competition there (as in Pérez-Salicrup, 2001), but above ground competition. In concrete, cut lianas may have droped down their leaves, increasing the light reaching the ground, but sunligth reaching the understory was not measured.

A noteworthy exception is that saplings grew similarly in plot Rosendo55-A (lianacut) compared to Rosendo55-B (liana-uncut), suggesting a spatial variation of the effects of lianas respect to other plots of the same $\geq 55 \mathrm{yr}$-old forest.

Surprisingly, when saplings of all species were pooled for the analysis, liana-cutting enhanced the growth of saplings for the 18-yr-old trio of plots (Saúl18-B, C, and D, Table 3.3), while having no-effects on plot-trio Pepe10A-A + Saúl18-A; specifically for E.axillaris and L.rugosus (fig.3.5.b). That implies that the effects of lianas on saplings are not allways deleterious as previously reported (e g Pérez-Salicrup, 2001). Again, it also implies a spatial variation of the effects of lianas on saplings and their potential role on tree regeneration 
(Pérez-Salicrup, 2001). For example, in earlier stages of our studied forest dominated by Dalbergia glabra, lianas apparently favor the growth of some sapling species (E.axillaris and L.rugosus), but when the forest is alredy $\geq 55 \mathrm{yr}$-old, now dominated by Bignoniaceae lianas, such a positive effect does not occur, but a reduction of the growth of many sapling species besides no-effect of lianas on other places $\geq 55 \mathrm{yr}$-old.

Other factors measured in our study cannot explain the unexpected response of saplings in general growing faster in the trio of plots Saúl18-B, C, and D. For example, lianas were cut in plots Saúl18 B and C and the soil was more moist there compared to the uncut Saúl18 D plot (Table 3.2); however, saplings grew less when soil moisture was higher (the soil never became saturated with water during our study, E.Garrido-Pérez, pers. obs).

Moreover, tree-basal area and tree-density were higher in Saúl 18 D (the plot where saplings grew more), suggesting that tree-sapling competition did not occur or did not reduce the size of saplings. Litter fall was similar between liana-cut and liana-uncut plots (Tables 3.1 and 3.2) suggesting that it did not determine differences of sapling growth. There is no reason why Litter fall would have been different during the years immediately before our study, when litter accumulation and decomposition provided the nutrients that were taken up by the saplings during our study. Also, given the relative floristic similarity between the plots it is unlikely that the chemical composition of litter was significantly different between liana-cut and liana-uncut plots (though no chemical analyses were performed to test this).

Consequently, at least from the measured factors and treatments, liana-cutting is the only one that can be related to the faster growth of saplings in Saúl18-D with respect to Saúl18B-C, but other, non-measured factors may play a role. The same applies for all studied groups of plots. We did not measure other factors potentially affecting the growth of our saplings like incident light on the forest floor and the understorey and the availability of soil nutrients (Denslow et al, 1998; Dalling and Hubbell, 2002; Makana and Thomas, 2005). These factors, and not necessarily lianas, may have had the major impact on the different growth of saplings. For 
instance, liana-cutting had no-effects on plot trio Pepe10A-C + Saúl18A, but probably the effect of incident light was similar in our liana-cut vs liana-uncut plots there because the canopy is generally open due to the early successional stage of the forest there. In contrast, in the $\geq 55 \mathrm{yr}$-old stands the canopy openness was heterogeneous because of selective logging, hurricanes and forest manipulations during latex extractions from Manilkara zapota trees. It creates patches at the forest floor that have receive different incident light (E. Garrido-Pérez, pers. obs.). Since lianas colonize gaps rapidly (Schnitzer et al, 2000), lianas and sapling species growing more may have just coincided. Thus, light micro-environments may have enhanced the growth of our saplings (see Lambers et al, 2000 for ecophysiological details). This argumentation applies for our species growing better where lianas were cut, i.e. incident light and not necessarily liana-cutting enhanced growth, but it remains untested. Hence it is appropiate to be conservative asserting that lianas favored saplings in our younger forest stand. At least a possible negative effect of the lianas was not pronounced enough to outrivial other factors favoring saplings (e.g. incident light).

There is a paucity of information about microenvironmental requirements (e.g. incident light, soil moisture, temperature) and life-history traits of our sapling species. All species are common in very early- and early successional stages of the Yucatan Peninsula (Sánchez-Sánchez and Islebe, 2002) and may be considered as pioneers. But there is a wide range of life history strategies and environmental requirements tolerable for plants, even within the "pioneers" (Grime 1974, Gilbert et al, 2006). Since the early stages of tree development (seedlings and saplings), light demanding species grow fast and, once trees are adults, it results in lighter wood compared to shade-tolerant species (see also MartínezRamos, 1994; Dalling and Burslem, 2005). Indeed, we use the wood density of the adult stage of our sapling species documented in Reyes et al (1992) as an indicator of their light requirements and life-history traits respect to other pioneers. For species in figure 3.5, Chrysophyllum cainito has the less dense wood (for its genus, wood density $=0,56 \mathrm{~g} \cdot \mathrm{cm}^{-3}$ ). On 
ascending order of wood density given in $\mathrm{g} . \mathrm{cm}^{-3}$ per genera in Reyes et al (1992) we have: Nectandra: 0,57, Eugenia: 0,69, Diospyros: 0,71, Lonchocarpus: 0,74, Randia: 0,78, and the one with slower growth is Swartzia: (wood density $=0,95 \mathrm{~g} . \mathrm{cm}^{-3}$; remainin genera of fig. 3.5 are not enlisted in Reyes et al, 1992). That suggests that our results of possible liana-effects may be applicable for a wide range of life-histories within the guild of the pioneers, from fastgrowing Chrysophyllum cainito to slow-growing Swartzia cubensis. Probably, S.cubensis and other species grow too slowly to us to detect liana-induced size changes during our study (suggesting that more time is necessary), while results for C.cainito, Eugenia axilaris and Lonchocarpus rugosus are more reliable because they grow faster.

Liana-cutting did not affect the relatively slow-growing E.axillaris on the $\geq 55$ yr-old forest (fig. 3.5a), but it grew better in the liana-uncut plots of the 10-18yr-old stands (fig. 3.5b). Also, the fast-growing species C.cainito was negatively affected by non-cut lianas in the $\geq 55 \mathrm{yr}$-old stand, but non-affected on the younger stand (fig. 3.5.a-b). We conclude that the effects of lianas on saplings change not only among species, but also spatially and probalby during secondary succession, even for the same species of saplings. We propose that the wide spatio-temporal variability of effects of lianas on co-specific saplings implies that the negative effects of lianas on some individuals is compensated by the positive or null-effect on others. It may be occurring at the landscape level, for example among neighboring patches of different successional ages, like in this study; but also and among gaps within a forest. This challenges the idea that lianas are a driving force changing the relative abundance of tree species by favoring the growth of some sapling species more than others (Pérez-Salicrup, 2001; see also Schnitzer and Bongers, 2002).

This is not the first study to discuss that lianas are generally threatening trees. In Barro Colorado, Panama, pioneer species are favored with respect to slow-growing ones when lianas dominate gaps (Schnitzer et al, 2000). In Bolivia, water uptake of Switenia macrophylla is not affected by lianas (Barker and Pérez-Salicrup, 2000). Also, some tree species on Barro 
Colorado are not affected by their neighboring lianas because such lianas obtain water from deeper layers of the soil (Andrade et al, 2005). The latter could be a possible reason why the studied saplings were not affected (but see Restom and Nepstad, 2004). In fact, the groundwater level is between two to eight meters depth in our study region (Bautista-Zúñiga et al, 2003), and sometimes between one to two meters (E. Garrido-Pérez, pers. obs). Our non-affected saplings may have reached such water, avoiding competition in this way. Therefore our data and reported studies suggest that it is not possible yet to claim that lianas generally hinder the growth of saplings. We think it also helps to explain their co-existence with trees species: when lianas do not affect saplings, saplings have more chances to become adult trees, co-existing with lianas.

We recognize that many of our sapling species were poorly represented, so we recommend similar studies using more subplots. Meanwhile, potential positive effects of lianas in our 10-18yr-old plots suggest that liana-cutting is at least not necessary for enhancing the recruitment of new adult trees for logging. In contrast, the same point of view indicates that cutting lianas when the forest has reached the age of approximately $55 \mathrm{yr}$ can be recommended (deduced from Table 3.3 and fig. 3.5).

Finally, reasons of the dominance of the liana D.glabra on our younger stands and many other aspects of this species remain poorly studied. It is a very common species in seasonal wetlands of the lowlands of the Yucatan Peninsula (Olmsted et al, 1999; Carnevali et al, 2003) suggesting that the swalow underground waters of our study site (Bautista-Zúñiga et al, 2003) explain partially its abundance there. Also, D. glabra seems to colonize quickly places exposed to recent fires (E. Garrido-Pérez, pers. obs.). It suggests that recent slash-andburn agriculture on our 10yr- and 18yr-old stands determined its abundance there and, during the succession, the shade of trees emerging through the canopy of D.glabra shadow such liana species (see also Lex et al. 1998), making its populations to decline. Meanwhile, bignones become dominant because of their fast growth compared to many other liana taxa (Avalos and 
Mulkey, 1999). Since both, D.glabra and Bignoniaceae are common lianas in many areas (e.g. Grauel and Putz, 2004; Gentry, 1991, this report), studies on their natural history and effects on saplings and trees are recommended. 


\section{Chapter 4}

\section{STRUCTURAL EFFECTS OF LIANAS AND HURRICANE WILMA ON TREES IN A SEMI-EVERGREEN TROPICAL FOREST IN QUINTANA ROO, MEXICO}

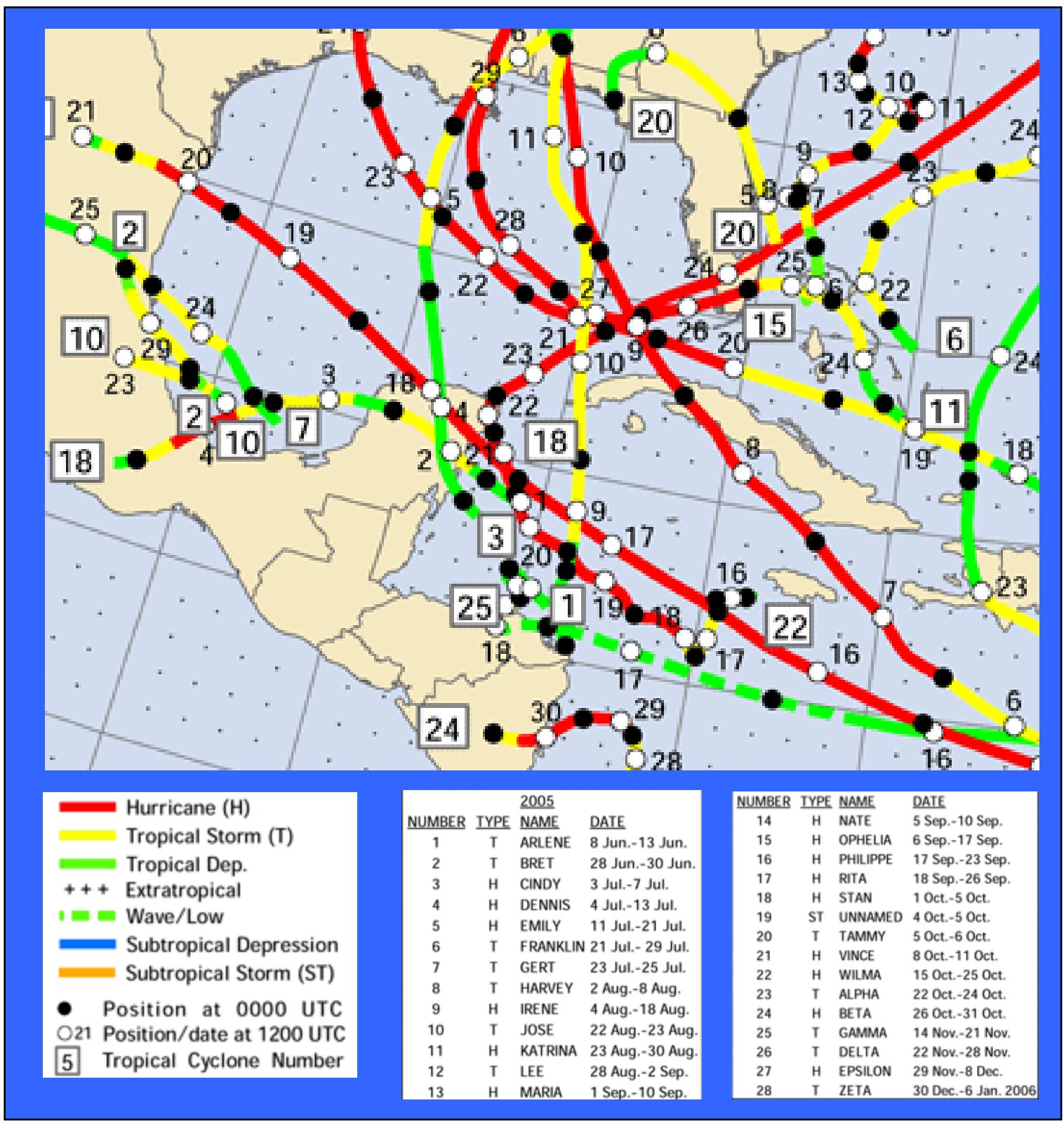

Strong winds are very common in the Caribbean and in the Gulf of Mexico, and produce gaps where lianas may increase their abundances. The trajectories of just some of such storms are shown in the map (not all the enlisted ones appear in the figure). Results from this chapter suggest that, for forests located "in the eye of the storm", lianas do not necessarily make trees to collapse. (Courtesy of (C) National Oceanic and Atmospheric Administration -NOAA, USA- 2006: Chart of trajectories of hurricanes in the Atlantic, Caribbean and Gulf of Mexico). 


\subsection{Introduction}

Climate change has been suggested as a cause for an increasing intensity and destructive power of hurricanes (Emanuel, 1987; 2003). This may enhance the abundance of lianas respect to trees by opening more gaps able to be colonized by lianas (Phillips et al, 2002; Wright et al, 2004). Lianas are considered to be structural parasites reducing tree reproduction (Stevens, 1987; Kainer et al, 2006). Lianas can also damage the structure of trees by breaking trunks and branches of them, for example, when they pull trees connected to falling ones by the same liana (Putz, 1984, 1991; Schnitzer and Bongers, 2002; Kainer et al, 200; but see Parren et al, 2001).

About $25 \%$ of the flora of tropical forests corresponds to lianas and $33-79 \%$ of trees host them (Putz, 1984a; Gentry, 1991; Pinard and Putz, 1994; Campbell and Newberry, 1993). Since liana-abundance increases, their structural effects may be increasing too, but such effects are poorly understood. For example, while lianas are proposed to enhance the fall of trees (e.g. Putz, 1984a, 1991; Schnitzer and Bongers, 2002) it is not explained how lianaloaded a tree must be in order to that to occur. Also hurricanes produce structural damages on trees (e.g. Whigham et al, 1991; Ostertag et al, 2005) but it is not known wheather lianas increase or reduce such damages.

Liana-induced damages to trees may change according to the biomechanics of each liana. Some lianas have wide vascular vessels (e.g. genera Serjania, Cydista and Arabidaea) and are lighter and more flexible than other lianas. Other lianas have narrower vessels forming compact tissues (Carlquist, 1991; Acevedo-Rodríguez, 2003). Moreover, because of such narrow and compact vascular tissues, where no-tree is present, some lianas display an arbustive habit (for example, different species of Dalbergia, Carlquist, 1991; AcevedoRodríguez, 2003). Thus, heavy and rigid lianas may harm trees more strongly than light and flexible ones. Due to these differences among lianas, it is not clear if they contribute to 
produce or to avoid structural damages of trees. There is also a paucity of studies testing mechanical effects of lianas on trees in the field.

Putz (1984a) formulated two alternative hypotheses about liana-induced damages when some trees are broken: 1) lianas may cause more damage by pulling more trees, and 2) lianas may tie canopies together, provide more stability and thus there will be less damaged trees. If hypothesis one is true, lianas enhance gap forming that, conversely, favor more lianas to proliferate (Schnitzer and Bongers, 2002). If hypothesis two is true, the just mentioned feedback effect does not occur and lianas contribute to forest resistence during disturbances like the ones generated by strong winds. The impact of Hurricane Wilma on forests stands where we had a liana cutting experiment became a "natural experiment" helping us to test this and to quantify hurricane damages on trees hosting living and non-living lianas.

Structural damages of trees may depend on (a) local variation in collapsing risks (e.g. due to different liana species compositions), (b) size of trees, being larger trees more prone to collapse (Tovilla and Orihuela, 2004; Michener et al, 1997; but see Sánchez and Islebe, 1999), (c) number of hosted lianas per tree (e.g. trees hosting more lianas may be more endangered), (d) pre-hurrican liana-induced bowing of trees, (e) liana-coverage of each tree (more liana-entangled trees should collapse easier), and (f) pre-hurricane position of the trunk of the tree (sloped trees being more susceptible than vertical ones). Factors (c), (d), (e), and (f) may be associated to a displacement of the gravity center of trees, potentially increasing their risks to collapse (Bueche, 1988). We explored the effects of such factors when hurricane Wilma stroke our study site.

Hurricane Wilma (minimum central pressure $=882 \mathrm{mb}$; maximum winds $=295 \mathrm{~km} \cdot \mathrm{h}^{-1}$ ) was the most powerful cyclone registered to date in the History of the Caribbean. On October 21th 2005, Wilma stroke our study site in northern Quintana Roo (Mexico). Before the hurricane we had 12 plots where we tagged, measured and identified both, lianas and trees. We also determined how many lianas hosted each tree and estimated the liana-coverage per 
tree, and if trees were bowed by lianas as well as sloped before the hurricane. We cut all lianas in six of our plots before the hurricane and here we report the resulting damages.

\subsection{Materials and Methods}

Study site, location and Land Use History of the plots

The study was conducted in the peasants' community of Ejido Solferino, Quintana Roo, Mexico, near Yum Balam Reserve of Flora and Fauna $\left(21^{\circ} 26^{\prime} \mathrm{N}, 8^{\circ} 28^{\prime} \mathrm{W}\right.$; $10 \mathrm{~m}$ above see level; INEGI; 1993). Soils are poorly developed luvisols, rendzines and vertisols upon a calcareous base emerged after the Pleistocene, (Municipio de Lázaro Cárdenas, 1987; Olmsted et al, 2000; Bautista-Zúñiga et al, 2003). The topography is mainly flat; life zone is semi-evergreen tropical forest (Selva Mediana Subperennifolia, sensu Miranda and Hernández, 1963; Tropical Dry Forest, sensu Holdridge et al, 1971). Average annual rainfall is $1250 \mathrm{~mm}$, the dry season lasts from February to April, and the wet season from May to January, including strong winds and some hurricanes, especially in September-October (Orellana et al, 1999; 2003). As part of a wider study, we settled 12 plots of 20m x 20m each (described in Table 4.1).

\section{Field work}

Between November 2003 and March 2004 we tagged and measured the girths of all trees $\geq 10 \mathrm{~cm}$ girth $(3,16 \mathrm{~cm}$ diameter at $1,3 \mathrm{~m}$ above ground level- $\mathrm{dbh})$, painting the point of such measurements.

By visually observing each tree we idealized Newton's force diagrams for them (Bueche, 1988) in order to determine if it was bowed by: a) only lianas, b) lianas and other agents, mainly neighboring trees, c) only other agents, and d) non-bowed. We report only liana-bowed trees because there were very few ones bowed by other agents. A target tree was considered bowed by lianas if: a) lianas were pulling or pushing the tree by means of any organ, b) such a pushing or pulling was in the same direction than tree-trunk bowing, and c) 
there was not any other bowing agents like other trees or sinuous growth due to phototropic growth caused by the shade of neighboring trees in the past. Trees having lianas close, but not contacting them during our survey, may have been bowed by lianas before our visit. Such trees were considered bowed by "other causes" in order to our estimations of liana-bowed trees to be as conservative as possible. We also determined whether trees were sloped. Such trees were not bowed at least in their first $1,5 \mathrm{~m}$ above ground, but their boles were not in a vertical position (perhaps due to strong winds in the past).

We identified and measured the diameter at ground level of all lianas $\geq 1 \mathrm{~cm}$ diameter and tagged them with a unique code number. Diameters were measured with a caliper in nonhunched regions of stem internodes. When stems were not transversally round but elliptical, only the smaller diameter was measured. We marked all hand-reachable stems of each liana individual with its respective code number to avoid counting and measuring the same individual more than once. When stems seemed to be branches from underground stems, we excavated to approx. $10 \mathrm{~cm}$ depth around them to find and measure the main stem. When it was not reached, each aerial stem was marked and considered as a different individual. When we reached the main stem but it was impossible to be measured (e.g. stems decomposing or surrounded by large stones), we considered the sum of the basal areas of the branches as the basal area of the individual. Herbaceous vines (mainly juvenile individuals of Smilax spp, Smilacaceae) having at least one stem $\geq 1 \mathrm{~cm}$ diameter were included as lianas, assuming that they could pull trees. The few lianas rooting within the plot but climbing upon trees outside the plot were not included in our basal area calculations because they had no chance to pull trees within our plots during the hurricane. However, lianas rooting outside but climbing on trees inside plots were included, since they applied forces on our studied trees.

Because lianas may produce mechanical stress on trees (see also Putz, 1991) their effects do not depend only on how many lianas a target tree hosts (e.g. Putz, 1984a). It will also depend on how much does lianas cover a given tree (fig.1). For example, one single liana 
may just contact one tree without applying a significant torque on it, but a similar liana can be very entangled on a similar tree, applying a stronger torque that may make the tree to collapse. Accordingly, we visually classified each tree based on the percentage of its woody area covered by lianas into the following liana-cover categories: $(0)=$ no lianas, $(1)=1-25 \%$, $(2)=25-75 \%$, and (3) $>75 \%$ (fig. 4.1 ). This ordination is very similar to the one of Clark and Clark (1990) and Kainer et al (2006), although they used the crown area of trees as reference. In our study site, liana-cover categories averaged the following numbers of liana individuals: cat-1=1,6 $(\mathrm{SD}=0,93)$, cat-2=2,3 $(\mathrm{SD}=1,72)$, and cat-3= 5,6 $(\mathrm{SD}=3,75)$.
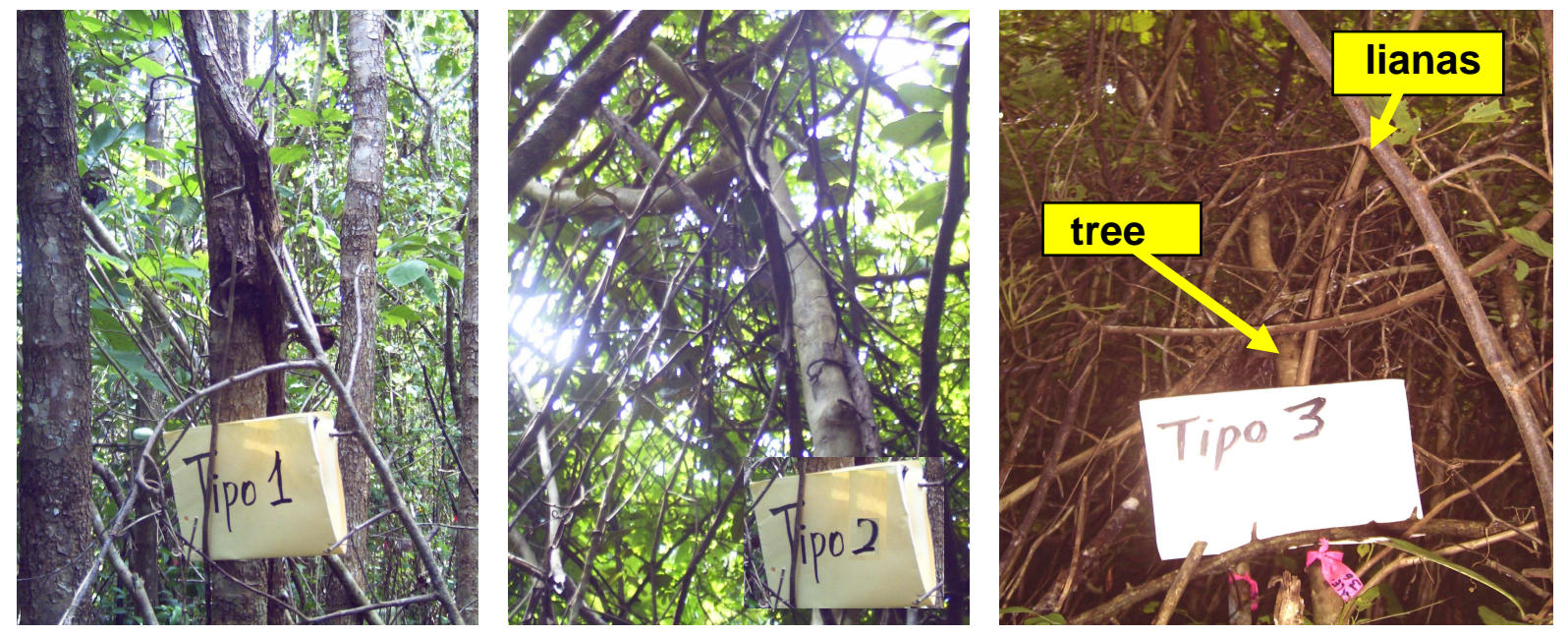

Fig.4.1. Representatives of three categories (in Spanish tipos) of liana-cover hosted on trees. Category 0 (no lianas) is not shown.

We classified our liana-species into two mechanical kinds. The first kind were the "light-and-flexible lianas", mainly the genera Cydista, Arrabidaea, Melloa (Bignoniaceae), and Serjania (Sapindaceae). Such genera have very wide vascular vessels and aerenchyma, being possible to be seen without a microscope. The second kind were the "heavy-and-rigid lianas", mainly Dalbergia glabra (Papilionoideae), and Tournefortia spp (Boraginaceae), having small vascular vessels and virtually no-aerenchyma resulting in a harder wood compared to the lianas of the first kind (see also Acevedo-Rodríguez, 2003 and fig.4.2). 

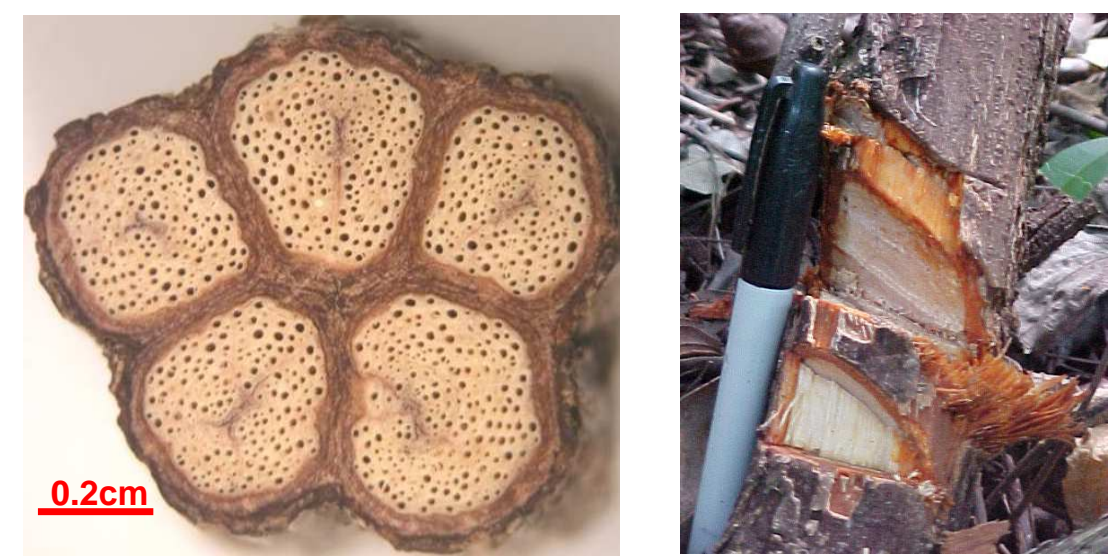

Fig.4.2. Examples of light-and-flexible lianas and heavy-and-rigid lianas. The light liana (left) is a Serjania sp. (Sapindaceae, picture by @ G.U.C. Araújo and C.G. Costa). The heavy-and-rigid liana is Dalbergia glabra (Leguminosae Papilionoideae, picture by E.I. Garrido Pérez, May 2004). See text for details.

We made such a liana classification after noticing that the mentioned mechanical kinds dominate different plots of our study site. This was one criterion for pooling our data before analyzing them, assuming that hurricane-induced damages were different according to the mechanical kind of lianas dominating each plot.

On May 22 and 232004 we cut all lianas and herbaceous vines in the plots indicated in Table 4.1. We recut the few re-sprouting lianas every 2,5 to 3 months in order to avoid them to reach trees. We did not pull any cut liana or vine down from the canopy in order to this manipulation to do not affect the experiment of Chapter 2. We re-censused trees on August 18-23, 2005 (fifteen months after cutting lianas) and death trees found during this census were not included in this study. On October 21, 2005 (seventeen months after cutting lianas), Hurricane Wilma stroke our plots. On January 16-25 2006, we revisited trees and classified them into the following, mutually exclusive structural damage types (Whigham et al, 1991): CR = Crown removed, trunk not snapped, OLB = only largest branches remaining, $\mathrm{MLB}=$ most large branches remaining, $\mathrm{t}-\mathrm{sB}=$ only twigs and small branches removed, $\mathrm{TS}=$ trunks snapped, and TU = tree uprooted. Trees not having these damage categories were classified as "non-damaged", though they had no leaves. 


\section{Data analysis}

Since liana-mechanical types depend on liana-species, we used a Cluster Analysis (WPGA, Manhattan distances) for assessing similarities of liana-species composition among plots. Based on this, plots were grouped as follows: group I: all plots in the $\geq 55 \mathrm{yr}$-old forest; group II: three plots in the 18yr-old stand (Saúl18 B, C, and D), and group III: plots Pepe10A, C, plus plot Saúl18 A. Group I was dominated by light lianas; Group II by a mixture of light lianas and heavy lianas, and Group III was dominated by heavy and rigid lianas. Because of differences in their liana kinds or other factors not included in our study, hurricane effects could be different among groups. We tested this for all damage categories with Chi-Square contingency table test. Tests were repeated excluding damage categories in a Jacknife fashion using Bonferoni corrections, until nonsignificant results appeared. Because there were differences among groups, further analyses were made within groups.

For testing the effects of the girth of trees and their numbers of hosted lianas, we ran Logistic binary regression (LBR) within each group using damaging events as the dependent variable. Logistic binary regressions were also the most straightforward way to test the effect of other factors: liana-cutting treatment, pre-hurricane liana-induced bowing, liana-cover, and pre-hurricane sloping of trees on their chances to get damages. However, the number of affected trees for such variables was too small, making results from such regressions nonreliable (de Irala et al, 1997; Domíguez and Aldana, 2001). Instead we used Chi Sqare contingency table tests like the one above described for testing each of the mentioned factors on tree damages.

\subsection{Results}

Total studied trees were 1717 that were alive immediately before the hurricane (August 2005). Table 4.1 summarizes the tree- and liana basal areas, and the tree- and lianadensities in the 12 plots based on the census made before cutting lianas. Fig. 4.3 shows how 
similar the relative abundances and species compositions of lianas were between plots based on the census of 2004. Figure 4.4 shows the number of individuals and basal areas of liana species found in each plot (used for making the dendrogram of fig.4.3). The six plots in group I ( $\geq$ 55yr-old forest) were dominated by light-bodied lianas, specially genera Arabidaea and Cydista (Bignoniaceae, fig.4.4). In contrast, the heavy-and-rigid bodied liana Dalbergia glabra (Papilionoideae) dominated in group III. Group II had an intermediate liana-species composition respect to the other two groups (fig.4.4). Note also that after excluding the five larger trees from the data of plots having higher tree basal areas, the basal area of such plots were more similar to the other ones of their groups (Table 4.1).

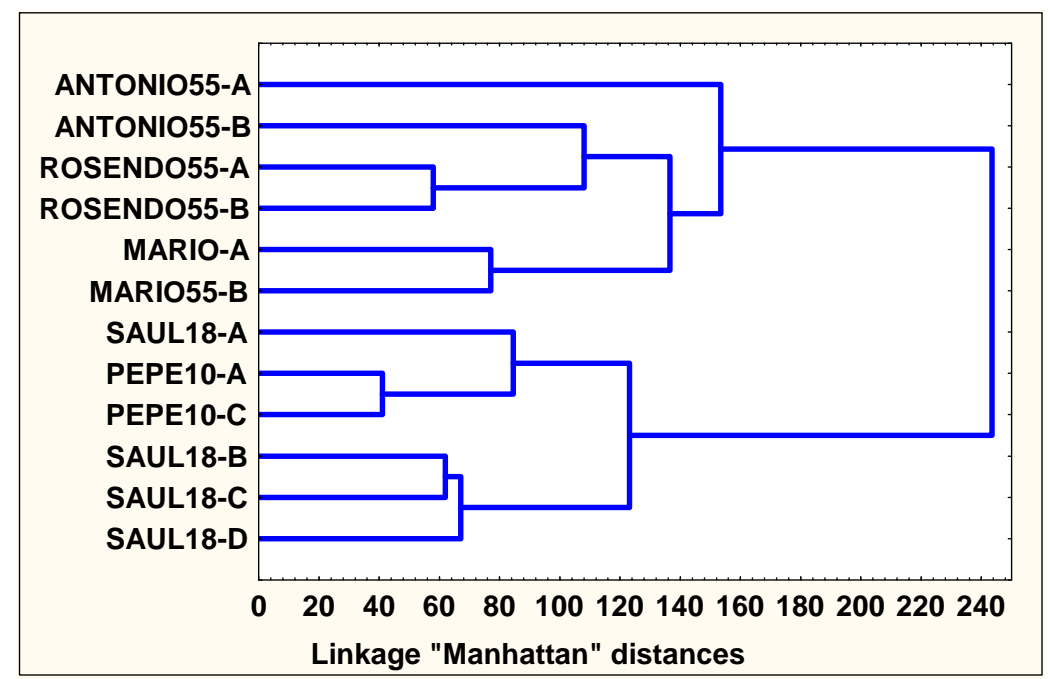

Fig.4.3. Dendrogram clustering plots according to their shared liana species and to the numbers of individuals per species after Weighted Pair-group Average (WPGA). Plots separated by smaller Manhattan distances share more species and individuals per species. See fig. 4.3 for liana species and their relative abundances. 

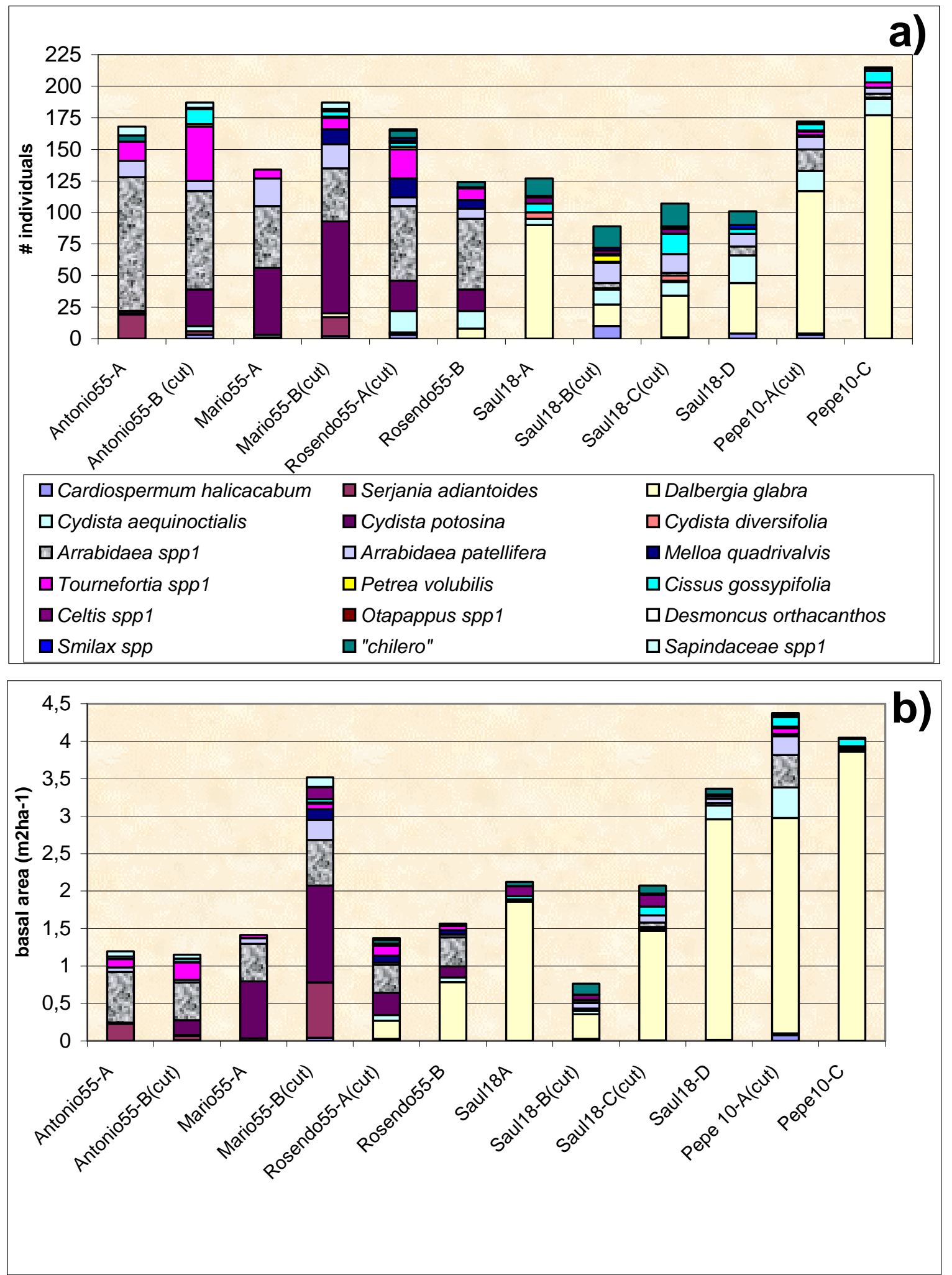

Fig.4.4. (a) Liana-number of individuals and (b) liana-basal area per plot. Notice that genera Arrabidaea and Cydista (Bignoniaceae) dominated plots in the $\geq 55 y r-o l d$ forest (group I). Meanwhile, Dalbergia glabra (Papilionoideae) dominateed in plots Pepe10 A-C and Saúl18 A (group III). Also, D.glabra dominated in plots Saúl18 B-C-D (group II), but its abundance is not as high respect to other species as in group III. According to liana-abundance per species shown in this figure, dendrograms in fig.4.3 were made. Species considered as heavy-bodied were (represented with bright colors): Tournefortia spp1, Celtis spp1, Otapappus spp1, Dalbergia glabra and Cissus gossypifolia; the other species (represented with dark colors) were considered as "lightbodied". "Chilero" is the common name of a legume non identified to date. 


\section{Table 4.1. Summarized description of twelve $400 \mathrm{~m}^{2}$ plots of Semi-Evergreen Tropical Forest.}

\begin{tabular}{|c|c|c|c|c|c|c|}
\hline $\begin{array}{l}\text { Age and Land } \\
\text { use history }\end{array}$ & Plot & $\begin{array}{l}\text { Liana-cut } \\
\text { or un-cut }\end{array}$ & $\begin{array}{l}\text { pre-hurricane } \\
\text { basal area } \\
\text { of trees }\left(\mathrm{m}^{2} \mathrm{ha}^{-1}\right)\end{array}$ & $\begin{array}{l}\text { pre-hurricane } \\
\text { density } \\
\text { of trees } \\
\text { (indiv. } \mathrm{m}^{-2} \text { ) }\end{array}$ & $\begin{array}{l}\text { pre-cut } \\
\text { basal area } \\
\text { of lianas } \\
\left(\mathrm{m}^{2} h \mathrm{~h}^{1}\right)\end{array}$ & $\begin{array}{l}\text { pre-cut } \\
\text { density } \\
\text { of lianas } \\
\text { (indiv. } \mathrm{m}^{-2} \text { ) }\end{array}$ \\
\hline $\begin{array}{l}\text { Group I: } \\
\geq 55 \mathrm{yr} \text {, selective }\end{array}$ & Antonio55 A & un-cut & $\begin{array}{l}37,86(21,55) \\
27,27\end{array}$ & $\begin{array}{l}0,42 \\
0,38\end{array}$ & $\begin{array}{l}1,41 \\
1,16\end{array}$ & $\begin{array}{l}0,45 \\
046\end{array}$ \\
\hline & $\begin{array}{l}\text { Mario55 A } \\
\text { Mario55 B }\end{array}$ & $\begin{array}{l}\text { un-cut } \\
\text { cut }\end{array}$ & $\begin{array}{l}16,30 \\
28,23(16,75)\end{array}$ & $\begin{array}{l}0,32 \\
0,32\end{array}$ & $\begin{array}{l}1,43 \\
3,65\end{array}$ & $\begin{array}{l}0,23 \\
0,46\end{array}$ \\
\hline & $\begin{array}{l}\text { Rosendo55 A } \\
\text { Rosendo55 B }\end{array}$ & $\begin{array}{l}\text { cut } \\
\text { un-cut }\end{array}$ & $\begin{array}{l}19,17 \\
25,11(17,20)\end{array}$ & $\begin{array}{l}0,39 \\
0,28\end{array}$ & $\begin{array}{l}1,37 \\
1,65\end{array}$ & $\begin{array}{l}0,42 \\
0,35\end{array}$ \\
\hline $\begin{array}{l}\text { Group II: } \\
18 \text { yr, slash-and- } \\
\text { burn agriculture } \\
\text { (milpa) per } 1 \mathrm{yr} \\
\text { without fertilizer }\end{array}$ & $\begin{array}{l}\text { Saúl18 B } \\
\text { Saúl18 C } \\
\text { Saúl18 D }\end{array}$ & $\begin{array}{l}\text { cut } \\
\text { cut } \\
\text { un-cut }\end{array}$ & $\begin{array}{l}16,53 \\
12,88\{\mathbf{1 5 , 1 6}\} \\
24,32(22,07)\end{array}$ & $\begin{array}{l}0,46 \\
0,28 \\
0,43\end{array}$ & $\begin{array}{l}0,77 \\
2,12 \\
3,40\end{array}$ & $\begin{array}{c}0,20 \\
0,21 \\
0,25\end{array}$ \\
\hline
\end{tabular}

Group III:
10 yr, cattle

$\begin{array}{lllllll}\text { range per 20yr, } & \text { Pepe10 A } & \text { cut } & 11,10 & 0,28 & 4,06 & 0,37 \\ \text { milpa with } & \text { Pepe10 C } & \text { un-cut } & 11,32 & 0,36 & 3,92 & 0,49 \\ \text { fertilizer per } & \text { Saúl18 A } & \text { un-cut } & 15,21 & 0,49 & 2,12 & 0,32 \\ \text { 4yr (except } & & & & & \end{array}$

$4 \mathrm{yr}$ (except

Saúl18 A)

Notes: Forest ages were estimated respect to 2003. Lianas were cut in May 22-23, 2004. Only live trees in the census of August 18-20, 2005 are included. Liana-basal area comprises all lianas rooted in each plot, excluding the ones rooting in each plot but climbing upon trees outside it. Lianas outside plots but climbing upon trees inside plots are included for basal area estimations. Plots in the $\geq 55 \mathrm{yr}-\mathrm{old}$ forest were settled in pairs indicated by the same name (e g Antonio), and were collapsed into group I. Distance between such paired plots ranged from 5 to 20m. Plots in the 18- and 10yr-old (Saúl and Pepe) were grouped according to their similar liana-species compositions (fig.4.3, relative abundances of liana species are shown in fig.4.4). Plots are named according to the land owners: Antonio Lara, Mario Ucan, Rosendo Can, Saúl Ancona and José "Pepe" Quintal. Digits in brackets besides tree basal areas indicate basal areas

excluding the five biggest trees of their respective plots. Highlighted tree basal area digits $\{\mathbf{1 5 , 1 6}\}$ indicate tree basal area before the accidental cut of some trees in plot Saúl18 C by some farmers. Land Use History was re-constructed by formal and non-formal interviews with land owners and elder inhabitants of the study site, aerial pictures from 1979,1985 , 2001, satellite images from 2005 and historical information about Quintana Roo State and Solferino Village (Reed, 1971; Careaga, 1994; Kiernan, 2000). 
The chances of suffering no-damage in group I were larger than in group II and in this group again larger than in group III. Group I also had hgher risks of getting almost all damage types except crown removal, wich was higher in group III (fig.4.5, Contingency Table $\chi^{2}=$ 436.734, df $=12, \mathrm{P}<0.001$ ). Differences were significant due to (a) more undamaged trees in group I > group II > group III (when excluding these trees, Contingency Table $\chi^{2}=$ 183.196, df $=10, \mathrm{P}<0.001<$ Bonferoni's corrected $\mathrm{P}=0.025)$, (b) more CR in group III respect to the other groups (when adding such trees to the exclusion: $\chi^{2}=34,163, \mathrm{df}=8, \mathrm{P}<$ 0,001 < Bonferoni's corrected P = 0,0167), (c) more TS trees in group I than in the other groups (when adding TS trees to the exclusion: $\chi^{2}=33,755$, $\mathrm{df}=6, \mathrm{P}<0,001<$ Bonferoni's corrected $\mathrm{P}=0,0125$, see small graph in fig.4.5), and (d) more t-sB in group I respect to the other groups (when such trees are added to the exclusion: $\chi^{2}=24,803$, $\mathrm{df}=4, \mathrm{P}<0,001<$ Bonferoni's corrected $\mathrm{P}=0,01$; small graph in fig.4; see Appendix IV for contingency tables for this and all other $\chi^{2}$ tests). Risks of CR were for group III > group II $\approx$ group I (fig.4.5). Risks of TS and t-sB as well were for group I > group II $\approx$ group III (fig.4.5). 


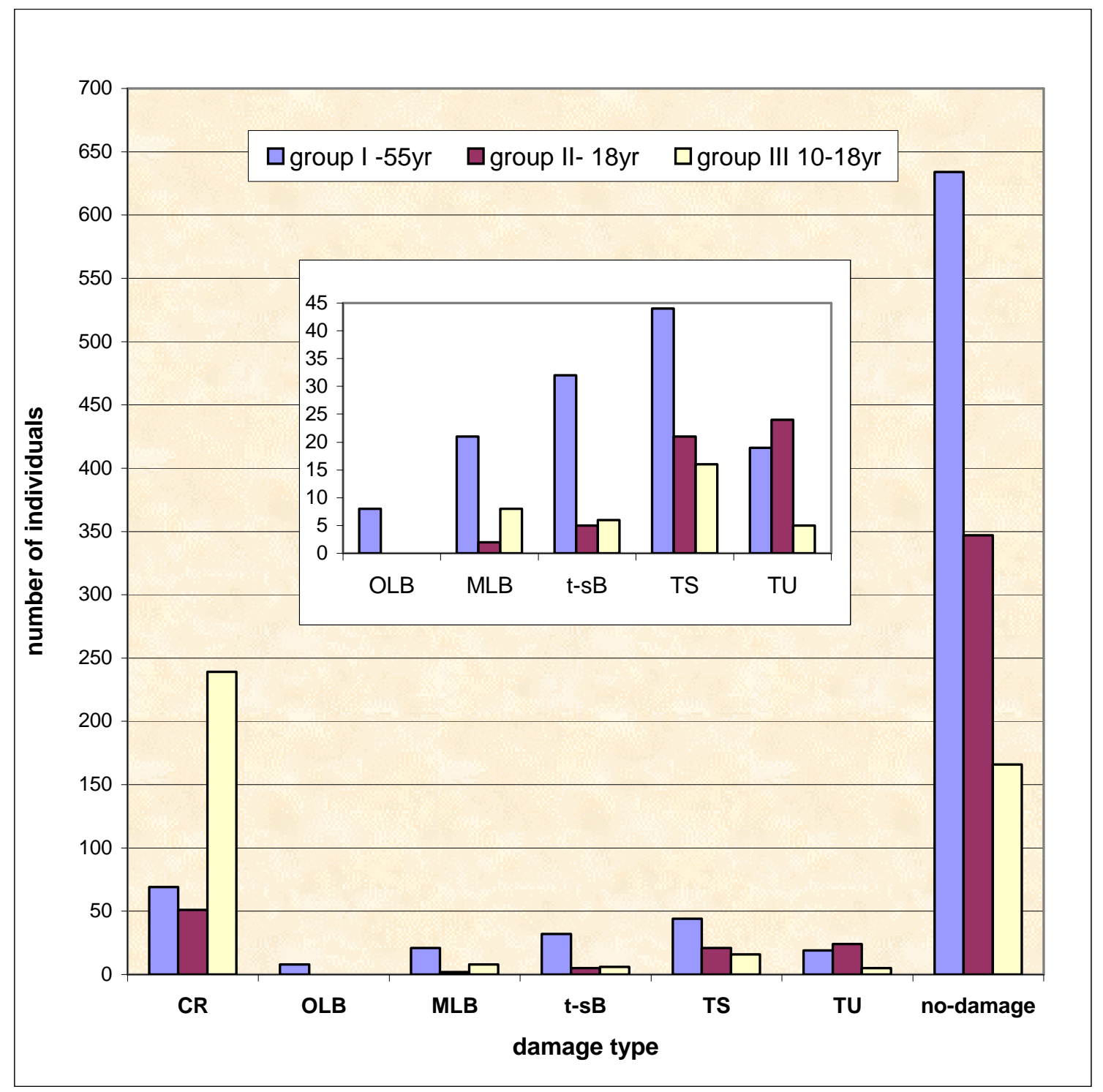

Fig.4.5. Number of hurricane damaged trees according to their structural damage types for three different forest stands (groups of plots I, II and III). Damage types are: CR= Crown removed, trunk not snapped, OLB= Only largest branches remaining, MLB= Most large branches remaining, $\mathrm{t}-\mathrm{sB}=$ Only twigs and small branches removed, $\mathrm{TS}=$

Trunk snapped, and TU= Tree uprooted (Whigham et al, 1991). Results are statistically significant because of non-damaged, $\mathrm{CR}, \mathrm{TS}$, and $\mathrm{t}-\mathrm{sB}$ trees (see text for $\chi^{2}$ and $\mathrm{P}$-values).

\section{Damages according to girth of trees and their numbers of hosted lianas}

According to our logistic regressions, neither the girths of trees nor their numbers of hosted lianas affected the chances of trees to suffer trunk snapping or uprooting in groups I and III (both are the most severe damages caused by the hurricane, Table 4.2).

Crown removal was the third most severe damage. Such a damage occurred more often the bigger the trees were in group I ( $\geq$ 55yr-old forest, regression coefficient $=0,02$, 
odds $=1,02, \mathrm{P}=0,000001$, Table 4.2a). However, odd values slightly larger than 1 suggest the chances of crown removal were low for such trees.

Trees in group II shared similar girths, making Logistic Regression for testing girth effects non-applicable there. In the same group, the higher the number of hosted lianas, the higher the risks of threes to suffer crown removal during the hurricane, though such trend was marginally significant (regression coefficient $=0,16$, odds $=1,17, \mathrm{P}=0,05$, Table 4.2b). Also in group II, chances of trees to loose only their small branches was lower for trees hosting more lianas (regression coefficient $=-1,13$; odds $=0,32 ; \mathrm{P}=0,02$; Table $4.2 \mathrm{~b}$ ).

Tree girth was not related to damages of trees in group III. In contrast, in such a group higher numbers of hosted lianas were a protection factor against crown removal respect to other trees in the same stand (regression coefficient $=-0,01$; odds $=0,99 ; \mathrm{P}<0,000001$; Table 4.2c), but odds value close to 1 suggest this effect was low. 
Table 4.2. Results from Logistic Regressions indicating the chances of trees to sufer any of six types of damage during Hurricane Wilma, according to their girths and numbers of hosted lianas.

a) Group I ( $\geq 55$ yr-old forest; $\mathrm{N}=827$ trees)

\begin{tabular}{|c|c|c|c|c|c|c|c|c|}
\hline & & \multicolumn{2}{|l|}{ Girth } & \multicolumn{2}{|c|}{ Number of lianas } & \multirow[b]{2}{*}{$\begin{array}{l}\text { odds } \\
\text { rate }\end{array}$} & \multirow[b]{2}{*}{$\chi^{2}$} & \multirow[b]{2}{*}{$\mathrm{P}$} \\
\hline \multicolumn{2}{|c|}{ Damage $\beta$} & $\begin{array}{l}\text { regression } \\
\text { coefficient }\end{array}$ & odds & $\begin{array}{l}\text { regression } \\
\text { coefficient }\end{array}$ & odds & & & \\
\hline$\overline{\mathrm{CR}}$ & -3.13 & 0.02 & 1.02 & 0.01 & 1.01 & 8.57 & 31.79 & $0.000001 *$ \\
\hline OLB & -5.31 & 0.02 & 1.02 & 0.01 & 1.01 & ---- & 5.43 & 0.07 \\
\hline MLB & -4.16 & 0.02 & 1.02 & -0.15 & 0.85 & 40.25 & 11.15 & $0.004 *$ \\
\hline t-sB & -3.89 & 0.02 & 1.02 & -0.004 & 1.00 & 13.23 & 15.16 & $0.0005^{*}$ \\
\hline $\mathrm{TS}$ & -2.74 & -0.005 & 0.06 & -0.01 & 1.00 & ---- & 0.51 & 0.77 \\
\hline TU & -3.92 & 0.01 & 1.01 & -0.008 & 1.00 & ---- & 0.53 & 0.77 \\
\hline
\end{tabular}

b) Group II (18yr-old forest, plots Saúl18 B, C and D; N=450 trees, effect of girths not possible to be analyzed due to similarity of girths)

\begin{tabular}{llllll}
\multicolumn{7}{c}{ Number of lianas } \\
\cline { 3 - 4 } \multicolumn{1}{c}{ Damage $\beta$} & $\begin{array}{l}\text { regression } \\
\text { coefficient }\end{array}$ & odds & & \\
& & & & \\
& & & & \\
\hline CR & $-2,36$ & 0,16 & 1,17 & 3,82 & 0,05 \\
OLB & ---- & --- & ---- & --- & --- \\
MLB & $-6,11$ & 0,30 & 1,35 & 0,83 & 0,36 \\
t-sB & $-3,50$ & $-1,13$ & 0,32 & 5,31 & $0,02^{\S}$ \\
TS & $-2,78$ & $-0,15$ & 0,86 & 1,14 & 0,28 \\
TU & $-2,87$ & $-0,001$ & 1,00 & 0,0001 & 0,99
\end{tabular}

c) Group III (10yr-and 18yr-old forests; plots Pepe10A-C and Saúl18-A; N = 440 trees)

\begin{tabular}{|c|c|c|c|c|c|c|c|c|}
\hline & & \multicolumn{2}{|l|}{ Grith } & \multicolumn{3}{|c|}{ Number of lianas } & \multirow[b]{2}{*}{$\chi^{2}$} & \multirow[b]{2}{*}{$\mathrm{P}$} \\
\hline \multicolumn{2}{|c|}{ Damage $\beta$} & $\begin{array}{l}\text { regression } \\
\text { coefficient }\end{array}$ & odds & $\begin{array}{l}\text { regression } \\
\text { coefficient }\end{array}$ & odds & $\begin{array}{l}\text { odds } \\
\text { rate }\end{array}$ & & \\
\hline$\overline{\mathrm{CR}}$ & $-0,52$ & $-0,01$ & 0,99 & 0,47 & 1,60 & 3,24 & 44,36 & $0,000000^{\$}$ \\
\hline OLB & ---- & ---- & ---- & --- & ---- & ---- & ---- & ---- \\
\hline MLB & $-3,84$ & $-0,005$ & 0,99 & 0,01 & 0,99 & ---- & 0,09 & 0,96 \\
\hline $\mathrm{t}-\mathrm{sB}$ & $-4,21$ & $-0,02$ & 0,98 &, 15 & 1,16 & ---- & 0,45 & 0,80 \\
\hline TS & $-3,21$ & $-0,04$ & 0,96 & ,31 & 1,67 & ---- & 4,33 & 0,11 \\
\hline TU & $-2,25$ & $-0,13$ & 0,87 & 0,03 & 0,97 & ---- & 3,46 & 0,18 \\
\hline
\end{tabular}

* = significant results due only to the girths of trees.

$\S=$ significant results due only to the number of lianas per tree. Damage types are: $\mathrm{CR}=\mathrm{Crown}$ removed, trunk not snapped, $\mathrm{OLB}=$ Only largest branches remaining, $\mathrm{MLB}=$ Most large branches remaining, $\mathrm{t}-\mathrm{sB}=\mathrm{Only}$ twigs and small branches removed, TS $=$ Trunks snapped, and TU $=$ Tree uprooted (Whigham et al, 1991). 


\section{Liana-cutting and other causes of damage}

Liana-cutting did not affect the chances of trees to suffer damages in any of the groups, where the chances of suffering no damage were similar to the ones of getting any damage type (Contingency Tables $\chi^{2}$ tests, group I: $\chi^{2}=6,697, \mathrm{df}=6, \mathrm{P}>0,05$; group II: $\chi^{2}=$ $0,178, \mathrm{df}=6, \mathrm{P}>0,05$; group III: $\left.\chi^{2}=3,613, \mathrm{df}=6, \mathrm{P}>0,05\right)$. The same applied for prehurricane liana-bowing of trees (Contingency Tables $\chi^{2}$ tests, group I: $\chi^{2}=3,057, \mathrm{df}=6, \mathrm{P}>$ 0,05; group II: $\chi^{2}=0,532, \mathrm{df}=6, \mathrm{P}>0,05$; group III: $\left.\chi^{2}=3,226, \mathrm{df}=6, \mathrm{P}>0,05\right)$.

In group I, trees hosting no lianas and liana-cover category 1 had a higher probability of getting no damage compared to trees with liana-cover categories 2 and 3, and that chances of no damage were higher than the ones of getting damaged (Contingency Table $\chi^{2}$ test, $\chi^{2}=$ 39,601. $\mathrm{df}=18, \mathrm{P}<0,01$, fig.4.6). Moreover, when non-damaged trees are excluded for the analysis, no-significant differences appear, suggesting that, once the winds make damage, such damages will not depend on liana-coverage per tree in group I (Contingency Table $\chi^{2}=$ 18,889, $\mathrm{df}=15, \mathrm{P}>0,1>$ Bonferoni's corrected $\mathrm{P}=0,025$, fig.4.6). 


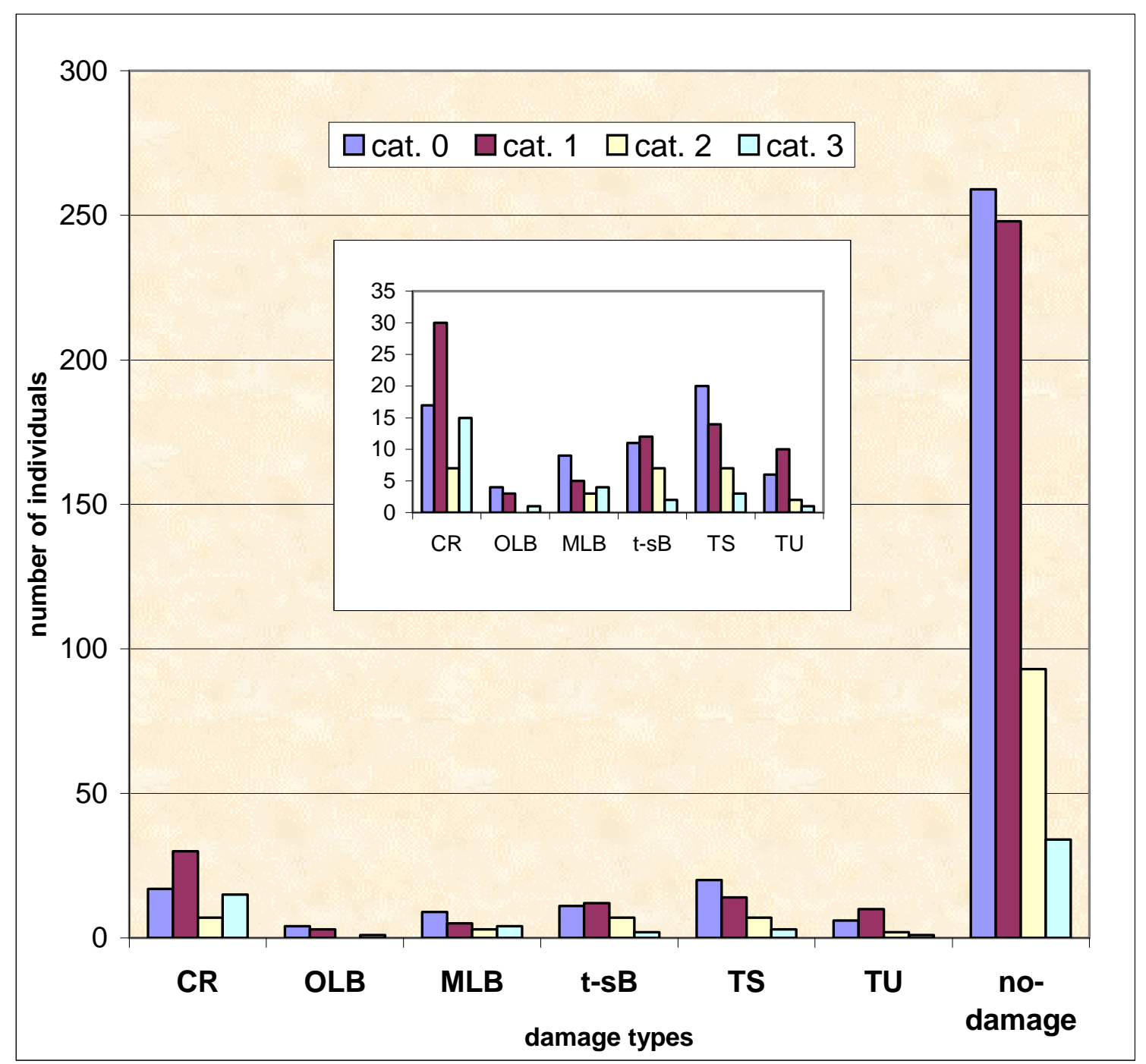

Fig.4.6. Damages of trees in the $>55 y$ r-old forest stand (group I) according to their liana-coverage categories. Significant differences only due to non-damaged trees (Contingency table $\chi^{2}$ test, $\chi^{2}=39,601, \mathrm{df}=18, \mathrm{P}<0,01$ ). Small graph shows results after excluding non-damaged trees $\left(\chi^{2}=18,889, \mathrm{df}=15, \mathrm{P}>0,1>\right.$ Bonferoni's corrected $\left.\mathrm{P}=0,025\right)$. Damage types are: $\mathrm{CR}=$ Crown removed, trunk not snapped, $\mathrm{OLB}=$ Only largest branches remaining, MLB= Most large branches remaining, $\mathrm{t}-\mathrm{sB}=$ Only twigs and small branches removed, $\mathrm{TS}=$ Trunks snapped, and $\mathrm{TU}=$ Tree uprooted (Whigham et al, 1991, see liana-cover categories in fig.4.1).

For groups II and III, chances of no damage were similar to the ones of getting damaged among liana-cover categories, suggesting that strong-wind effects are independent of liana-coverage there (group II: Contingency Table $\chi^{2}=1,987, \mathrm{df}=18, \mathrm{P}>0,05$; group III: $\chi^{2}=6,636, \mathrm{df}=18, \mathrm{P}>0,05 ;$ Appendix IV).

Refering to vertical vs sloped-trunk trees in group I, chances of getting no-damage were higher than the ones of getting damage, being vertical trees less endangered (Contingency Table $\chi^{2}=25,248, \mathrm{df}=6, \mathrm{P}<0,001$; fig.4.7). When exlcluding non-damaged 
trees in the analysis, $\chi^{2}=25.413, \mathrm{df}=5, \mathrm{P}<0,001<$ Bonferoni's corrected $\mathrm{P}=0,025$; and when CR trees were added to the exclusion $\chi^{2}=19,661$, df $=4, \mathrm{P}<0,001<$ Bonferoni's corrected $\mathrm{P}=0,0167$. It suggests that, once damages occur, $\mathrm{CR}$ risks in group I are higher for vertical trees (fig.4.7).

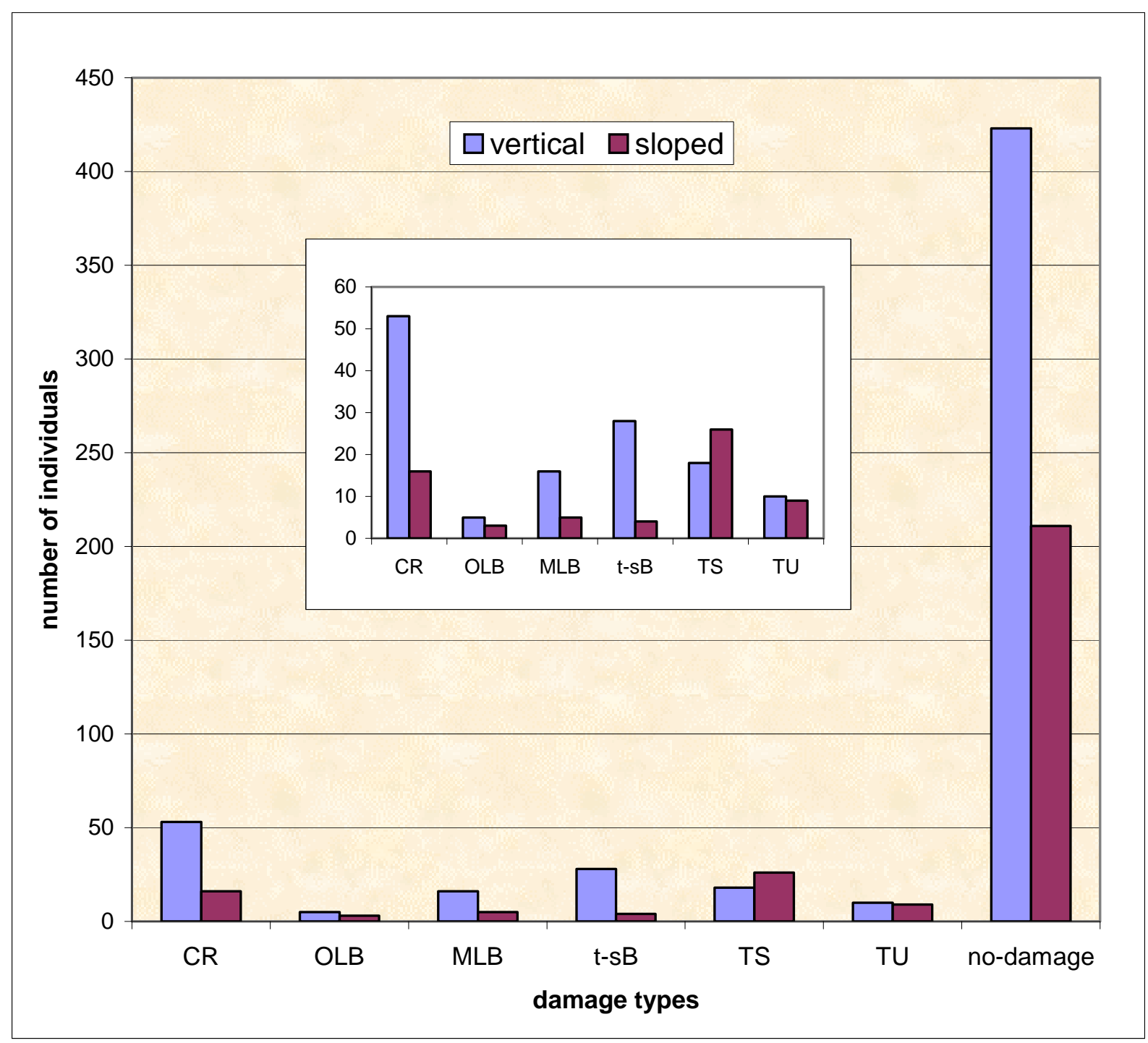

Fig.4.7. Damages of trees in the $>55 y$ r-old forest stand (group I) for trees being vertical and sloped before hurricane Wilma. Significant differences only due to non-damaged trees $\left(\chi^{2}\right.$ test, $\left.\chi^{2}=25,248 . \mathrm{df}=6, \mathrm{P}<0,01\right)$ and Crown Removal $\left(\chi^{2}\right.$ test, $\chi^{2}=25,413$. $\mathrm{df}=5, \mathrm{P}<0,01<$ Bonferoni's corrected $\left.\mathrm{P}=0,025\right)$. Small graph shows results after excluding non-damaged trees. Damage types are: $\mathrm{CR}=$ Crown removed, trunk not snapped, $\mathrm{OLB}=\mathrm{Only}$ largest branches remaining, $\mathrm{MLB}=$ Most large branches remaining, $\mathrm{t}-\mathrm{sB}=$ Only twigs and small branches removed, $\mathrm{TS}=$ Trunks snapped, and $\mathrm{TU}=\mathrm{Tree}$ uprooted (Whigham et al, 1991). 
For groups II and III, the chances of vertical and sloped trees to get damage were the same than to do not get damaged, and there were no-differences between damage-types according to verticality or sloping of trees (Contingency Tables $\chi^{2}$, for group II: $\chi^{2}=1,160$, df =6, P > 0,05; for group III: $\chi^{2}=1,043, \mathrm{df}=6, \mathrm{P}>0,05$, Appendix IV).

\subsection{Discussion}

Our results suggest that lianas do not always damage trees in our study area. For example, liana-cutting had no effect in any stand, whereas liana-coverage had effects only in our $\geq 55$-yr old stand. Fig. 4.5 indicates that more trunks snapped in the $\geq 55$-yr old stand than in the other stands during the hurricane. Since results from liana cutting, liana-coverage and other factors disentangle the role played by lianas and other causes of such pattern, we start discussing the effects of lianas within stand, followed by the effects of lianas between stands. After that, we discuss the effects of tree size and other causes of tree damage and, finally, a possible role of lianas in forests located in hurricane zones.

\section{Structural damages within forest stands: when the lianas play no-role}

Liana cutting had no effect on the chances of damage within any of our forest stands, suggesting that lianas neither pulled down nor stabilized trees in the canopy (as expected by Putz, 1984a). Also, the risk of wind throw for trees bowed by lianas was not higher than for unbowed trees. Furthermore, hurricane Wilna produced damage independently of lianacoverage for the plot groups II and III. Suggesting that the effect of the hurricane within these stands was independent of lianas. Supporting this, trunk snapping and tree uprooting (the two most severe damage types) were not affected by the number of hosted lianas (and the girth of trees) within any of our stands. That implies that lianas played no-role in tree-fall gap forming (but see Schnitzer and Bongers, 2002). The number of lianas also did not affect Crown Removal (the third most severe damage type) in groups I and II (Table 4.2). 


\section{Where are lianas harmful, where they protect trees and how}

In contrast, in our $\geq 55$ yr old stand (group I, fig.4.6) trees hosting smaller lianacoverages had a lower risk of damage compared to trees with larger liana-coverages. Since it occurred in spite of liana cutting, we propose that the result was due to a displacement of the gravity center of liana tangle in the canopy during the remotion of trees; it certainly was not due to a "liana-pulling-to-ground" effect. This is consistent to the first hypothesis of Putz (1984a) and also to studies where trees with high numbers and basal areas of hosted lianas were more structurally damaged (Kainer et al, 2006; see also Putz, 1991). Therefore, we were surprised because trees within group III were less broken when hosting more lianas, even if such an effect was not strong (odds $=-0,99$; Table 4.2). Because liana cutting had no effects on damage risks in the same group, lianas appeared to tie canopies together instead of displacing the gravity center of trees in group III. Therefore trees there were protected as suggested by the second hypothesis of Putz (1984a). Such a holding effect even protected sloped and liana-bowed trees, otherwise these trees would suffer more damages than vertical and non-bowed ones in group III. Because the rigid-bodied liana D.glabra dominates group III by far and is not dominating the other two stands (fig.4.4), we hypothesize that this species is responsible for the mentioned results. But it has to remain untested.

In summary, results within groups suggest that (a) only larger liana-coverages, but not necessarily higher numbers of liana individuals, harmed trees in group I, (b) larger numbers of lianas slightly reduced crown removal in group III. Also (c) the response mentioned in (a) was because lianas destabilized trees in the canopy, according to the first hypothesis of Putz (1984a) while in (b) lianas stabilized crowns in the canopy (second hypothesis of Putz, 1984). Finally, (d) positive or negative effects of lianas were not the norm: as we discussed under the preious subtitle, wind throw damage by the hurricane in most cases was independent of lianas. 
Structural damages between stands: which lianas are harmful for trees?

The previous argument implies a spatial variation in the participation of lianas in damaging, protecting or not affecting trees. For example, crown removal risks in group III were > group II $\approx$ group I (fig.4.5), whereas the abundance of heavy and rigid bodied lianas (especially $D$. glabra) respect to light and flexible ones decreases in a similar fashion (group III > group II > group I, fig.4.4). Because of this we suggest that rigid-bodied lianas like $D$. glabra enhanced crown removal in the canopy during the hurricane in group III (but, as we have seen, within group III, trees hosting more lianas individuals suffered less crown removal). Meanwhile, light bodied lianas (e.g. genera Arabidaea and Cydista) may be mainly non-harmful by producing not enough mechanical stress on trees.

D. glabra is often associated to places where fires previously occurred (E. I. GarridoPérez and J.M. Dupuy, pers. obs.). This suggests that its high abundance in groups II and III may be due to the land-use history (Table 4.1). Also, D. glabra is common in wetlands of the Yucatan Peninsula (Olmsted et al, 1999; Carnevali et al, 2003). Different spatial distributions of liana species according to these factors imply different roles of lianas depending on their local relative abundances in a landscape level. Other possibilities seem to be less plausible in our study site. For example, the whole Northern Yucatan Peninsula has a soil coverage of approximately $10 \mathrm{~cm}$ above a calcareous base (Bautista-Zúñiga et al, 2003; see also Whigham et al, 1991). Indeed, differences in tree-to-ground anchoring-forces are not the reason for differences in wind throw damages among our stands.

\section{Tree size and other risk factors}

Besides lianas, differences in tree size between stands determined the risks for damage types to occur. Larger trees were more prone to suffer crown removal in group I ( $\geq 55 \mathrm{yr}$ old forest) but not in group III. It was not possible to test this in group II because of the similar widths of trees. However, it also implies that such a result does not alter the prediction that 
larger trees may suffer more crown removal (see also Tovilla and Orihuela, 2004; Michener et al, 1997; but see Sánchez and Islebe, 1999). Also in group I, the risks of trunk snapping and removal of only twigs and small branches was higher than in groups II and III. This confirms that emergent trees, the ones whose crowns are more exposed to the wind, are more susceptible to damage (Tovilla and Orihuela, 2004; Michener et al, 1997; but see Sánchez and Islebe, 1999).

Since larger trees are more exposed to winds, it may be expected them to suffer more uprootings just as they suffered more snapping of their trunks in our $\geq 55 \mathrm{yr}$-old forest; however, uprootings occurred independently of the sizes of trees (Table 4.2). It suggests that the anchoring force of roots of both, large and small trees, was enough to the hurricane to do not pull them, as also ocurred in Hawaii (Asner and Goldstein, 1997) and Puerto Rico (Ostertag et al 2005).

According to the laws of Newton about static bodies (Bueche, 1988), sloped trees should be more susceptible to get damaged than vertical ones because of the position of their gravity center. Consistent with this, our sloped trees in group I had fewer undamaged individuals (fig.4.7). However, crown removal risk was higher for vertical trees (fig.4.7), suggesting that the higher position in the canopy exposed their crowns more directly to the wind. In contrast, chances of damage were similar for vertical and sloped trees in groups II and III. It can imply a protection effect of abundant rigid lianas, but alternatively may be due to similar canopy heights between sloped and vertical trees, since the canopy is more irregular in the $\geq 55$ yr-old stand compared to the younger ones (E.Garrido-Pérez, pers. obs).

As our results indicate, other studies suggest that trunk snapping, uprooting and crown removal are usually the most common damages caused by hurricanes (Sánchez and Islebe, 1999; Pavelka and Behie, 2005; Ostertag et al, 2005). This produces gaps in tropical forests and we now discuss the relationship between lianas and such gaps formed by hurricanes. 
Hurricanes, gap dynamics and the role of lianas in forest dynamics

Lianas rapidly colonize spaces with intense incident light and concomitant high evaporation of soil water. This occurs in gaps, forest edges and other disturbed areas (De Walt et al, 2000; Laurance et al, 2001; Schnitzer, 2005). Indeed, the opening of large extensions of the canopy by hurricanes offers wide areas for colonization by lianas. Lianas also colonize gaps produced when hurricanes snap or uproot single trees (Schnitzer et al, 2000) and such gaps last longer than the ones produced by other types of damage like crown removal (Whigham et al, 1991, but see Asner and Goldstein, 1997; and Van Bloem et al, 2005). Compared to trees, the high ability of lianas to colonize tree-fall gaps may also allow them to colonize ephemeral gaps as the ones produced by crown removal. Furthermore, it has been suggested that large scale disturbances resulting from hurricanes produce so many gaps in so wide areas, that the banks of propagules of trees cannot fill all of them (Vandermeer et al, 2000; see also Lomáscolo and Aide, 2001). All these factors enhance the chances of lianas to increase their abundance in hurricane zones (see Schnitzer et al, 2000). Where larger lianacoverages enhance gap-forming by hurricanes as in our $\geq 55 \mathrm{yr}$ old stand, they enhance the chances of other lianas to proliferate by colonizing such gaps in a feedback fashion (Schnitzer and Bongers, 2002; see also Schnitzer et al, 2000). Thus, hurricanes enhance liana abundance by many ways.

Moreover, when one tree is broken by a hurricane but survives after it, further hurricanes are able to break it again (e g Ostertag et al, 2005). This effect may result in the formation of more gaps when the previous ones are still not fully regenerated. This accumulation of gaps may result in a larger abundance of lianas through time (Phillips et al, 2002; Wright et al, 2004). For instance, at least 5\% of the gaps formed annually in a forest outside hurricane zones (Barro Colorado Island, Panama) become dominated by lianas and such lianas delay the resprouting of slow growing tree species (Schnitzer et al, 2000). This accumulation must be faster in hurricane zones, given their higher frequency of gap 
formation, so liana- and pioneer tree dominated gaps accumulate with time (Schnitzer et al, 2000). This may be occurring in the Mexican Caribbean (Quintana Roo State, where our study site is located), which has been impacted by more than 30 major hurricanes in the last 100 years (Sánchez and Islebe, 1999) contributing to the proliferation of lianas there and to the forest to do not reach successional maturity (Whigham et al, 1991).

It has been suggested that, given the increase of liana abundance (Phillips et al, 2002; Wright et al, 2004), their participation in forest processes like damaging trees may increase when cyclones occur. There is a paucity of surveys of liana-abundance on Hurricane zones and many liana-surveys use different minimum studied liana-sizes respect to each other, making comparisons non-viable (Gerwing et al, 2006). Nevertheless, higher liana-abundances in disturbed and secondary growth areas respect to non-disturbed ones is very well documented (Babweteera et al, 2000; De Walt et al, 2000; Schnitzer et al, 2000; Caballé and Martin, 2001; Laurance et al, 2001, Pérez-Salicrup et al, 2001b). Our results suggest that, at least in patches like our 10- and 18 yr old forest stands, structurally negative effects of lianas do not occur, suggesting that lianas should not be cut there during forest management to protect the structure of trees. 


\section{Chapter 5}

\section{GENERAL DISCUSSION AND GENERAL CONCLUSIONS}

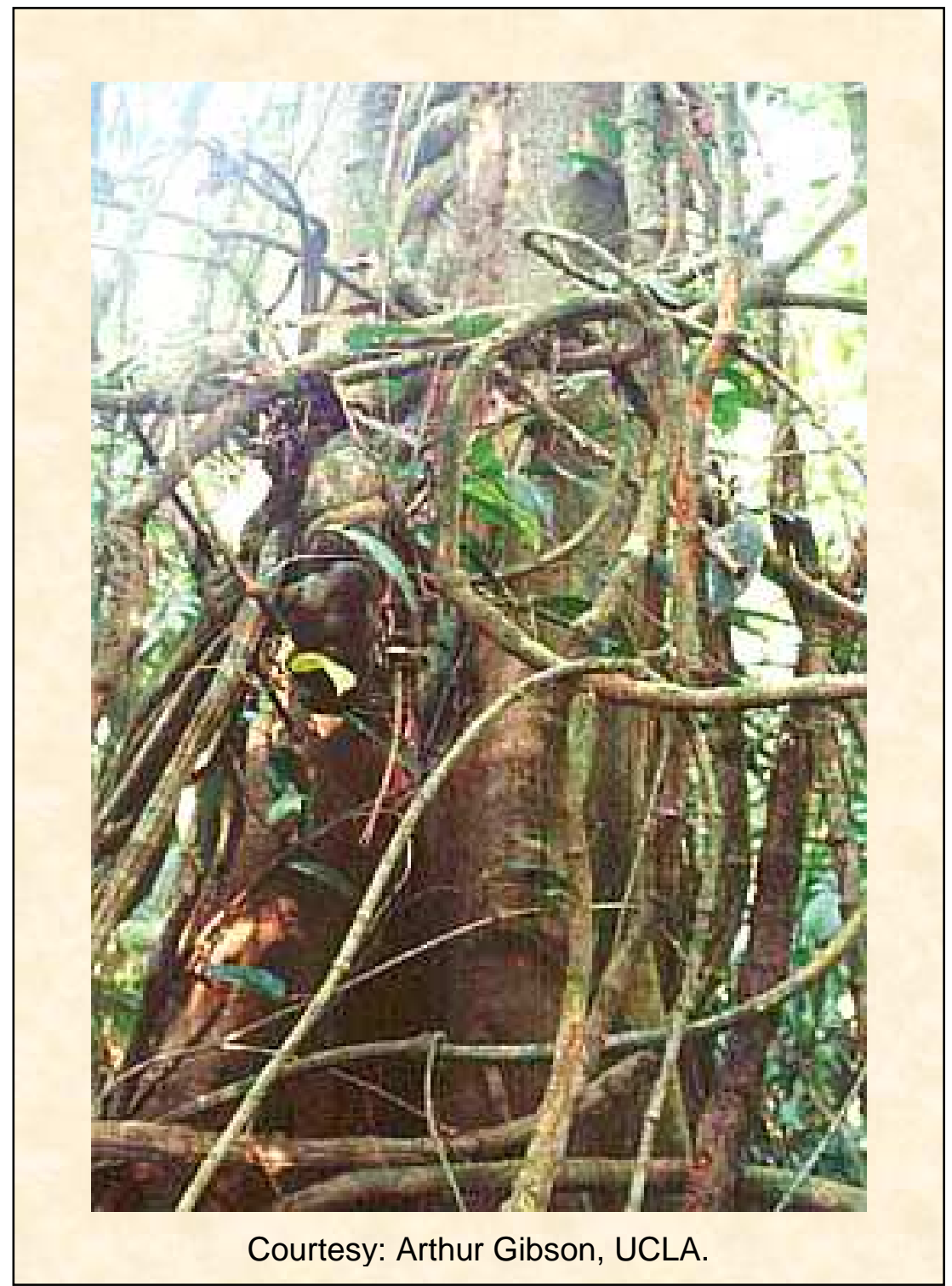

This figure shows a liana-tangle, mainly from the genera Cydista, and Arrabidaea (Bignoniaceae) around a Ceiba pentandra tree. Even hosting liana tangles like the one of this figure, trees do not necessarily reduced their growths in this research: there were cases where lianas seem to be harmul but also others where they seemed to do not disturb tree-growth and to stabilize them during strong winds. Indeed, the paradigm of the differential effects of lianas on trees remains after this research, but whith one modification: this differential effects may be not allways negative and may also change spatially. This and other implications of this dissertation are exposed in this fifth (and last) chapter. 


\subsection{Neither do Lianas generally delay the growth of trees nor do Lianas generally enhance hurricane damage}

I exposed in Chapter 1 a paradigm saying that the effect of lianas on trees may vary between species and sites (Pérez-Salicrup, 2001; Schnitzer and Bongers, 2002). The results from Chapters 2, and 3 underline and confirm such idea; the difference to many previous studies is that Chapters 2 and 3 demonstrated that lianas do not always reduce the growth of trees. Furthermore, lianas did not always enhanced structural damages of trees during strong wind (Chapter 4) but it changed among forests belonging to the same landscape. Both, growth and structural damages of trees by lianas depended on how target trees were covered by lianas in some areas. Also the identity and abundance of liana species was apparently important, but it could not be tested sufficiently by this research. The presence of living lianas reduced the growth of some saplings and may have enhanced it for others. However, further researches are needed to test if factors like incident light, and not lianas, are responsible. Even for saplings, the growth changed spatially and lianas seemed to play a causal role on this.

\subsection{Studies on liana-tree interactions require larger spatio-temporal scales}

As explained in Chapters 2 and 3, fifteen months was not enough to capture the effect of growing differences for trees and saplings, although it included two growing seasons. Other studies lasted one year (Pérez-Salicrup and Barker, 2000), 18 months (Pérez-Salicrup, 2001); two years (Putz, 1984a; Gerwing, 2001; Grauel and Putz, 2004; Schnitzer et al, 2005; Kainer et al, 2006), and three years (Whigham, 1984; Vidal et al, 2002). Only one study was backed by data of 10 years of growth (Putz, 1984a for Luehea seemanii). Also Clark and Clark (1990) analyzed long-term growth of trees according to their liana-loads during a non-specified number of years. Moreover, mostly of tree species had too few individuals per plot in this study and in many previous studies as well. Nevertheless, results of this dissertation provide hints to reconsider the idea that lianas only have negative effects on trees (e g Ewel and 
Hiremath, 2005; Clark and Clark, 1990). Since liana-effects changed spatially, the results also start to challenge the idea that lianas are a driving force driving long-term tree species turnover of trees, at least within within the guild of the Pioneers (the only guild of trees studied here).

\subsection{Lianas affect succession in North-Eastern Yucatan Peninsula}

None of my tree species was represented by sufficient individuals to evaluate the effects of lianas in combination with strong winds on them. However, gaps in the forest created by strong winds in NE Yucatan Peninsula are mainly colonized by pioneer trees and lianas (Schnitzer et al, 2000; see also Vandermeer et al, 2000 and Lomáscolo and Aide, 2001). Indeed, in hurricane zones lianas contribute to the forest to do not become successionaly mature (see also Whigham et al, 1991), unfavoring shade-tolerants in the long-term. Notice that the proposed mechanism implies that lianas enhance the proliferation of pioneers respect to shade-tolerants, but does not imply a role of lianas for the species turnover within these functional groups (guilds of trees see also Hubbell, 2001).

\subsection{Do lianas influence tree species turnover within functional groups or guilds of trees?}

Because mostly of the forests of the Yucatan Peninsula are secondary forests including mine (see for example Sánchez-Sánchez and Islebe, 2002), they are composed by far by pioneer species. It makes relevant to discuss the role of lianas on species turn-over within the guild of the pioneers. It remains poorly studied if, in the absence of hurricanes, liana-induced stress reduces the fitness and population sizes of trees (Lex et al, 1998). Nevertheless, it has been suggested that lianas contribute to change the relative abundance of tree species throughout time because some species are more affected than others (Pérez-Salicrup, 2001; Schnitzer and Bongers, 2002). This hypothesis is based on the effects of lianas on the growth of many tree species (Putz, 1984a; Dillenburg et al, 1993a-b; Pérez-Salicrup and Barker, 
2000; Gerwing, 2001; Vidal et al, 2002; Pérez-Salicrup, 2001; Grauel and Putz, 2004;

Schnitzer et al, 2005, Clark and Clark,1990; see also Chapters 2 and 3 of this Dissertation) and on the fruiting of others (Stevens, 1987; Wright et al, 2005; Kainer et al, 2006). Few species have compared co-existing tree species; Wright et al (2005) compared the fruiting of trees finding a differential effect of lianas on tree-species; and this dissertation compared the growth of trees, finding also a differential effect of lianas. However, only this dissertation reports differences of liana-effects among stands of the same landscape.

I found disparate results for many tree species which tended to be negatively affected in one stand and positively in another, and something similar applied for some sapling species. This suggests that, at a landscape level, local conditions in very near stands are so different that it is impossible for lianas to always have the same effects on identical tree species within guilds. In other words, negatively affected individuals on one area may be compensated by positively affected ones of the same region, and it may also apply for patches within single forests. Consequently, I suggest that it is highly unlikely that lianas drive species turnover within guilds of trees by "pushing" any tree-species to local extinction.

In my study site, the role of lianas as one factor altering tree-species composition within guilds may be linked to ecological drift (Hubbell, 2001). Moreover, to lianas consistently change the growth and reproduction of tree species of the same guild requires that many individuals of target tree populations must be consistently exposed to circumstances of direct lianas affections (e.g. large tangles of harmful liana species). Many studies demonstrate that lianas do not associate to trees in a species-specific way (PérezSalicrup et al, 2001b; Pérez-Salicrup and de Meijere, 2005; Malizia and Grau, 2006). It is because of three reasons: (a) the large body of lianas make single individuals to host on different tree individuals, (b) such tree individuals usually belong to different species because of the extremely high local diversity of trees in tropical forests; and (c) lianas themselves are locally very diverse, thoug such diversity is lower than the one of trees (Gentry, 1991). 
Indeed, the probability for liana-tree species-specific engagements to occur across large areas during many generations are tended towards null. I propose that the lack of such engagements hinders that lianas are major drivers for tree-species turnover within functional groups of trees: lianas are hardly able to "push" any given species to local extinction.

\subsection{Do lianas drive tree species turn-over within guilds?: an Evolutionary point of view}

Under the scope of the Evolutionary Theory, species-specific liana-tree engagements seem to have been impossible in the past. The Biogeography (Gentry, 1991), and different local Floras of lianas (Gentry, 1991, Apanah et al, 1993; Parren and Bongers, 2001; PérezSalicrup et al, 2001b; De Walt et al, 2000; Burnham, 2002; Hora and Soares, 2002) indicate many lianas belong to recently evolved families compared to the much older origin of trees and shrubs (Futuyma, 1998; Bateman et al, 1998; Stewart and Rothwell, 1993; but notice relatively old families like the Leguminosae in Gentry, 1991). By the time lianas radiated and spread over the land, they already met a high diversity of hosting trees and microhabitats associated to those trees. I propose that such an unpredictable environment could not favor the rise of species-specific engagements leading to liana-induced, consistent changes on tree relative abundance within tree guilds. The evolution of the climbing habit seems to be another chapter of the conquest of land and air by vascular plants and not the cause of liana-induced shifts of tree species composition. Trees just became new habitats to be occupied and woody plants radiated evolving ito lianas while occupying these new habitats.

In summary, this dissertation: (a) confirmed negative effects of lianas on co-existing trees, (b) discovered cases where lianas were associated to a faster growth of some trees (though not necessarily causing it), (c) confirmed that effects of lianas on trees depend on target tree species, but (d) suggest that lianas do not drive tree species turnover within functional groups of trees in the studied area. Latter is not well demonstrated, but is consistent to: (a) results among the studied stands, (b) other studies suggesting that there is no tree- 
specific engagement with lianas, and (c) the History of the conquest of land by woody plants. Ecological drift has been proposed as a mechanism for tree species turnover within functional groups in the tropics (Hubbell, 2001). Lianas seem to be related to such mechanism in the studied site. Meanwhile, more studies comparing liana-effects on co-specific trees in different stands are needed to determine to what degree lianas affect some target tree species more than others.

\subsection{To cut or not to cut lianas: where and when?}

This research and the literature herein indicate that there is no general answer to this question. Each forest manager should take the intentions of liana-cutting into account. For example, if the intention is to enhance the growth of trees in general (and not of a small number of target species), lianas in our $\geq 55 \mathrm{yr}$ old stand are to be cut, according to fig. $2.9 \mathrm{a}$, Chapter 2. Because it potentially produces biodiversity reduction of lianas and related animals (Vidal et al, 1997; Gerwing and Vidal, 2002), such negative effects of liana-cutting in our $\geq$ $55 \mathrm{yr}$ old stands would be reduced by cutting only around trees with liana-coverage categories 2 and 3 (fig.2.7a, Chapter 2). In contrast, if the intention is to enhance the growth of trees regardless their species in our 10 to18 yr old stands it would be the best not to cut lianas (fig. 2.7b, see also fig. 2.9b, both in Chapter 2). I did not test if lianas, and not high illumination, favored trees there, but at least lianas did not hinder the growth of trees in general.

If the intention is to protect target tree species of the studied $\geq 55 \mathrm{yr}$ old stands, large liana tangles should be cut around the following tree species : Pouteria campechiana, Zygia stevensonii, and Lonchocarpus rugosus, and probably Bursera simaruba, Metopium brownei and Vitex gaumeri (figs. 2.3 and 2.5, Chapter 2). In the 10- to 18 yr old stands, a similar suggestion applies to: Guettarda combsii, Spondias mombin and Luehea speciosa. But, also in the 10- to 18 yr old stand, lianas should not be cut around: Coccoloba spicata, Allophyllus cominia, L.rugosus and V.gaumeri (figs. 2.4 and 2.6, Chapter 2). Also, in order to protect 
saplings (trees for the future), at least two species should be protected in the studied $\geq 55 \mathrm{yr}$ old stands: Chrysophyllum cainito and Malmea depressa (fig.2.5a, Chapter 3). In the 10- to 18 yr old stands, saplings of Eugenia axillaris and Lonchocarpus rugosus grew better where lianas were not cut (fig.2.5b, Chapter 3). Finally, since the growth of no species seemed to be significantly hindered by lianas in all my stands, and because of the lack of species-specific liana-tree consistent engagements (Pérez-Salicrup et al, 2001b; Pérez-Salicrup and de Meijere, 2005; Malizia and Grau, 2006), I warn that there is no general rule to protect any species everywhere. It seems better to determine liana-effects experimentally on each location and take the decission afterwards; or at least confirm if there are evidences from similar life zones. Meanwhile, large scale studies lasting longer periods than the ones reported are necessary too.

Hurricanes must be considered for the protection of trees in our study site. Cutting lianas is not helpful to avoid trunk snapping and tree up-rooting -since such damages occurred independently of liana-cutting. Crown removal by hurricanes is another severe damage that potentially reduces growth. Thereby further wood production is reduced for affected trees. But lianas were not related to such damages in the $\geq 55 \mathrm{yr}$ old stand, suggesting that cutting there is not necessary. Moreover, though heavy-bodied lianas (especially Dalbergia glabra) may have caused many damages where it largely dominates (our plot group III, 10- to18 yr old forest), cutting it there is even worse. Hurricane Wilma removed more crowns of trees hosting less lianas there, although such effect was slight (results in Chapter 4). Recall that lianas (probably Dalbergia glabra) were also associated to a better growth of trees and saplings of the 10- to $18 \mathrm{yr}$ old stands; another reason to do not cut this liana species.

Other studies also provide criteria to decide whether to cut or not to cut. If the intention is to avoid lianas to reduce the fruiting of trees, cutting lianas is recommended for 100\% infested Bursera simaruba individuals and liana-hosting individuals of Bertholletia excelsa (Stevens, 1987; Kainer et al, 2006; see also Wright et al, 2005). In contrast, studies in 
tree plantations where the diversity of trees and microenvironments is much smaller than in the wild, introduced lianas may become plagues reducing the growth and profitability of timber (Whigham, 1984; Dillenburg et al, 1993b). Indeed, cutting lianas is recommended there; but such conclussions may not be extrapolated to natural forests where tree diversity is higher. Meanwhile, the role of particular species of native lianas remains poorly understood.

\subsection{General conclusions}

1. Although studying larger plots and longer duration is recommended, results suggest that lianas have species-specific effects on target trees.

2. Lianas do not always delay the growth of trees. In the younger forest stands they: enhanced the growth of trees in general and of some species, or at least its effects did not out-balanced other factors favoring them (e.g. incident light).

3. In general, mechanical damages of trees during hurricane Wilma were not reduced by liana-cutting and smaller liana-coverage. It suggests that strong-wind induced damages are not enhanced by lianas.

4. Liana-effects on trees and saplings change among contiguous forests in a single landscape and probably within patches of the same forest, even for single tree species. Since it may avoid lianas to affect tree-populations substantially, lianas may play a neutral role on structuring tree communities.

5. In the 10- to $18 \mathrm{yr}$ old stand (plot group III), rigid bodied lianas (especially Dalbergia glabra) may have contributed to avoid crown removal during Hurricane Wilma. Simultaneously, in the same stands trees grew better when D.glabra was not cut and when having larger liana-coverage. Therefore studying the role of this liana species is recommended. 


\section{REFERENCES}

Acevedo-Rodríguez, P., 2003. Bejucos y plantas trepadoras de Puerto Rico e Islas Vírgenes. Sheridan Press, Hannover, Pennsiylvania.

Andrade, J.L., Meinzer, R., Goldstein, G., and Schnitzer, S.A., 2005. Water uptake and transport in lianas of a seasonally dry tropical forest. Trees: Structure and Function. 19, 282-289.

Apanah, S., Gentry, A.H., and LaFrankie, J.V., 1993. Liana diversity and species richness of Malaysian Rain Forests. Jor. Trop. For. Sci. 6 (2): 116-123.

Apanah, S., Putz, F.E., 1984. Climber abundance in virgin dipterocarp forest and the effect of pre-felling climber cutting on logging damage. Mal. Fores. 47 (4), 335-342.

Asner, G.P., Goldstein, G., 1997. Correlating stem biomechanichal properties of Hawaiian canopy trees with hurricane wind damage. BIOTROPICA 29(2), 145-150.

Avalos, G., and Mulkey, S.S. 1999. Seasonal changes in liana cover in the upper canopy of a Neotropical Dry Forest. BIOTROPICA 31(1), 186-192.

Babweteera, F., Plumptre, A., and Obua, J., 2000. Effect of gap size and age on climber abundance and diversity in Budongo Forest Reserve, Uganda. Afr. Jor. Ecol. 38, 230-237.

Balam-Ku, M.; Bañuelos, I.; García E.; González-Iturbe, J.A.; Herrera, F.; Orellana, R. and Vidal, J., 1999. Clima. In: García, A. and Córdoba, J. (eds.), Atlas de procesos territoriales de Yucatán. Universidad Autónoma de Yucatán, Fac. Arquitectura. Mérida, Yucatán, México.

Balfour, D.A., and Bond, W.J., 1993. Factors limiting climber distribution and abundance in a southern African forest. Jor. Ecol. 81, 93-99.

Barker, M.G., Pérez-Salicrup, D.R., 2000. Comparative water relations of mature mahogany Switenia macrophylla) tees with and without lianas in a subhumid seasonally dry forest in Bolivia. Tree Physiol. 20, 1167-1174.

Bateman, R.M., Crane, P.R., DiMichele, W.A., Kenrick, P.R., Rowe, N.P., Speck, T., and Stein, W.E., 1998. Early evolution of land plants: Phylogeny, Physiology, and Ecology of the Primary Terrestrial Radiation. Annu. Rev. Ecol. Syst. 29, 263-292.

Bautista-Zúñiga, F., Batllori-Sampedro, E., Ortiz-Pérez, M.A., G. Palacio-Aponte, G., and Castillo-González, M., 2003. "Península de Yucatán". In: Colunga-Garcíamarín, P., and Larqué-Savedra, A. (eds). Naturaleza y Sociedad en el área maya: Geoformas, agua y suelo en la pasado, presente y futuro. Academia Mexicana de Ciencias and Centro de Investigación Científica de Yucatán.

Begon, M., Harper, J.L, and Townsend, C.R., 1996. Ecology; individuals, populations and communities. Blackwell Science, Oxford.

Benzing, D.H. 1990. Vascular Epiphytes (especifically Chapter 1). Cambridge University Press, Cambridge.

Bueche, F., 1988. Física para estudiantes de ciencias e ingeniería (T-1). Mc Graw-Hill Interamericana de México S.A de C.V. México D.F.

Burnham, R.J., 2002. Dominance, diversity and distribution of lianas in Yasuní, Ecuador: who is on top?. Jor. Trop. Ecol. 18, 845-864.

Caballé Guy, and Martin, A., 2001. Thirteen years of change in trees and lianas in a Gabonese rainforest. Plant Ecol. 152(2): 167-173.

Campbell, E.J.F., Newberry, D.McC., 1993. Ecological relationships between lianas and trees in lowland rain forest in Sabah, East Malaysia. Jor. Trop. Ecol. 9, 469-490.

Careaga, L., 1994. Quintana Roo: Monografía estatal. Secretaría de Educación Pública, México D.F. 
Carlquist, S., 1991. Anatomy of vine and liana stems: a review and synthesis. In: Putz, F.E., and Mooney, H.A. (eds). The Biology of Vines. Cambridge University Press, Cambridge, ps 53-72.

Carnevalli Fernández-Concha, G., Ramírez-Morillo, I., González-Iturbe, J.A., 2003. Flora y vegetación de la Península de Yucatán. In: In: Colunga-Garcíamarín, P., and Larqué-Savedra, A. (eds). Naturaleza y Sociedad en el área maya. Academia Mexicana de Ciencias and Centro de Investigación Científica de Yucatán.

Chermin, J., 2000. Parasitology. Taylor and Francis, London.

Clark, D., Clark, D., 1990. Distribution and effects on tree growth of lianas and woody hemiepiphytes in a Costa Rican tropical wet forest. Jor. Trop. Ecol. 6, 321-331.

Cramer, V., Hobbs, R. J., Sandish, R. J. in press. What's new about old fields? Land abandonment and ecosystem assembly. Trends in Ecology and Evolution doi: 10.1016/j.tree.2007.10.005.

Connell, J. H., 1990. Apparent versus "Real" competition in plants. In Grace, J.B., and Tillman, D. (eds). Perspectives in plant competition. Academic Press, San Diego.

Dalling, H.W., Hubbell, S.P., Silvera, K., 1998. Seed dispersal, seedlin establishment and gap partitioning among tropical pioneer trees. Jor. Ecol. 86, 674-689.

Dalling, J.W., and Burslem, D.F.R.P., 2005. Role of life-history trade-offs in the equalization and differentiation of tropical tree species. In: Pinard, M.A., and Hartley, S.E. (eds), Biotic interactions in the Tropics, their role in the maintainance of species diversity. Cambridge University Press, Cambridge.

Dalling, J.W., and Hubbell, S.P., 2002. Seed size, growth and gap microsite conditions as determinants of recruitment success for pioneer species. Jor. Ecol. 90, 557-568.

De Irala, J., Fernandez-Crehuet, N., Serrano, A., 1997. Intervalos de confianza anormalmente amplios en regresión logística: interpretación de resultados de programas estadísticos. Rev. Panam. Salud Pública/Pan. Am. J. Publich Health. 1(3), 230-234.

De La Torre, C.L., 2003. Etnoecología de los bejucos aretesanales en tres comunidades del NW de Quintana Roo, México: Implicaciones para su manejo sostenible (Tesis de Maestría), Fac. de Medicina Veterinaria y Zootecnia, Universidad Autónoma de Yucatán. Mérida, Yucatán, México.

De Walt, S.J., Schnitzer, S.A., Denslow, J.S., 2000. Density and diversity of lianas along a chronosequence in a central Panamanian lowland forest. Jor. Trop. Ecol. 16, 1-19.

Denslow, J.S., Ellison, A.M., and Sanford, R.E., 1998. Treefall gap size effects on above- and below-ground processes in a tropical wet forest.

Dillenburg, L.R., Whigham, D.F., Teramura, A.H., Forseth, I.N., 1993-a. Effects of vine competition on availability of light, water and nitrogen to a tree host (Liquidambar styraciflua). Amer. Jor. Bot. 80(3), $244-252$.

1993-b. Effects of below and above ground competition from the vines Lonicera japonica and Parthenocissus quinquifolia on the growth of the host Liquidambar styraciflua. Oecologia 93, 48-54.

Domínguez, E., Aldana D., 2001. Regresión logística. Un ejemplo de su uso en Endocrinología. Rev. Cubana Endocrinol. 12(1)58-64.

Dupuy, J.M., González-Iturbe, J.A., Iriarte-Vivar, S., Calvo-Irabien, L.M., Espadas-Manrique, C., Tun-Dzul, F., Dorantes-Euan, A., 2007. Cambios de la cobertura y uso del suelo (1970-2000) en dos comunidades rurales en el noroeste de Quintana Roo. Investigaciones Geográficas. 62, 104-124.

Emanuel, K.A., 1987. The dependence of hurricane intensity on climate. Nature 326 (6112), 483-485. 2003. Tropical Cyclones. Ann. Rev. Eatrh Planet. Sci. 31, 75-104. 
Ewel, J.J. 1974. Litter fall and leaf decomposition in a tropical frest succession in Eastern Guatemala. The Journal of Ecology. 64(1), 293-308.

Ewel, J.J., and Hiremath, A.J., 2005. Plant-plant interactions in tropical forests. In: Pinard, M.A., and Hartley, S.E. (eds), Biotic interactions in the Tropics, their role in the maintainance of species diversity. Cambridge University Press, Cambridge.

Ewers, F.W., Fischer, J.B., Fitchner, K., 1991. Water flux and xylem structure in vines. In: Putz, F.E., Mooney, H.A. (eds.), The Biology of Vines. Cambridge University Press, Cambridge.

Ewers, F.W., Fisher, J.B., Chiu, S.T., 1990. A survey of vessel dimensions in stems of tropical lianas and other growth forms. Oecologia 84, 544-552.

Fitchner, K., Schultze, E.D., 1990. Xylem water flow in tropical vines as measured by a steady state heating method. Oecologia 82, 355-361.

Futuyma, D.J., 1998. Evolutionary Biology. Sinauer Associates Press, Sunderlands, Massachusets.

Gartner, B.L., Bullock, S.H., Mooney, H.a., Brown, V.B., Whitbeck, J.L., 1990. Water transport properties of vines and tree stems in a tropical deciduous forest. Amer. Jor. Bot. 77(6), 742-749.

Gentry, A.H., 1991. The distribution and evolution of climbing plants. In: Putz, F.E., Mooney, H.A. (eds.), The Biology of Vines. Cambridge University Press, Cambridge.

Gerold, G., 1994. Pedo-Ecological changes of tropical forest-soils by different land-use impacts.

INTERCIENCIA 19(6), 297-301.

Gerwing, J.J., 2001. Testing liana cutting and controlled burning as silvicultural treatments for a logged forest in the eastern Amazon. Jor. Appl. Ecol., 38, 1264-1276.

Gerwing, J.J., Schnitzer, S.A., Burnham, R.J., Bongers, F., Chave, J., DeWalt, S., Ewango,C. E.N., Foster, R., Kenfack, D., Martínez-Ramos, M., Parren, M., Parthasarathy, N., Pérez-Salicrup, D., Putz, F.E., and Thomas, D.W., 2006. Censusing lianas. BIOTROPICA, 38 (2) 1-6.

Gerwing, J.J., Vidal, E., 2002. Changes in liana abundance and species diversity eight years after liana cutting and logging in an Eastern Amazonian Forest. Cons. Biol., 16(2), 544-548.

Gilbert, B., Wright, S.J., Muller-Landau, H.C., Kitajima, K., and Hernández, A., 2006. Life-History trade-offs in Tropical trees and lianas. Ecology 87(5), 1281-1288.

Gilbert, G., 2005. Dimensions of plant disease in tropical forests. In: Burslem, D.F.R.P., Pinard, M.A., and Hartley, S.E. (eds), Biotic interactions in the Tropics, their role in the maintainance of species diversity. Cambridge University Press, Cambridge.

Granados, J., Körner, C., 2002. In deep shade, elevated $\mathrm{CO}_{2}$ increases the vigor of tropical climbing plants. Global Change Biol. 8, 1-9.

Grauel, W.T., and Putz, F.E., 2004. Effects of lianas on growth and regeneration of Prioria copaifera in Darien, Panama. For. Ecol. Man., 190, 99-108.

Grime, J.P., 1974. Vegetation classification by reference to strategies. Nature 250, 26-31.

Guariguata, M.R., Ostertag, R., 2002., Sucesión Secundaria. In: Guariguata, M.R., Catan, G.H. (eds), Ecología y Conservación de Bosques Neotropicales. Ed. Tecnológica de Costa Rica, Cartago, C.R.

Hegarthy, E.E., 1991. Vine-host interactions. In: Putz, F.E., Mooney, H.A. (eds.), The Biology of Vines. Cambridge University Press, Cambridge.

Holdridge, L., Grenke, W., Hatheway, W., Lian, T., and Tosi Jr., J., 1971. Forest environments in tropical life zones: a pilot study. Pergamon Press, Oxford.

Hora, R.C., and Soares, J.J., 2002. Estrutura fitossociológica da comunidade de lianas em uma floresta estacional semidecidual na Fazenda Canchim, Sao Carlos, SP. Revista Brasil. Bot. 25 (3) 323-329. 
Hubbell, S.P., 2001. The Unified Neutral Theory of Biodiversity and Biogeography. Monographs in Population Biology. Princeton University Press, Princeton.

Hubbell, S.P., and Foster, R.B., 1986. Biology, chance and history and the structure of tropical rain forest tree communities. In Diamond, J., and Case, T.J. (eds) Community Ecology. Harper and Row, New York.

Instituto Nacional de Estadística, Geografía e Informática (INEGI), Gobierno del Estado de Quintana Roo, Honorable Ayuntamiento de Lázaro Cárdenas, 1993. Cuaderno Estadístico Municipal. Aguascalientes, México.

Jiménez-Osornio, J.J., Caballero, A., Quezada, D., and Bello, E., 2003. Estrategias tradicionales de apropiación de los recursos naturales. In: Colunga-Garcíamarín, P., and Larqué-Savedra, A. (eds). Naturaleza y Sociedad en el área maya: pasado, presente y futuro. Academia Mexicana de Ciencias and Centro de Investigación Científica de Yucatán.

Kainer, K.A., Wadt, L.H.O., Gomes-Silva, D.A.P., and Capanu, M., 2006. Liana loads and their association with Bertholletia excelsa fruit and nut production, diameter growth and crown attributes. Jor. Trop. Ecol., 22, 147154.

Kiernan, M.J., 2000. The Forest Ejidos of Quintana Roo. USAID, Washington D.C.

Lambers, H., Chapin III, F.S., and Pons, T.L., 2000. Plant Physiological Ecology. Springer-Verlag, New York.

Laurance, W.F., Pérez-Salicrup, D., Delamonica, P., Fearnside, P.M., Agra, S., Jerozolinski, A., Pohl, L., and Lovejoy, T.E., 2001. Rain forest fragmentation and the structure of Amazonian liana communities. Ecology 82, 105-116.

Laurance, D., and Foster, D., 2002. Changes in forest biomass, litter dynamics and soils following shifting cultivation in Southern Mexico: an overview. INTERCIENCIA, 27(8), 400-408.

Lex, V., Batista, R.C., and deOliveira, R.E., 1998. Ecologia de lianas e o manejo de fragmentos florestais. Série Técnica IPEF 12 (32) 43-64.

Lomáscolo, T., Aide, T.M., 2001. Seed and Seedling bank dynamics in Secondary Forest following Hurricane Georges in Puerto Rico. Caribbean Jor. Sci. 37 (3-4), 259-270.

Makana, J.R., Thomas, S.C., 2005. Effects of light gaps and litter removal on the seedling performance of six African timber species. BIOTROPICA 37(2), 227-237.

Malizia, A., and Grau, R., 2006. Liana-host tree associatins in a subtropical montane forest of north-western Argentina. Jor. Trop. Ecol. 22, 331-339.

Martínez-Ramos, M., 1994. Regeneración natural y diversidad de especies arbóreas en selvas húmedas. Bol. Soc. Bot. Mexico, 54, 179-224.

Michener, W.K., Blood, E.R., Bildstein, K.L., Brinson, M.M., Gardner, L.R., 1997. Climate change, hurricanes and tropical storms, and rising sea level in coastal wetlands. Ecol. Appl. 7(3), 770-801.

Miranda, F., and Hernández, E. X., 1963. Los tipos de vegetación de México y su clasificación. Sobretiro del Bol. Soc. Mex. Bot. \#28.

Moles, A.T., and Westoby, M., 2004. What do seedlings die from and what are the implications for evolution of seed size? Oikos 106(1), 193-199.

Municipio de Làzaro Càrdenas. 1987., Monografía del Municipio de Lázaro Cárdenas, Quintana Roo.

Olmsted, I., Durán, R., González-Iturbe, J.A., Calvo, L.M., Remolina, F., and Canela Rojo, J., 2000. Programa de Manejo del area de proteccion de flora y fauna silvestre Yum Balam, Informe final. Centro de Investigación Científica de Yucatán, Mérida, Yucatán, México. 
Olmsted, I., Durán-García, R., González-Iturbe, J.A., Granados, J., and Tun, F., 1999. Vegetación. In: García, A. and Córdoba, J. (eds.), Atlas de procesos territoriales de Yucatán. Universidad Autónoma de Yucatán, Fac. Arquitectura. Mérida, Yucatán, México.

Orellana, R.; Bañuelos, I.; García E.; González-Iturbe, J.A.; Herrera, F. Balam-Ku, M.; and Vidal, J., 1999. Clima. In: García, A. and Córdoba, J. (eds.), Atlas de procesos territoriales de Yucatán. Universidad Autónoma de Yucatán, Fac. Arquitectura. Mérida, Yucatán, México.

Orellana, R., Islebe, G., Espadas, C. 2003., Presente, pasado y futuro de los climas de la Penísula de Yucatán. In: Colunga-GarcíaMarín, P., Larqué, A. (Eds.), Naturaleza y sociedad en el Área Maya: presente, pasado y futuro. Accademia Mexicana de Ciencias, Centro de Investigación Científica de Yucatán, México.

Ostertag, R., Silver, W.L., Lugo, A.E., 2005. Factors affecting mortality and resistance to damage following Hurricanes in rehabilitated Subtropical Moist Forest. BIOTROPICA 37(1), 16-24.

Parren, M., 2003. Lianas and logging in West Africa, PhD. Thesis dissertation. Tropenbos International, Wageningen, The Netherlands.

Parren, M.P.E., and Bongers, F., 2001. Does climber cutting reduce felling damage in southern Cameroon? For. Ecol. Man. 141, 175-188.

Pavelka, M.S.M., Behie, A.M., 2005. The effect of Hurricane Iris on the food supply of Black Howlers (Alouatta pigra) in Southern Belize. BIOTROPICA 37(1), 102-108.

Pérez Salicrup, D. R. 2001. Effect of liana-cutting on tree regeneration in a liana forest in Amazonian Bolivia. Ecology 82, 389-396.

Pérez-Salicrup, D.R., and Barker, M.G. 2000., Effect of liana cutting on water potential an growth of adult Senna multijuga (Caesalpiniodae) trees in a Bolivian tropical forest. Oekologia 124, 469-475.

Pérez-Salicrup, D.R., and de Meijere, W., 2005. Number of lianas per tree and number of trees climbed by lianas at Los Tuxtlas, Mexico. BIOTROPICA 37 (1), 153-156.

Pérez-Salicrup, D.R., Claros, A., Guzmán, R., Licona, J.C., Ledezma, F., Pinard, M.A., and Putz, F.A., 2001 a. Cost and efficiency of cutting lianas in a lowland liana forest of Bolivia. BIOTROPICA 33 (2) 324-329.

Pérez-Salicrup, D.R., Sork, V.L., and Putz, F.E., 2001b. Lianas and trees in a Liana Forest of Amazonian Bolivia. BIOTROPICA 33 (1) 34-47.

Phillips, N., Oren, R., Zimmermann, R., Wright, S.J. 1999., Temporal patterns of water flux in trees and lianas in a Panamanian moist forest. Trees 14,116-123.

Phillips, O., Vásquez Martínez, R., Arroyo, L., Baker, T.R., Kileen, T., Lewis, S.L., Yadvinder, M., Monteagudo Mendoza, A., Neill, D., Núñez Vargas, P., Alexiades, M., Cerón, C., Di Fiore, A., Erwin, T., Jardim, A., Palacios, W., Saldias, M., Vinceti, B. 2002., Increasing dominance of large lianas in Amazonian forests. Nature 418,770-774.

Pinard, M.A., Putz, F.E. 1994., Vine infestation of large remnant trees in logged forest in Sabah, Malaysia: Biomechanical facilitation in vine succession. Jor. Trop. For. Sci. 6(3), 302-309.

Putz, F.E. 1984a., The natural history of lianas on Barro Colorado Island, Panama. Ecology 65(6), 1713-1724. 1984b. How trees avoid and shed lianas. BIOTROPICA 16 (1), 19-23

1991., Silvicultural effects of lianas. En Putz, F.E. and Mooney, H.A (Eds.), The Biology of Vines. Cambridge University Press, Cambridge, ps.493-501.

Putz, F.E., and Holbrook, N., 1986. Notes on the natural history of hemiepiphytes. Selbyana 9, 61-69.

Raes, N., and Ek, R.C., 2002. Climbers of Guyana-website: http://www.bio.uu.nl/ herba/lianas

Reed, N., 1971. La Guerra de castas de Yucatán. Editorial Era, México. 
Restom, T.G., and Nepstad, D.C., 2004. Seedling growth dynamics of a deeply rooting liana in a secondary forest in eastern Amazonia. For. Ecol. Man. 190, 109-118.

Reyes, G., Brown, S., Chapman, J., and Lugo, A., 1992. Wood densities of tropical tree species. General Technical Report S0-88, United States Department of Agriculture, New Orleans.

Rich, P., Shawn, L., Muñoz, L., and Quesada, M., 1987. Shedding of vines by the palms Welfia georgii and Iriartea gigantea. Principes 31 (1), 31-34.

Sánchez, O. S., Islebe, G.A., 1999. Hurricane Gilbert structural changes in a tropical forest in south-eastern Mexico. Global Ecol. and Biogeog. 8, 29-38.

Sánchez-Sánchez, O., Islebe, G.A., 2002. Tropical forest communities in southeastern Mexico. Plant Ecol. 158, 183-200.

Schnitzer, S.A., 2005. A mechanistic explanation for global patterns of liana abundance and distribution. Amer. Nat., 166(2), 262-276.

Schnitzer, S.A., Bongers, F. 2002., The Ecology of lianas and their role in forests. Trends Ecol. Evol. 17(5), 223230.

Schnitzer, S.A., Dalling, J.W., Carson, W.P. 2000., The impact of lianas on tree regeneration in tropical forest canopy gaps: evidence for an alternative pathway of gap-phase regeneration. Jor. Trop. Ecol. 88, 655-666.

Schnitzer, S.A., Kuzee, M.E., and Bongers, F., 2005. Disentangling above- and below-ground competition between lianas and trees in a tropical forest. Jor. Ecol. 93, 1115-1125.

Stevens, G. 1987., Lianas as structural parasites: the Bursera simarouba example. Ecology 68(1), 77-81.

Stewart, W.N., and Rothwell, G.W. 1993. Paleobotany and the evolution of plants. Cambridge University Press (mainly Chapters 21, 23, 25, 30, and 31).

The Field Museum, 2005. Environmental and conservation programs: rapid color guides. Available on-line: http://fm2.fieldmuseum.org/plantguides/rcg_intro.asp

Tovilla H.,C., Orihuela B., D.E., 2004. Impacto del huracán Rosa sobre los bosques de manglar de la costa norte de Nayarit, México. Madera y Bosques Número especial 2, 63-75.

Uriarte, M., Hubbell, S.P., John, R., Condit, R., and Canham, C., 2005. Neighbourhood effects on sapling growth and survival in a neotropical forest and the ecological-equivalent hypothesis. In: Pinard, M.A., and Hartley, S.E. (eds), Biotic interactions in the Tropics, their role in the maintainance of species diversity. Cambridge University Press, Cambridge.

Van Bloem, S.J., Murphy, P.G., Lugo, A.E., Ostertag, R., Rivera Costa, M., Ruiz Bernard, I., Molina Colón, S., Canals Mora, M., 2005. The influence of hurricane winds on Caribbean Dry Forest structure and nutrient pools. BIOTROPICA special edition 37(4), 571-583.

Vandermeer, J., Granzow de la Cerda, I., Boucher, D., Perfecto, I., Ruiz, J., 2000. Hurricane disturbance and tropical tree species diversity. SCIENCE 290, 788-791.

Vidal, E., Johns, J., Gerwing, J., Barreto, P., Uhl, C. 1997., Vine management for reduced-impact logging in eastern Amazonia. For. Ecol. Man. 98, 105-114.

Vidal, E., Viana, V.M., and Ferreira, J.L., 2002. Crescimento de floresta tropical trés anos após colheita de madeira com e sem manejo florestal na Amazónia oriental. Scientia Forestalis 61, 133-143.

Whigham, D. 1984., The influence of vines on the growth of Liquidambar styraciflua L. (sweetgum). Can. Jor. For. Res. 14(1), 37-39. 
Whigham, D.F., Olmsted, I., Cabrera Cano, E., Harmon, M.E., 1991. The impact of Hurricane Gilbert on trees, literfall, and woody debris in a Dry Tropical Forest in the Northeastern Yucatan Peninsula. BIOTROPICA 23(a), 434-441.

Wieder, R.K., Wright, S.J. 1995. Tropical forest litter dynamics and dry season irrigation on Barro Colorado Island, Panama. Ecology 76 (6), 1971-1979.

Wright, S.J., Calderón, O., Hernández, A., Patton, S. 2004., Are lianas increasing in importance in tropical forests? A 17-year record from Panama. Ecology 85(2), 484-489.

Wright, S.J., M.A. Jaramillo, J. Pavón, R. Condit, S.P. Hubbell, \& R.B. Foster. 2005. Reproductive size thresholds in tropical trees: variation among individuals, species and forests. Jor. Trop. Ecol. 21: 307-315. 
APPENDIX I

SPECIES LIST AND NUMBERS OF INDIVIDUALS PER SPECIES PER PLOT 15 MONTHS AFTER LIANA-CUTTING

(2 MONTHS BEFORE HURRICANE WILMA) 


\begin{tabular}{|c|c|c|c|c|c|c|c|c|c|c|c|c|c|c|}
\hline TREE SPECIES & FAMILY & Ant.55 A & $\begin{array}{c}\text { cut } \\
\text { Ant.55 B }\end{array}$ & Mar.55 A & $\begin{array}{c}\text { cut } \\
\text { Mar.55 B }\end{array}$ & $\begin{array}{c}\text { cut } \\
\text { Ros.55 A }\end{array}$ & Ros.55 B & Sau18 A & $\begin{array}{c}\text { cut } \\
\text { Sau18 B }\end{array}$ & $\begin{array}{c}\text { cut } \\
\text { Sau18 C }\end{array}$ & Sau18 D & $\begin{array}{c}\text { cut } \\
\text { Pep10 A }\end{array}$ & Pep10 C & $\begin{array}{l}\text { Total per } \\
\text { species }\end{array}$ \\
\hline Acacia dolichostachya & Leguminosae (M) & 0 & 0 & 0 & 0 & 0 & 0 & 1 & 3 & 4 & 0 & 0 & 2 & 10 \\
\hline Albizia tomentosa & Leguminosae (M) & 1 & 0 & 0 & 0 & 0 & 0 & 0 & 0 & 0 & 0 & 0 & 7 & 8 \\
\hline Allophylus cominia & Sapindaceae & 8 & 1 & 6 & 1 & 2 & 0 & 4 & 0 & 10 & 6 & 5 & 4 & 47 \\
\hline Amyris spp & Rutaceae & 1 & 0 & 0 & 0 & 0 & 1 & 0 & 4 & 0 & 0 & 0 & 0 & 6 \\
\hline Apoplanesia paniculata & Leguminosae $(\mathrm{P})$ & 1 & 0 & 0 & 0 & 0 & 0 & 0 & 0 & 0 & 0 & 0 & 0 & 1 \\
\hline Ardisia escallonioides & Myrsinaceae & 2 & 0 & 0 & 0 & 0 & 1 & 0 & 0 & 0 & 0 & 0 & 0 & 3 \\
\hline Astrocasia tremula & Euphorbiaceae & 0 & 0 & 0 & 0 & 0 & 0 & 0 & 0 & 0 & 0 & 1 & 0 & 1 \\
\hline Brosiumu alicastrum & Moraceae & 0 & 1 & 0 & 0 & 0 & 1 & 0 & 0 & 1 & 0 & 0 & 0 & 3 \\
\hline Bucida bucidaefolia & Combretaceae & 0 & 0 & 0 & 0 & 1 & 0 & 0 & 0 & 0 & 0 & 0 & 0 & 1 \\
\hline Bunchosia swartziana & Malpighiaceae & 2 & 0 & 0 & 1 & 3 & 0 & 0 & 0 & 0 & 0 & 0 & 0 & 6 \\
\hline Bursera simaruba & Burseraceae & 14 & 8 & 5 & 6 & 10 & 5 & 30 & 8 & 4 & 50 & 4 & 19 & 163 \\
\hline Byrsonima bucidaefolia & Malpighiaceae & 21 & 1 & 0 & 0 & 1 & 1 & 0 & 0 & 0 & 0 & 0 & 0 & 24 \\
\hline Byrsonima crassifolia & Malpighiaceae & 0 & 0 & 0 & 0 & 0 & 0 & 0 & 0 & 0 & 0 & 2 & 0 & 2 \\
\hline Caesalpinia gaumeri & Leguminosae (C) & 3 & 0 & 2 & 1 & 0 & 0 & 0 & 0 & 0 & 0 & 0 & 0 & 6 \\
\hline Casimiroa tetrameria & Rutaceae & 0 & 0 & 0 & 0 & 0 & 0 & 0 & 0 & 0 & 1 & 0 & 0 & 1 \\
\hline Cecropia spp & Cecropiaceae & 0 & 1 & 0 & 0 & 0 & 0 & 0 & 0 & 0 & 0 & 0 & 0 & 1 \\
\hline Ceiba pentandra & Bombacaceae & 1 & 0 & 0 & 0 & 0 & 0 & 0 & 0 & 0 & 0 & 0 & 0 & 1 \\
\hline Chrysophyllum cainito & Sapotaceae & 1 & 0 & 0 & 3 & 7 & 4 & 1 & 2 & 0 & 4 & 14 & 12 & 48 \\
\hline Chlorophora tinctoria & Moraceae & 0 & 0 & 0 & 0 & 0 & 1 & 0 & 0 & 0 & 0 & 0 & 0 & 1 \\
\hline Coccoloba acapulcensis & Polygonaceae & 0 & 4 & 1 & 0 & 4 & 1 & 0 & 0 & 0 & 0 & 0 & 0 & 10 \\
\hline Coccoloba cozumelensis & Polygonaceae & 0 & 0 & 2 & 0 & 0 & 1 & 0 & 0 & 0 & 0 & 0 & 0 & 3 \\
\hline Coccoloba spicata & Polygonaceae & 1 & 2 & 6 & 5 & 1 & 3 & 9 & 2 & 0 & 10 & 8 & 18 & 65 \\
\hline Cochlospermum vitifolium & Cochlospermaceae & 0 & 0 & 0 & 0 & 0 & 0 & 1 & 5 & 0 & 0 & 0 & 0 & 6 \\
\hline Colubrina arborescens & Rhamnaceae & 0 & 0 & 0 & 0 & 0 & 0 & 0 & 2 & 1 & 0 & 0 & 0 & 3 \\
\hline Colubrina spp & Rhamnaceae & 0 & 0 & 0 & 0 & 0 & 0 & 0 & 0 & 0 & 0 & 2 & 0 & 2 \\
\hline Croton arboreus & Euphorbiaceae & 3 & 0 & 1 & 1 & 0 & 0 & 0 & 0 & 0 & 0 & 0 & 0 & 5 \\
\hline Cupania belizensis & Sapindaceae & 0 & 0 & 3 & 0 & 0 & 0 & 0 & 0 & 0 & 0 & 0 & 0 & 3 \\
\hline Dendropanax arboreus & Araliaceae & 4 & 0 & 4 & 19 & 4 & 8 & 9 & 8 & 8 & 15 & 1 & 10 & 90 \\
\hline Diospyros cuneata & Ebenaceae & 7 & 23 & 10 & 22 & 2 & 7 & 6 & 3 & 1 & 1 & 0 & 0 & 82 \\
\hline Diphysa carthagenensis & Leguminosae $(\mathrm{P})$ & 0 & 0 & 0 & 0 & 0 & 0 & 0 & 0 & 0 & 1 & 0 & 0 & 1 \\
\hline Drypetes lateriflora & Euphorbiaceae & 1 & 0 & 0 & 0 & 0 & 0 & 0 & 0 & 0 & 0 & 0 & 0 & 1 \\
\hline
\end{tabular}




\begin{tabular}{|c|c|c|c|c|c|c|c|c|c|c|c|c|c|c|}
\hline TREE SPECIES & FAMILY & Ant.55 A & $\begin{array}{c}\text { cut } \\
\text { Ant.55 B }\end{array}$ & Mar.55 A & $\begin{array}{c}\text { cut } \\
\text { Mar.55 B }\end{array}$ & $\begin{array}{c}\text { cut } \\
\text { Ros.55 A }\end{array}$ & Ros.55 B & Sau18 A & $\begin{array}{c}\text { cut } \\
\text { Sau18 B }\end{array}$ & $\begin{array}{c}\text { cut } \\
\text { Sau18 C }\end{array}$ & Sau18 D & $\begin{array}{c}\text { cut } \\
\text { Pep10 A }\end{array}$ & Pep10 C & $\begin{array}{l}\text { Total per } \\
\text { species } \\
\end{array}$ \\
\hline Erythrina standleyana & Leguminosae $(\mathrm{P})$ & 0 & 0 & 0 & 0 & 1 & 0 & 0 & 0 & 0 & 0 & 0 & 0 & 1 \\
\hline Esenbechia spp & Rutaceae & 0 & 0 & 0 & 1 & 0 & 0 & 4 & 11 & 2 & 0 & 0 & 0 & 18 \\
\hline Eugenia acapulcensis & Myrtaceae & 2 & 1 & 0 & 0 & 0 & 0 & 0 & 0 & 0 & 0 & 0 & 0 & 3 \\
\hline Eugenia axillaris & Myrtaceae & 1 & 0 & 0 & 0 & 2 & 1 & 0 & 0 & 0 & 0 & 0 & 0 & 4 \\
\hline Exothea diphylla & Sapindaceae & 4 & 2 & 0 & 1 & 3 & 0 & 0 & 0 & 0 & 0 & 0 & 0 & 10 \\
\hline Ficus benjamina & Moraceae & 0 & 1 & 0 & 0 & 0 & 0 & 3 & 2 & 2 & 12 & 1 & 0 & 21 \\
\hline Ficus cotinifolia & Moraceae & 2 & 0 & 0 & 0 & 0 & 0 & 0 & 0 & 0 & 0 & 0 & 0 & 2 \\
\hline Ficus maxima & Moraceae & 0 & 0 & 0 & 1 & 0 & 0 & 0 & 0 & 0 & 0 & 0 & 0 & 1 \\
\hline Ficus pertusa & Moraceae & 1 & 0 & 0 & 0 & 0 & 0 & 0 & 0 & 0 & 0 & 0 & 0 & 1 \\
\hline Ficus spp & Moraceae & 0 & 0 & 0 & 3 & 1 & 1 & 0 & 0 & 0 & 0 & 0 & 0 & 5 \\
\hline Guettarda combsii & Rubiaceae & 3 & 2 & 1 & 0 & 1 & 3 & 7 & 9 & 1 & 4 & 1 & 3 & 35 \\
\hline Guettarda elliptica & Rubiaceae & 1 & 0 & 0 & 0 & 0 & 0 & 0 & 0 & 0 & 0 & 0 & 0 & 1 \\
\hline Guettarda gaumeri & Rubiaceae & 0 & 1 & 0 & 0 & 0 & 0 & 0 & 0 & 0 & 0 & 0 & 0 & 1 \\
\hline Gymnopodium floribundum & Polygonaceae & 0 & 1 & 0 & 0 & 0 & 0 & 0 & 0 & 0 & 0 & 0 & 1 & 2 \\
\hline Hampea trilobata & Malvaceae & 2 & 6 & 18 & 9 & 6 & 7 & 38 & 11 & 17 & 14 & 26 & 23 & 177 \\
\hline Hippocratea excelsa & Hippocrateaceae & 2 & 0 & 2 & 0 & 0 & 0 & 0 & 0 & 0 & 0 & 0 & 0 & 4 \\
\hline Jacquinia macrocarpa & Theophrastaceae & 0 & 2 & 1 & 0 & 0 & 0 & 0 & 0 & 0 & 0 & 0 & 0 & 3 \\
\hline Jatropha gaumeri & Euphorbiaceae & 0 & 2 & 3 & 0 & 0 & 0 & 0 & 0 & 0 & 0 & 0 & 0 & 5 \\
\hline Krugiodendron ferreum & Rhamnaceae & 1 & 0 & 0 & 2 & 0 & 0 & 0 & 0 & 0 & 0 & 0 & 0 & 3 \\
\hline Lonchocarpus rugosus & Leguminosae $(\mathrm{P})$ & 2 & 0 & 0 & 1 & 1 & 0 & 2 & 14 & 20 & 8 & 9 & 2 & 59 \\
\hline Lonchocarpus xuul & Leguminosae $(\mathrm{P})$ & 6 & 2 & 5 & 1 & 5 & 7 & 0 & 0 & 0 & 0 & 11 & 6 & 43 \\
\hline Lonchocarpus yucatanensis & Leguminosae $(\mathrm{P})$ & 1 & 0 & 0 & 0 & 0 & 0 & 26 & 8 & 0 & 1 & 6 & 2 & 44 \\
\hline Luehea speciosa & Tiliaceae & 0 & 1 & 1 & 0 & 0 & 0 & 17 & 37 & 9 & 0 & 1 & 0 & 66 \\
\hline Lysiloma latisiliquum & Leguminosae (M) & 2 & 0 & 2 & 1 & 1 & 0 & 0 & 3 & 1 & 0 & 0 & 1 & 11 \\
\hline Malmea depressa & Annonaceae & 0 & 0 & 2 & 4 & 4 & 3 & 0 & 0 & 0 & 0 & 0 & 0 & 13 \\
\hline Manilkara zapota & Sapotaceae & 2 & 6 & 0 & 2 & 5 & 7 & 0 & 0 & 0 & 0 & 0 & 0 & 22 \\
\hline Margaritaria nobilis & Euphorbiaceae & 0 & 0 & 0 & 0 & 0 & 0 & 0 & 1 & 0 & 0 & 0 & 0 & 1 \\
\hline Matayba oppositifolia & Sapindaceae & 0 & 0 & 0 & 0 & 11 & 5 & 1 & 1 & 6 & 0 & 0 & 0 & 24 \\
\hline Metopium brownei & Anacardiaceae & 7 & 1 & 3 & 4 & 9 & 3 & 0 & 1 & 0 & 1 & 0 & 0 & 29 \\
\hline Morinda spp & Rubiaceae & 0 & 0 & 0 & 0 & 0 & 0 & 0 & 0 & 1 & 0 & 0 & 0 & 1 \\
\hline Nectandra salicifolia & Lauraceae & 6 & 9 & 31 & 12 & 37 & 7 & 0 & 0 & 0 & 0 & 1 & 0 & 103 \\
\hline
\end{tabular}




\begin{tabular}{|c|c|c|c|c|c|c|c|c|c|c|c|c|c|c|}
\hline TREE SPECIES & FAMILY & Ant.55 A & $\begin{array}{c}\text { cut } \\
\text { Ant.55 B }\end{array}$ & Mar.55 A & $\begin{array}{c}\text { cut } \\
\text { Mar.55 B }\end{array}$ & $\begin{array}{c}\text { cut } \\
\text { Ros.55 A }\end{array}$ & Ros.55 B & Sau18 A & $\begin{array}{c}\text { cut } \\
\text { Sau18 B }\end{array}$ & $\begin{array}{c}\text { cut } \\
\text { Sau18 C }\end{array}$ & Sau18 D & $\begin{array}{c}\text { cut } \\
\text { Pep10 A }\end{array}$ & Pep10 C & $\begin{array}{l}\text { Total per } \\
\text { species } \\
\end{array}$ \\
\hline Piscidia piscipula & Leguminosae $(\mathrm{P})$ & 0 & 1 & 0 & 0 & 0 & 0 & 4 & 16 & 5 & 28 & 3 & 5 & 62 \\
\hline Pouteria campechiana & Sapotaceae & 7 & 4 & 5 & 4 & 0 & 3 & 4 & 0 & 0 & 0 & 0 & 2 & 29 \\
\hline Pouteria reticulata & Sapotaceae & 7 & 46 & 0 & 0 & 0 & 0 & 0 & 0 & 0 & 0 & 0 & 0 & 53 \\
\hline Protium copal & Burseraceae & 1 & 0 & 0 & 1 & 6 & 4 & 0 & 0 & 0 & 0 & 0 & 0 & 12 \\
\hline Psidium spp & Myrtaceae & 0 & 1 & 0 & 0 & 0 & 0 & 0 & 0 & 0 & 0 & 0 & 0 & 1 \\
\hline Randia truncata & Rubiaceae & 2 & 4 & 0 & 0 & 1 & 1 & 0 & 0 & 0 & 0 & 0 & 0 & 8 \\
\hline Sideroxylon obtusifolium & Sapotaceae & 0 & 0 & 0 & 1 & 0 & 0 & 0 & 0 & 0 & 0 & 0 & 0 & 1 \\
\hline Sideroxylon foetidissimum & Sapotaceae & 1 & 0 & 0 & 0 & 0 & 0 & 2 & 2 & 1 & 0 & 0 & 0 & 6 \\
\hline Sideroxylon salicifolium & Sapotaceae & 0 & 0 & 0 & 2 & 0 & 0 & 0 & 0 & 0 & 0 & 0 & 0 & 2 \\
\hline Simarouba glauca & Simaroubaceae & 1 & 1 & 1 & 0 & 2 & 2 & 1 & 1 & 0 & 0 & 0 & 0 & 9 \\
\hline Spondias mombin & Anacardiaceae & 0 & 1 & 0 & 0 & 0 & 0 & 3 & 0 & 2 & 0 & 4 & 3 & 13 \\
\hline Swartzia cubensis & Leguminosae (C) & 0 & 1 & 0 & 0 & 1 & 0 & 1 & 1 & 0 & 1 & 1 & 9 & 15 \\
\hline Tabebuia chrysantha & Bignoniaceae & 0 & 0 & 0 & 0 & 0 & 0 & 0 & 0 & 1 & 0 & 0 & 0 & 1 \\
\hline Tabebuia rosea & Bignoniaceae & 0 & 0 & 0 & 0 & 0 & 0 & 0 & 0 & 2 & 0 & 0 & 0 & 2 \\
\hline Thevetia gaumeri & Apocynaceae & 0 & 1 & 2 & 2 & 3 & 2 & 23 & 28 & 5 & 20 & 11 & 9 & 106 \\
\hline Thouinia paucidentata & Sapindaceae & 0 & 0 & 0 & 0 & 0 & 0 & 0 & 0 & 0 & 1 & 0 & 0 & 1 \\
\hline Trichilia hirta & Meliaceae & 0 & 0 & 0 & 1 & 0 & 0 & 0 & 0 & 0 & 0 & 3 & 0 & 4 \\
\hline Vitex gaumeri & Lamiaceae & 12 & 2 & 0 & 6 & 4 & 8 & 3 & 3 & 1 & 1 & 5 & 10 & 55 \\
\hline Xylosma flexuosum & Flacourtiaceae & 1 & 0 & 0 & 0 & 0 & 0 & 0 & 0 & 0 & 0 & 0 & 0 & 1 \\
\hline Zuelania guidonia & Flacourtiaceae & 0 & 0 & 0 & 0 & 0 & 0 & 5 & 5 & 6 & 3 & 6 & 0 & 25 \\
\hline Zygia stevensonii & Leguminosae (M) & 7 & 24 & 14 & 18 & 27 & 13 & 0 & 0 & 0 & 0 & 0 & 0 & 103 \\
\hline Total trees per plot & & 155 & 164 & 131 & 136 & 166 & 111 & 205 & 191 & 111 & 182 & 126 & 148 & 1826 \\
\hline
\end{tabular}

\section{(See next page for lianas)}




\begin{tabular}{|c|c|c|c|c|c|c|c|c|c|c|c|c|c|c|}
\hline LIANA SPECIES & FAMILY & Ant.55 A & $\begin{array}{c}\text { Cut } \\
\text { Ant.55 B } \\
\end{array}$ & Mar.55 A & $\begin{array}{c}\text { cut } \\
\text { Mar.55 B } \\
\end{array}$ & $\begin{array}{c}\text { cut } \\
\text { Ros.55 A }\end{array}$ & Ros.55 B & Sau18 A & $\begin{array}{c}\text { Cut } \\
\text { Sau18 B }\end{array}$ & $\begin{array}{c}\text { cut } \\
\text { Sau18 C }\end{array}$ & Sau18 D & $\begin{array}{c}\text { Cut } \\
\text { Pep10 A }\end{array}$ & Pep10 C & $\begin{array}{l}\text { Total per } \\
\text { species }\end{array}$ \\
\hline Cardiospermum halicabum & Sapindaceae & 0 & 3 & 0 & 2 & 3 & 0 & 0 & 10 & 0 & 4 & 3 & 0 & 25 \\
\hline Serjania adiantoides & Sapindaceae & 19 & 3 & 1 & 15 & 1 & 0 & 0 & 0 & 1 & 0 & 1 & 0 & 41 \\
\hline Dalbergia glabra & Leguminosae $(\mathrm{P})$ & 1 & 0 & 0 & 3 & 1 & 8 & 90 & 17 & 33 & 40 & 113 & 117 & 423 \\
\hline Cydista aequinoctialis & Bignoniaceae & 0 & 4 & 2 & 0 & 17 & 14 & 5 & 12 & 11 & 22 & 16 & 13 & 116 \\
\hline Cydista potosina & Bignoniaceae & 2 & 29 & 53 & 73 & 24 & 17 & 0 & 0 & 1 & 0 & 0 & 1 & 200 \\
\hline Cydista diversifolia & Bignoniaceae & 0 & 0 & 0 & 0 & 0 & 0 & 5 & 1 & 4 & 0 & 0 & 0 & 10 \\
\hline Arrabidaea spp1 & Bignoniaceae & 106 & 78 & 49 & 42 & 59 & 56 & 0 & 4 & 2 & 7 & 17 & 3 & 423 \\
\hline Arrabidaea patellifera & Bignoniaceae & 13 & 8 & 22 & 19 & 7 & 8 & 0 & 16 & 15 & 10 & 10 & 5 & 133 \\
\hline Melloa quadrivalvis & Bignoniaceae & 0 & 0 & 0 & 12 & 15 & 7 & 0 & 0 & 0 & 0 & 1 & 0 & 35 \\
\hline Tournefortia spp1 & Boraginaceae & 15 & 43 & 7 & 9 & 23 & 9 & 0 & 1 & 0 & 0 & 3 & 4 & 114 \\
\hline Petrea volubilis & Verbenaceae & 0 & 2 & 0 & 1 & 2 & 0 & 0 & 5 & 0 & 0 & 1 & 0 & 11 \\
\hline Cissus gossypifolia & Vittaceae & 0 & 12 & 0 & 4 & 3 & 1 & 7 & 1 & 16 & 4 & 5 & 9 & 62 \\
\hline Celtis spp1 & Ulmaceae & 0 & 0 & 0 & 1 & 0 & 0 & 5 & 3 & 4 & 0 & 1 & 2 & 16 \\
\hline Otapappus spp1 & Asteraceae & 0 & 0 & 0 & 0 & 1 & 0 & 0 & 0 & 1 & 0 & 0 & 0 & 2 \\
\hline Desmoncus orthacanthos & Arecaceae & 0 & 0 & 0 & 0 & 1 & 0 & 0 & 0 & 1 & 0 & 0 & 0 & 2 \\
\hline Smilax spp & Smilacaceae & 0 & 0 & 0 & 1 & 2 & 0 & 1 & 2 & 0 & 3 & 0 & 0 & 9 \\
\hline Chilero & Leguminosae & 5 & 1 & 0 & 0 & 6 & 4 & 14 & 17 & 18 & 11 & 1 & 0 & 77 \\
\hline Sapindaceae spp1 & Sapindaceae & 7 & 4 & 0 & 5 & 1 & 0 & 0 & 0 & 0 & 0 & 0 & 1 & 18 \\
\hline Total lianas per plot & & 168 & 187 & 134 & 187 & 166 & 124 & 127 & 89 & 107 & 101 & 172 & 155 & 1717 \\
\hline
\end{tabular}

Note: Characters in brackets near Leguminosae abbreviate subfamilies: $\mathrm{C}=$ Caesalpinioideae, $\mathrm{M}=$ Mimosoideae, and $\mathrm{P}=\mathrm{Papilionoideae}$.

Plot name abbreviations are as follows: Ant = Antonio, Mar= Mario, Ros= Rosendo, Sau= Saúl, Pep= Pepe. Digits besides such abbreviations indicate the age of plots respect to year 2003. The word "cut" indicates in what plots lianas were cut. Only trees alive in the census of August 2005 are included. All lianas rooted within plots are included, even if they climb upon trees outside the plot. Lianas rooted outside each plot but hosting on trees in such plots are excluded, resulting in unconsistencies of number of liana individuals per plot respect to Table 1 of Chapter 2 of this dissertation. 
APPENDIX II

INDEXES OF LIANA EFFECT $(\Omega)$ ON TREE GROWTH OF DIFFERENT TREE SPECIES AFTER A LIANA-CUT EXPERIMENT 
a) Stands $\geq 55 \mathrm{yr}$ -

\begin{tabular}{lccc}
\hline Species & $\begin{array}{c}\text { \# individuals } \\
\text { in liana-cut plots }\end{array}$ & $\begin{array}{c}\text { \# individuals in } \\
\text { liana-uncut plots }\end{array}$ & $\Omega$ \\
\hline Coccoloba spicata & 10 & 6 & $+0,2406$ \\
Diospyros cuneata & 24 & 43 & $+0,0046$ \\
Nectandra salicifolia & 44 & 46 & $+0,0016$ \\
Malmea depressa & 5 & 8 & $+0,0009$ \\
& & & \\
Lonchocarpus xuul & 18 & 6 & $7 \times 10^{-5}$ \\
Hampea trilobata & 27 & 20 & $-0,0007$ \\
Manilkara zapota & 9 & 12 & $-0,0028$ \\
Matayba oppositifolia & 5 & 11 & $-0,0033$ \\
Protium copal & 5 & 7 & $-0,0052$ \\
Dendropanax arboreus & 16 & 22 & $-0,0070$ \\
Zygia stevensonii & 34 & 66 & $-0,0108$ \\
Pouteria reticulata & 7 & 43 & $-0,0120$ \\
Metopium brownei & 12 & 13 & $-0,0127$ \\
Vitex gaumeri & 19 & 10 & $-0,0152$ \\
Chrysophyllum cainito & 5 & 9 & $-0,0193$ \\
Pouteria campechiana & 15 & 8 & $-0,0392$ \\
Bursera simarouba & 23 & 24 & $-0,0557$ \\
\hline
\end{tabular}

b) Stands 10-18yr-old

\begin{tabular}{lccl}
\hline Species & $\begin{array}{l}\text { \# individuals } \\
\text { in liana-cut plots }\end{array}$ & $\begin{array}{c}\text { \# individuals in } \\
\text { liana-uncut plots }\end{array}$ & $\Omega$ \\
\hline Allophylus cominia & 14 & 15 & $+0,0595$ \\
Lonchocarpus rugosus & 12 & 42 & $+0,0495$ \\
Lonchocarpus yucatanensis & 28 & 14 & $+0,0405$ \\
Chrysophyllum cainito & 17 & 15 & $+0,0138$ \\
Thevetia gaumeri & 42 & 38 & $+0,0085$ \\
Guettarda combsii & 13 & 11 & $+0,0055$ \\
Bursera simaruba & 97 & 16 & $+0,0047$ \\
Piscidia piscipula & 37 & 23 & $+0,0018$ \\
& & & \\
Coccoloba spicata & 37 & 9 & $-0,0040$ \\
Hampea trilobata & 64 & 43 & $-0,0074$ \\
Vitex gaumeri & 12 & 9 & $-0,0261$ \\
Lonchocarpus xuul & 6 & 8 & $-0,0273$ \\
Zuelania guidonia & 5 & 16 & $-0,0372$ \\
Luehea speciosa & 16 & 47 & $-0,0741$ \\
Spondias mombin & 5 & 6 & $-0,1029$ \\
\hline
\end{tabular}

Note: For each successional age, Relative Growths for each species were averaged (av) within both treatments, liana- cut and non-cut. Then, for each species, $\Omega= \pm / a v R G_{\text {cut }}-$ avg. $R G_{\text {un-cut }} /$. When avRG $G_{\text {un-cut }}>$ avRG $G_{\text {cut }}$, we assumeed the presence of intact lianas underground favored the species so we used a "+" sign. Negative signs (-) indicate the presence of intact lianas reduced the averaged growth of trees in a stand (avGR $\mathrm{un}_{\text {-cut }}<$ avGR $\mathrm{cut}_{\text {cut }}$. Zero values indicating that liana associated effects were not obtained, though many values tended to zero. Only species having $\mathrm{n} \geq 5$ individuals in both treatments per forest age were included for $\Omega$ calculations. (See figure 9 in Chapter 2). 
APPENDIX III

FALLEN DEBRIS (LEAF-LITTER AND WOODY DEBRIS)

IN LIANA-CUT AND LIANA-UN-CUT PLOTS 


\section{A) Plot pairs in the $\geq 55 y r-o l d ~ s t a n d s$}

Antonio55 A-B

Liana-uncut plots Liana-cut plots

\begin{tabular}{lll}
\hline $\begin{array}{l}\mathrm{t} \text { (months after } \\
\text { liana-cutting) }\end{array}$ & debris in kg-ha ${ }^{-1}(\mathrm{SD})$ & debris in ${\mathrm{kg}-h{ }^{-1}(\mathrm{SD})}$ \\
\hline & & \\
1 & $0,598(0,226)$ & $0,786(0,325)$ \\
2 & $0,216(0,140)$ & $0,189(0,085)$ \\
3 & $0,202(0,957)$ & $0,135(0,034)$ \\
4 & $0,279(0,114)$ & $0,255(0,120)$ \\
5 & $0,181(0,095)$ & $0,207(0,085)$ \\
6 & $0,239(0,070)$ & $0,244(0,102)$ \\
7 & $0,674(0,253)$ & $0,452(0,157)$ \\
8 & $0,675(0,227)$ & $0,554(0,146)$ \\
9 & $0,878(0,193)$ & $0,985(0,217)$ \\
10 & $0,633(0,155)$ & $0,817(0,250)$ \\
11 & $0,839(0,140)$ & $0,445(0,128)$ \\
12 & $0,345(0,147)$ & $0,385(0,201)$ \\
\hline
\end{tabular}

Mario55 A-B

Liana-uncut plots Liana-cut plots

\begin{tabular}{lll}
\hline $\begin{array}{l}\mathrm{t} \text { (months after } \\
\text { liana-cutting) }\end{array}$ & debris in kg-ha ${ }^{-1}(\mathrm{SD})$ & debris in $\mathrm{kg}_{\text {-ha }}{ }^{-1}(\mathrm{SD})$ \\
\hline & & \\
1 & $0,665(0,495)$ & $0,687(0,204)$ \\
2 & $0,117(0,059)$ & $0,148(0,100)$ \\
3 & $0,126(0,059)$ & $0,109(0,035)$ \\
4 & $0,327(0,169)$ & $0,194(0,026)$ \\
5 & $0,171(0,078)$ & $0,186(0,066)$ \\
6 & $0,118(0,071)$ & $0,119(0,062)$ \\
7 & $0,186(0,100)$ & $0,174(0,083)$ \\
8 & $0,437(0,225)$ & $0,425(0,277)$ \\
9 & $0,646(0,178)$ & $0,588(0,232)$ \\
10 & $0,598(0,198)$ & $0,680(0,302)$ \\
11 & $2,125(0)^{*}$ & $0,304(0,054)$ \\
12 & $0,304(0,054)$ & $0,296(0,117)$ \\
\hline
\end{tabular}

$\left.{ }^{*}\right)=$ debris from just one trap was recovered, the other traps were accidentally removed by farmers, we installed new traps for the rest of the study. 
Rosendo55 A-B

\begin{tabular}{lll} 
& Liana-uncut plots & Liana-cut plots \\
\hline $\begin{array}{l}\mathrm{t} \text { (months after } \\
\text { liana-cutting) }\end{array}$ & debris in kg-ha ${ }^{-1}(\mathrm{SD})$ & debris in $\mathrm{kg}^{-\mathrm{ha}^{-1}(\mathrm{SD})}$ \\
\hline & & \\
1 & $0,708(0,145)$ & $0,521(0,133)$ \\
2 & $0,217(0,167)$ & $0,147(0,068)$ \\
3 & $0,133(0,058)$ & $0,130(0,062)$ \\
4 & $0,249(0,174)$ & $0,528(0,343)$ \\
5 & $0,219(0,193)$ & $0,185(0,110)$ \\
6 & $0,167(0,122)$ & $0,216(0,127)$ \\
7 & $0,257(0,085)$ & $0,409(0,175)$ \\
8 & $0,469(0,143)$ & $0,854(0,284)$ \\
9 & $0,904(0,230)$ & $0,923(0,205)$ \\
10 & $0,990(0,329)$ & $0,667(0,280)$ \\
11 & $0,673(0,279)$ & $0,794(0,230)$ \\
12 & $0,265(0,092)$ & $0,376(0,193)$ \\
\hline
\end{tabular}

\section{B) Plot trios in the 10-18yr-old stands}

Saúl18 B-C-D

\begin{tabular}{|c|c|c|}
\hline & Liana-uncut plots & Liana-cut plots \\
\hline $\begin{array}{l}\mathrm{t} \text { (months after } \\
\text { liana-cutting) }\end{array}$ & debris in $k g-h a^{-1}(S D)$ & debris in $\mathrm{kg}-\mathrm{ha}^{-1}(\mathrm{SD})$ \\
\hline 1 & $0,740(0,253)$ & $0,666(0,283)$ \\
\hline 2 & $0,096(0,063)$ & $0,141(0,074)$ \\
\hline 3 & $0,192(0,123)$ & $0,215(0,078)$ \\
\hline 4 & $0,670(0,707)$ & $0,567(0,309)$ \\
\hline 5 & $0,219(0,105)$ & $0,189(0,127)$ \\
\hline 6 & $1,269(2,479)$ & $0,351(0,203)$ \\
\hline 7 & $0,390(0,109)$ & $0,416(0,189)$ \\
\hline 8 & $0,706(0,447)$ & $0,549(0,190)$ \\
\hline 9 & $1,049(0,317)$ & $1,016(0,274)$ \\
\hline 10 & $1,020(0,187)$ & $0,974(0,550)$ \\
\hline 11 & $0,604(0,294)$ & $0,542(0,258)$ \\
\hline 12 & $0,462(0,227)$ & $0,274(0,121)$ \\
\hline
\end{tabular}


Pepe10 A-C, Saúl18 A

\begin{tabular}{cll} 
& Liana-uncut plots & Liana-cut plots \\
\hline $\begin{array}{l}\mathrm{t} \text { (months after } \\
\text { liana-cutting) }\end{array}$ & debris in kg-ha $^{-1}(\mathrm{SD})$ & debris in $\mathrm{kg}_{\text {-ha }}{ }^{-1}(\mathrm{SD})$ \\
\hline & & \\
1 & $0,710(0,315)$ & $\mathbf{1 , 5 1 9}(0,577)$ \\
2 & $0,179(0,126)$ & $0,132(0,076)$ \\
3 & $0,325(0,121)$ & $0,277(0,157)$ \\
4 & $0,682(0,562)$ & $\mathbf{1 , 4 1 3}(0,889)$ \\
5 & $0,421(0,194)$ & $0,458(0,160)$ \\
6 & $0,408(0,160)$ & $0,390(0,316)$ \\
7 & $0,583(0,350)$ & $0,486(0,330)$ \\
8 & $0,606(0,260)$ & $0,527(0,169)$ \\
9 & $0,890(0,172)$ & $1,029(0,554)$ \\
10 & $1,354(0,417)$ & $0,533(1,299)$ \\
11 & $\mathbf{0 , 7 6 1}(0,247)$ & $0,546(0,288)$ \\
12 & $\mathbf{0 , 3 0 2}(0,138)$ & $0,164(0,109)$ \\
\hline
\end{tabular}

Highlighted digits indicate treatments (liana-un-cut vs liana-cut) having higher debris inputs in their respective months after Repeated Measurements ANOVA. 
APPENDIX IV

CONTINGENCY TABLES EXPLORING THE EFFECTS OF TREE LOCATION (FOREST STAND), LIANAS, AND TREE-SLOPING

ON RISKS OF TREES TO GET DAMAGED DURING

HURRICANE WILMA 


\section{A) NUMBER OF AFFECTED TREE INDIVIDUALS ACCORDING TO THEIR LOCATIONS (FOREST STANDS)}

Types of damage ${ }^{(*)}$

\begin{tabular}{lcccccccc} 
stand (plot-group) & CR & OLB & MLB & t-sB & TS & TU & No-damage & total \\
\hline I ( $\geq 55$ yr-old forest) & 69 & 8 & 21 & 32 & 44 & 19 & 634 & 827 \\
II (18yr-old forest) & 51 & 0 & 2 & 5 & 21 & 24 & 347 & 450 \\
III (10-18yr-old forest) & 239 & 0 & 8 & 6 & 16 & 5 & 166 & 440 \\
\hline total & 359 & 8 & 31 & 43 & 81 & 48 & 1147 & 1717 \\
\hline
\end{tabular}

For all categories combined: $\chi^{2}=436,734, \mathrm{df}=12, \mathrm{P}<0,001$. When excluding non-damaged trees: $\chi^{2}=183,196$, $\mathrm{df}=10, \mathrm{P}<0,001<$ Bonferoni's corrected $\mathrm{P}=0,025$. When adding $\mathrm{CR}$ to the excluded trees, $\chi^{2}=34,163, \mathrm{df}=8$, $\mathrm{P}<0,001<$ Bonferoni's corrected $\mathrm{P}=0,0167$. When adding TS trees to the exclusion: $\chi^{2}=33,755, \mathrm{df}=6, \mathrm{P}<0,001$ $<$ Bonferoni's corrected $\mathrm{P}=0,0125$. When adding t-sB to the exclusion: $\chi^{2}=24,803, \mathrm{df}=4, \mathrm{P}<0,001<$ Bonferoni's corrected $\mathrm{P}=0,01$.

(*) For this and all other tables, Types of damage are: $\mathrm{CR}=$ Crown removed, trunk not snapped, OLB= Only largest branches remaining, $\mathrm{MLB}=$ Most large branches remaining, $\mathrm{t}-\mathrm{sB}=$ Only twigs and small branches removed, TS $=$ Trunk snapped, and TU= Tree uprooted (Whigham et al, 1991).

Continues in nex pages. 


\section{B) NUMBER OF AFFECTED TREE INDIVIDUALS ACCORDING TO LIANA-}

CUTTING

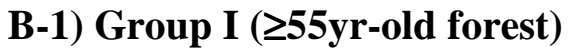

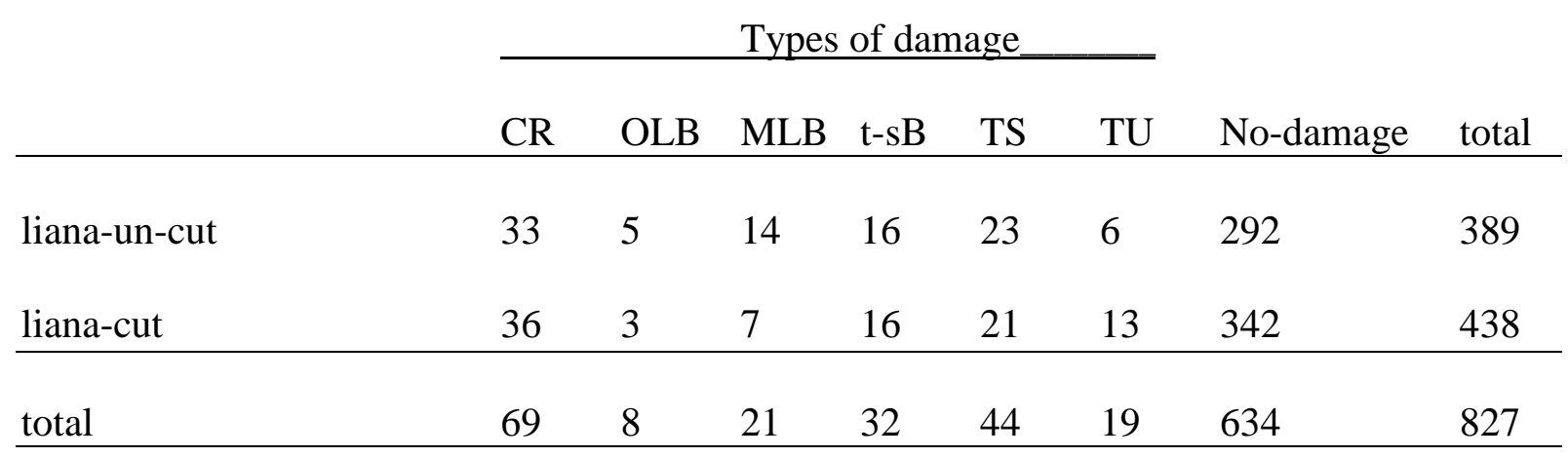

For all categories combined: $\chi^{2}=6,697, \mathrm{df}=6, \mathrm{P}>0,05$. Excluding non-damaged trees: $\chi^{2}=5,629, \mathrm{df}=5, \mathrm{P}>0,05>$ Bonferoni's corrected $\mathrm{P}=0,025$.

\section{B-2) Group II (18yr-old forest)}

\begin{tabular}{lccccccccc} 
& \multicolumn{8}{c}{ Types of damage } & \\
\cline { 2 - 7 } & CR & OLB & MLB & t-sB & TS & TU & No-damage & total \\
\hline liana-un-cut & 21 & 0 & 2 & 0 & 3 & 14 & 129 & 169 \\
liana-cut & 30 & 0 & 0 & 5 & 18 & 10 & 218 & 281 \\
\hline total & 51 & 0 & 2 & 5 & 21 & 24 & 347 & 450 \\
\hline
\end{tabular}

For all categories combined: $\chi^{2}=0,178, \mathrm{df}=6, \mathrm{P}>0,05$.

\section{B-3) Group III (10-18yr-old forest)}

Types of damage

\begin{tabular}{lcccccccc} 
& CR & OLB & MLB & t-sB & TS & TU & No-damage & total \\
\hline liana-un-cut & 145 & 0 & 8 & 6 & 6 & 0 & 63 & 228 \\
liana-cut & 94 & 0 & 0 & 0 & 10 & 5 & 103 & 212 \\
\hline total & 239 & 0 & 8 & 6 & 16 & 5 & 166 & 440 \\
\hline
\end{tabular}

For all categories combined: $\chi^{2}=3,613, \mathrm{df}=6, \mathrm{P}>0,05$. 


\section{C) NUMBER OF AFFECTED TREE INDIVIDUALS ACCORDING TO PRE- HURRICANE LIANA-INDUCED BOWING}

C-1) Group I ( $\geq 55 y$ r-old forest)

\begin{tabular}{lccccccccc} 
& \multicolumn{8}{c}{} & \multicolumn{7}{c}{ Types of damage } & & \\
\cline { 2 - 7 } & & CR & OLB & MLB & t-sB & TS & TU & No-damage & total \\
\hline non-bowed & 60 & 7 & 18 & 27 & 35 & 14 & 539 & 700 \\
liana-bowed & 9 & 1 & 3 & 5 & 9 & 5 & 95 & 127 \\
\hline total & 69 & 8 & 21 & 32 & 44 & 19 & 634 & 827 \\
\hline
\end{tabular}

For all categories combined: $\chi^{2}=3,057, \mathrm{df}=6, \mathrm{P}>0,05$.

\section{C-2) Group II (10-18yr-old forest)}

\begin{tabular}{lcccccccc} 
& \multicolumn{8}{c}{ Types of damage } \\
\cline { 2 - 7 } & CR & OLB & MLB & t-sB & TS & TU & No-damage & total \\
\hline non-bowed & 29 & 0 & 2 & 5 & 13 & 20 & 224 & 293 \\
liana-bowed & 22 & 0 & 0 & 0 & 8 & 4 & 123 & 157 \\
\hline total & 51 & 0 & 2 & 5 & 21 & 24 & 347 & 450 \\
\hline
\end{tabular}

For all categories combined: $\chi^{2}=0,532, \mathrm{df}=6, \mathrm{P}>0,05$.

\section{C-3) Group III (10-18yr-old forest)}

Types of damage

\begin{tabular}{lcccccccc} 
& CR & OLB & MLB & t-sB & TS & TU & No-damage & total \\
\hline Non-bowed & 81 & 0 & 3 & 3 & 3 & 1 & 91 & 182 \\
liana-bowed & 158 & 0 & 5 & 3 & 13 & 4 & 75 & 258 \\
\hline total & 239 & 0 & 8 & 6 & 16 & 5 & 166 & 440 \\
\hline
\end{tabular}

For all categories combined: $\chi^{2}=3,226, \mathrm{df}=6, \mathrm{P}>0,05$. 


\section{D) NUMBER OF AFFECTED TREE INDIVIDUALS ACCORDING TO THEIR HOSTED LIANA-TANGLE CATEGORIES ${ }^{(*)}$}

D-1) Group I ( $\geq 55 y$ r-old forest)

\begin{tabular}{cllllllll} 
& \multicolumn{7}{c}{ Types of damage } & \\
\cline { 2 - 7 } liana-tanngle category & CR & OLB & MLB & t-sB & TS & TU & No-damage & total \\
\hline 0 & 17 & 4 & 9 & 11 & 20 & 6 & 259 & 326 \\
1 & 30 & 3 & 5 & 12 & 14 & 10 & 248 & 322 \\
2 & 7 & 0 & 3 & 7 & 7 & 2 & 93 & 119 \\
3 & 15 & 1 & 4 & 2 & 3 & 1 & 34 & 60 \\
\hline total & 69 & 8 & 21 & 32 & 44 & 19 & 634 & 827 \\
\hline
\end{tabular}

For all categories combined: $\chi^{2}=39,601, \mathrm{df}=18, \mathrm{P}<0,01$. Excluding non-damaged trees: $\chi^{2}=18,889, \mathrm{df}=15, \mathrm{P}>$ $1>$ Bonferoni's corrected $\mathrm{P}=0,025$. $^{*}$ ) See text for description of liana-tangle categories.

\section{D-2) Group II (18yr-old forest)}

Types of damage

\begin{tabular}{cllllllll} 
liana-tanngle category & CR & OLB & MLB & t-sB & TS & TU & No-damage & total \\
\hline 0 & 11 & 0 & 0 & 3 & 9 & 7 & 111 & 148 \\
1 & 25 & 0 & 1 & 2 & 7 & 13 & 166 & 214 \\
2 & 6 & 0 & 1 & 0 & 4 & 4 & 46 & 61 \\
3 & 9 & 0 & 0 & 0 & 1 & 0 & 17 & 27 \\
\hline total & 51 & 0 & 2 & 5 & 21 & 24 & 347 & 450 \\
\hline
\end{tabular}

For all categories combined: $\chi^{2}=1,987, \mathrm{df}=18, \mathrm{P}>0,05$.

\section{D-3) Group III (10-18yr-old forest)}

Types of damage

\begin{tabular}{cllllllll} 
liana-tanngle category & CR & OLB & MLB & t-sB & TS & TU & No-damage & total \\
\hline 0 & 20 & 0 & 1 & 0 & 0 & 0 & 44 & 65 \\
1 & 109 & 0 & 5 & 2 & 8 & 3 & 92 & 219 \\
2 & 59 & 0 & 1 & 2 & 4 & 2 & 24 & 92 \\
3 & 51 & 0 & 1 & 2 & 4 & 0 & 6 & 64 \\
\hline total & 239 & 0 & 8 & 6 & 16 & 5 & 166 & 440 \\
\hline
\end{tabular}

For all categories combined: $\chi^{2}=6,636, \mathrm{df}=18, \mathrm{P}>0,05$. 


\section{E) NUMBER OF AFFECTED TREE INDIVIDUALS ACCORDING TO THEIR PRE- HURRICANE POSITION (VERTICAL vS SLOPED)}

E-1) Group I ( $\geq 55 y$ yr-old forest)

\begin{tabular}{lccccccccc} 
& \multicolumn{8}{c}{ Types of damage } & \\
\cline { 2 - 6 } position & CR & OLB & MLB & t-sB & TS & TU & No-damage & total \\
\hline vertical & 53 & 5 & 16 & 28 & 18 & 10 & 423 & 553 \\
sloped & 16 & 3 & 5 & 4 & 26 & 9 & 211 & 274 \\
\hline total & 69 & 8 & 21 & 32 & 44 & 19 & 634 & 827 \\
\hline
\end{tabular}

For all categories combined: $\chi^{2}=25,248, \mathrm{df}=6, \mathrm{P}<0,001$. Excluding non-damaged trees: $\chi^{2}=25,413, \mathrm{df}=5, \mathrm{P}<$ $0,001<$ Bonferoni's corrected $\mathrm{P}=0,025$. Adding CR to the exclusion: $\chi^{2}=19,661, \mathrm{df}=4, \mathrm{P}<0,001<$ Bonferoni's corrected $\mathrm{P}=0,017$. Adding t-sB to the exclusion: $\chi^{2}=7,401, \mathrm{df}=3, \mathrm{P}>0,1>$ Bonferoni's corrected $\mathrm{P}=0,0125$.

\section{E-2) Group II (18yr-old forest)}

\begin{tabular}{lccccccccc} 
& \multicolumn{8}{c}{ Types of damage } & \\
\cline { 2 - 6 } position & CR & OLB & MLB & t-sB & TS & TU & No-damage & total \\
\hline vertical & 27 & 0 & 1 & 5 & 14 & 17 & 229 & 293 \\
sloped & 24 & 0 & 1 & 0 & 7 & 7 & 118 & 157 \\
\hline total & 51 & 0 & 2 & 5 & 21 & 24 & 347 & 450 \\
\hline
\end{tabular}

For all categories combined: $\chi^{2}=1,160, \mathrm{df}=6, \mathrm{P}>0,05$.

\section{E-3) Group III (10-18yr-old forest)}

Types of damage

\begin{tabular}{lcccccccc} 
position & CR & OLB & MLB & t-sB & TS & TU & No-damage & total \\
vertical & 113 & 0 & 4 & 3 & 2 & 3 & 104 & 229 \\
sloped & 126 & 0 & 4 & 3 & 14 & 2 & 62 & 211 \\
\hline total & 239 & 0 & 8 & 6 & 16 & 5 & 166 & 440 \\
\hline
\end{tabular}

For all categories combined: $\chi^{2}=1,043, \mathrm{df}=6, \mathrm{P}>0,05$. 
Name

Geburtsdatum und -ort

Adresse

Staatsangehörigkeit:

Familienstand:

Studium

02/05 - heute
Edgardo I. Garrido Pérez

(für Zeitschrifte Edgardo Garrido-Pérez)

29.12.1970, Panama, Panama

Freiligrathstr.3

30171, Hannover

Deutschland

Tel. 0511-3532705

Panamaisch

verheiratet, eine Tochter

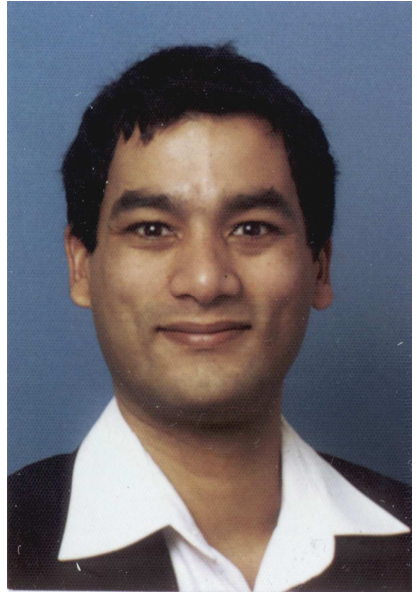

$10-88-12 / 98$

Feb/01, Mär/00, Jul/97

Berufserfahrung

Jul-Okt/04

\section{Georg-August Universität Göttingen}

Doktoranden am Geographisches Institut, Abt. für

Landschaftsökologie, Georg-August Universität, Göttingen; sieben

Kongresse während der Promotion (Mexiko, Dominikanische

Republik, China, Deutschland), vier Artikel im Process

Universidad de Panamá, Panamá

Studium der Biologie

Abschluss: Diplom-Biologe, Schwerpunkt Botanik
Jul/98, Apr/97

Stipendien

Mai/05 - Juli/05

Sep/01 - Aug/03

Sep/01 - Aug/05

Feb/99 - Apr/1999

Mär/98 - Mai/98
Subdirección de Desarrollo Social Municipal, Ayuntamiento de Lázaro Cárdenas, Quntana Roo, México

Wissenschaftlicher Berater, Projekt: Management der Lianen

Smithsonian Tropical Research Institute (STRI), Barro Colorado Island Biological Station (Panama Kanal)

Wissenschaftliche Assistent für Ökologie und Physiologie der Pflanzen

Smithsonian Tropical Research Institute, Universidad de Panamá, Universidad Autónoma de Chiriquí (Panama) Lehrer für Freiland Biologie Workshops 